\title{
THE SAFETY OF
} $\mathrm{UO}_{3}$ PRODUCTION IN THE A-LINE AT THE SAVANNAH RIVER PLANT

by

W. C. PERKINS, W. S. DURANT, and M. L. HYDER

Approved by:

M. L. Hyder, Research Manager Separations Chemistry Division

Publication Date: March 1977

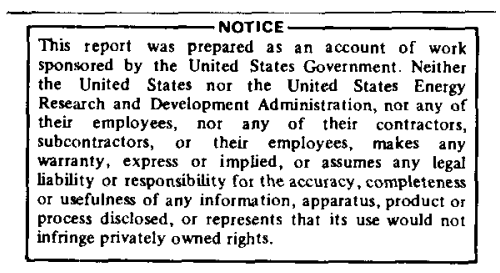

E. I. DU PONT DE NEMOURS AND COMPANY SAVANNAH RIVER LABORATORY AIKEN. SOUTH CAROLINA 29801

PREPARED FOR THE U. S. ENERGY RESEARCH AND DEVELOPMENT ADMINISTRATION UNDER CONTRACT AT(07-2)-1

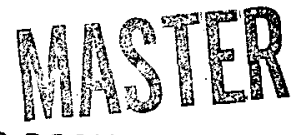




\section{DISCLAIMER}

This report was prepared as an account of work sponsored by an agency of the United States Government. Neither the United States Government nor any agency Thereof, nor any of their employees, makes any warranty, express or implied, or assumes any legal liability or responsibility for the accuracy, completeness, or usefulness of any information, apparatus, product, or process disclosed, or represents that its use would not infringe privately owned rights. Reference herein to any specific commercial product, process, or service by trade name, trademark, manufacturer, or otherwise does not necessarily constitute or imply its endorsement, recommendation, or favoring by the United States Government or any agency thereof. The views and opinions of authors expressed herein do not necessarily state or reflect those of the United States Government or any agency thereof. 


\section{DISCLAIMER}

Portions of this document may be illegible in electronic image products. Images are produced from the best available original document. 
The safety of $\mathrm{UO}_{3}$ production by thermal denitration in the A-Line facility at the Savannah River Plant is reviewed in the light of corrective measures instituted following the explosion and fire in this facility in February 1975. This incident was attributed to the introduction of an excessive amount of tributyl phosphate into a denitrator. Modifications to procedures, process instrumentation, and process control techniques have greatly improved the control of organic material in the A-Line process, restricting the organic input to the denitrator to a recognized safe level of 1.2 gallons or less. Analysis of the process using. the fault-tree method and data from operating experience indicate that the expected frequency of a similar explosion in the future in this facility is about one per 4000 years. 


\section{CONTENTS}

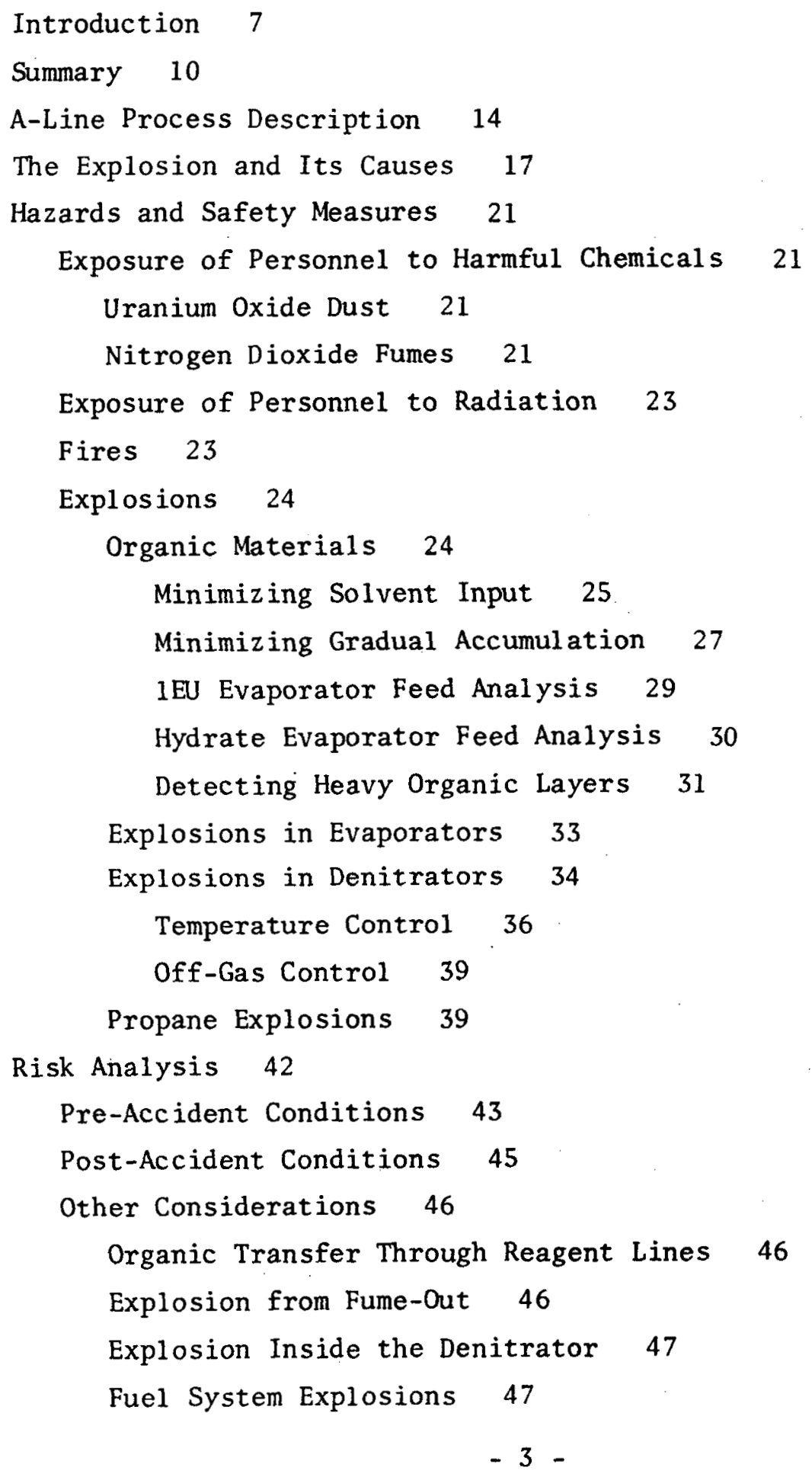


Additional Safety-Related Occurrences

0 il Leaks 47

Foam-Outs 48

References 49

Appendix: Fault Tree Analysis 51. 


\section{LIST OF FIGURES}

1 SRP Separations Area 8

2 A-Line Facility 9

3 Uranyl Nitrate Process Flow Diagram 11

4 A-Line Process 15

5 A-Line Flow Diagram 16

6 Specific Gravity of A-Line Solutions at $25^{\circ} \mathrm{C} \quad 20$

7 Solubility of TBP in Aqueous Uranyl

Nitrate Solution at $25^{\circ} \mathrm{C} \quad 26$

8 Thermal Stability of $\mathrm{UO}_{2}\left(\mathrm{NO}_{3}\right)_{2}(\mathrm{TBP})_{2}$ Adduct 33

9 Denitrator Temperatures 37

10 Denitrator Furnace Controls 40

A-1 Fault-Tree Symbols 53

A-2 Guide to Fault Trees 54

A-3 Fault Tree for Explosion in A-Line Facilities 55 


\section{LIST OF TABLES}

1 Major Changes in A-Line Operating Procedures 12

2 New A-Line Controls and Instrumentation 13

3 Potential Explosion Mechanisms 13

4 Denitrator Services and Instrumentation 22

5 A-Line Tank Operation 28

6 A-Line Sampling Data 31

7 Denitrator Heatup Rates 37

8 Denitrator Skin Temperatures; Operating Values 38 


\section{INTRODUCTION}

Natural or depleted uranium product solutions from Purex operations at the Savannah River Plant (SRP) are converted to solid $\mathrm{UO}_{3}$ in a facility called the A-Line. The location and plan of this facility are shown in Figures 1 and 2, respectively. In A-Line operations, the urany1 nitrate solution received from Building $221-\mathrm{F}$ is concentrated, dehydrated, and denitrated to produce $\mathrm{UO}_{3}$ powder, a compact form of uranium that can readily be stored, shipped, or converted to other compounds as desired. ${ }^{1}$

On February 12, 1975, an explosion occurred in this facility, causing two minor injuries to personnel and considerable damage to the building from fire and blast. ${ }^{2}$ The cause of this explosion has been identified as the accidental introduction of a large quantity of tributyl phosphate (TBP) into a denitrator. Rapid decomposition of this TBP caused flammable gases to be emitted into the denitrator room, where they ignited. Before A-Line processing resumed, a thorough study was made of the causes of this explosion, the adequacy of measures adopted to prevent a recurrence, and the behavior of TBP under conditions encountered in A-Line. ${ }^{3,4}$ Mechanisms for introduction of TBP into the denitrator were identified and evaluated. Identifiable hazards associated with denitrator operation were evaluated by the faulttree method ${ }^{5}$ based on historical data for A-Line and related SRP processes. As the result of these studies, the safety of resumed operation of A-Line has been greatly increased from safety levels associated with prior operation. study:

This report summarizes several portions of this safety

- Description of the explosion incident and its causes.

- Review of hazards and safety measures for A-Line operation.

- The fault-tree analysis and its conclusions. 


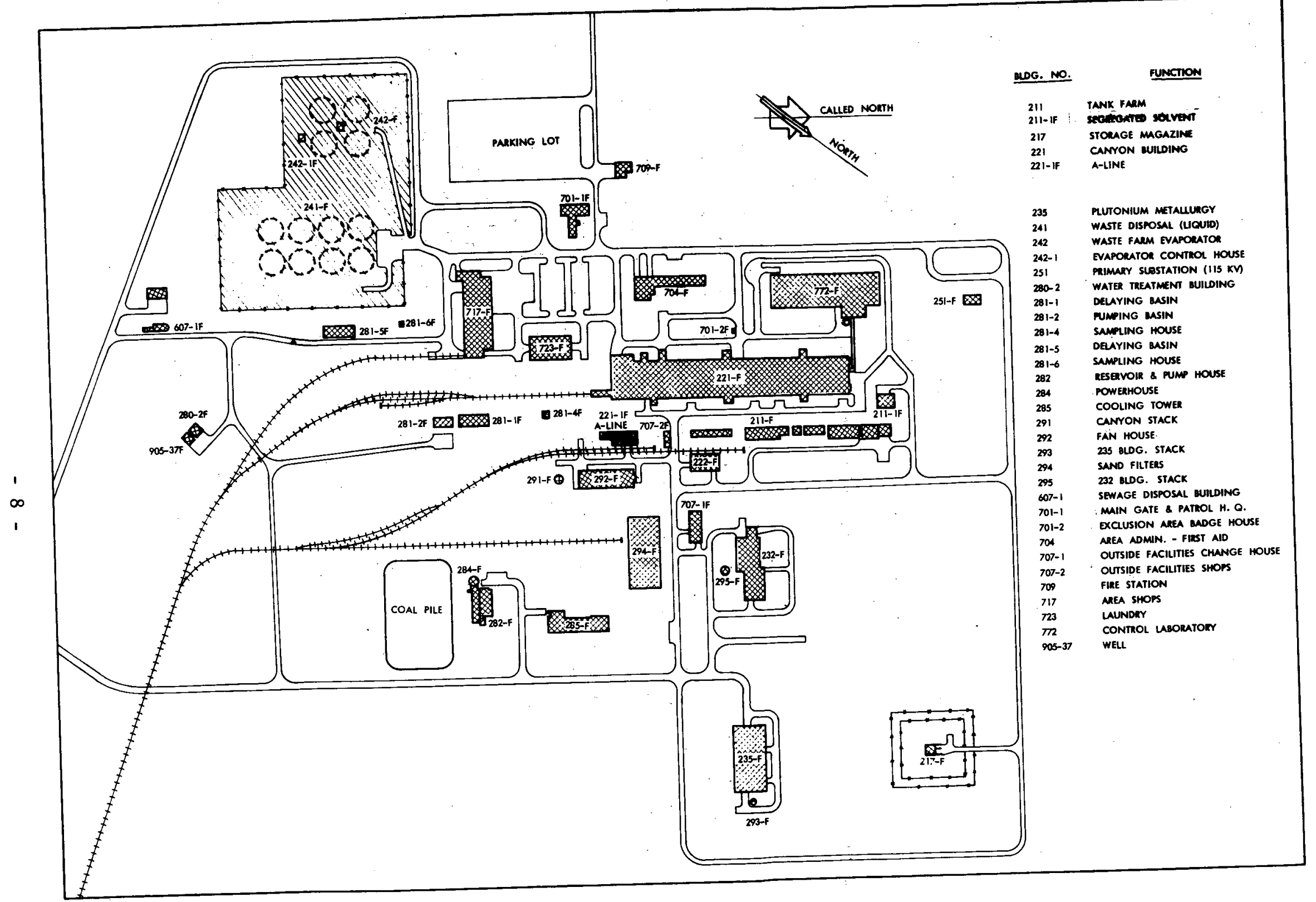

FIGURE 1. SRP Separations Area 


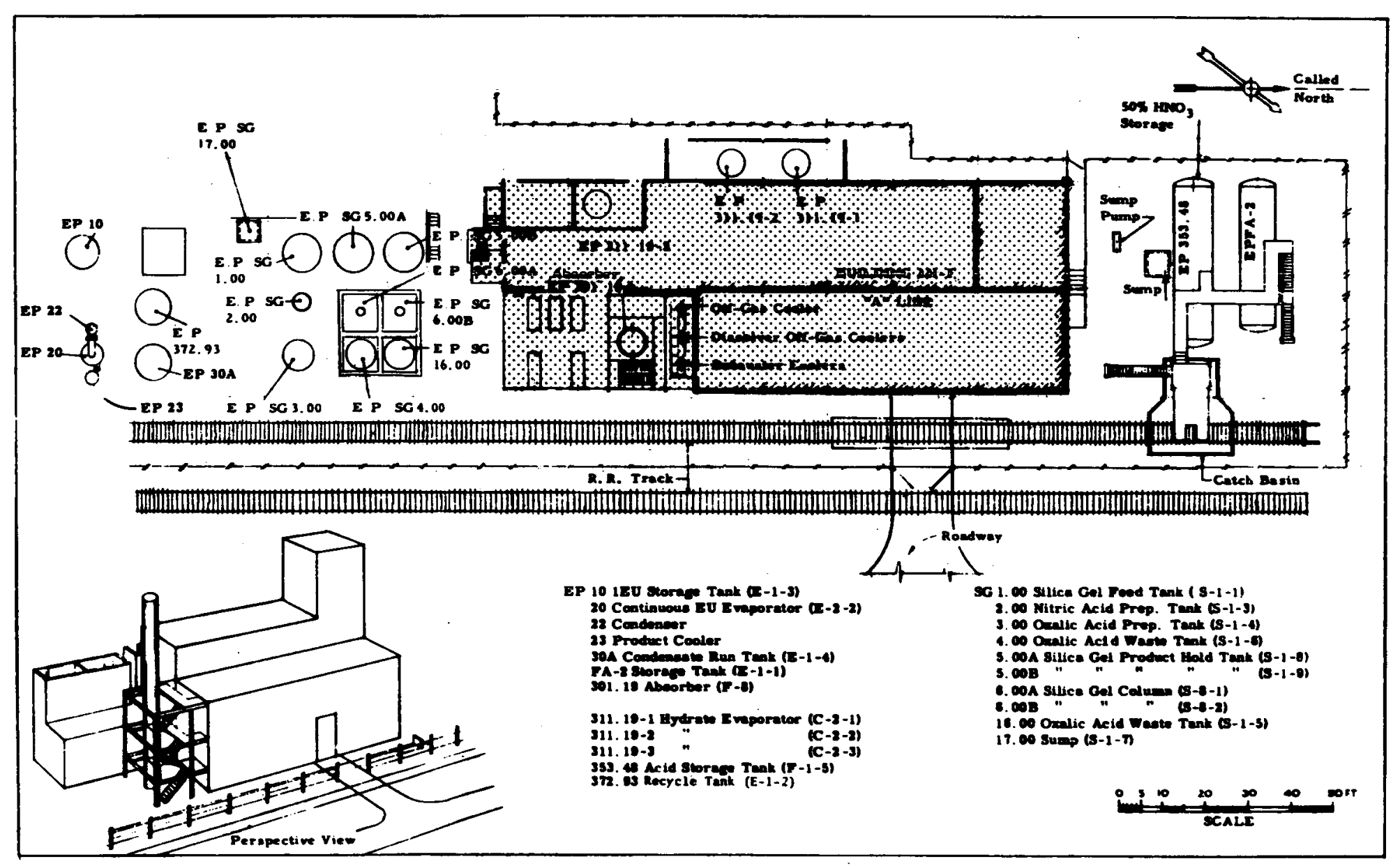

FIGURE 2. A-Line Facility 
SUMMARY

A-Line resumed production of $\mathrm{UO}_{3}$ by thermal denitration (Figure 3) in August 1975. Operating safety in A-Line is now enhanced by a combination of improvements in procedure, process instrumentation, and process control. These improvements are listed in Tables 1 and 2 .

Procedural improvements include a five-fold reduction in the allowable quantity of organic material (TBP) in a process batch, increased sampling frequency, increased frequency of tank inspections and organic removal, and agitation of some tanks to prevent accumulation between inspections. The specific gravities of solutions fed to the hydrate evaporator are controlled above a minimum value to ensure that heavy, unobserved organic material does not accumulate. As a result of these improvements, the quantity of TBP reaching the denitrators is at least 25-fold smaller than the quantity that caused the explosion.

New process instrumentation has been installed to determine that the new limitations on denitration conditions are being met. These limitations include a more gradual increase of operating temperature so that any TBP present in the denitrator decomposes at a safe rate. Also, an air purge of each denitrator ensures that the gaseous reaction products are diluted to safe concentrations. This new instrumentation also provides for more rapid response to violation of critical controls, either manually (following an alarm) or automatically.

Proper use of the new instrumentation and adherence to the new operating procedures and guidelines will prevent A-Line explosions caused by heating of hazardous quantities of TBP in a denitrator. This conclusion is based on the results of a risk analysis made by a fault-tree comparison method, ${ }^{5}$ summarized in Table 3 . These results show that the expected frequency of an explosion in the A-Line denitrator has been reduced from once in 20 years to once in about 4000 years. The consequence of an explosion is assumed to be unchanged; therefore, the decrease in risk is directly proportional to the decrease in probability. The probability of accumulation and transport of gross quantities of organic material (which initiated the recent explosion) has been reduced by $2 \times 10^{5}$. However, other potential mechanisms, such as material handling errors, become dominant and limit the reduction of risk. 


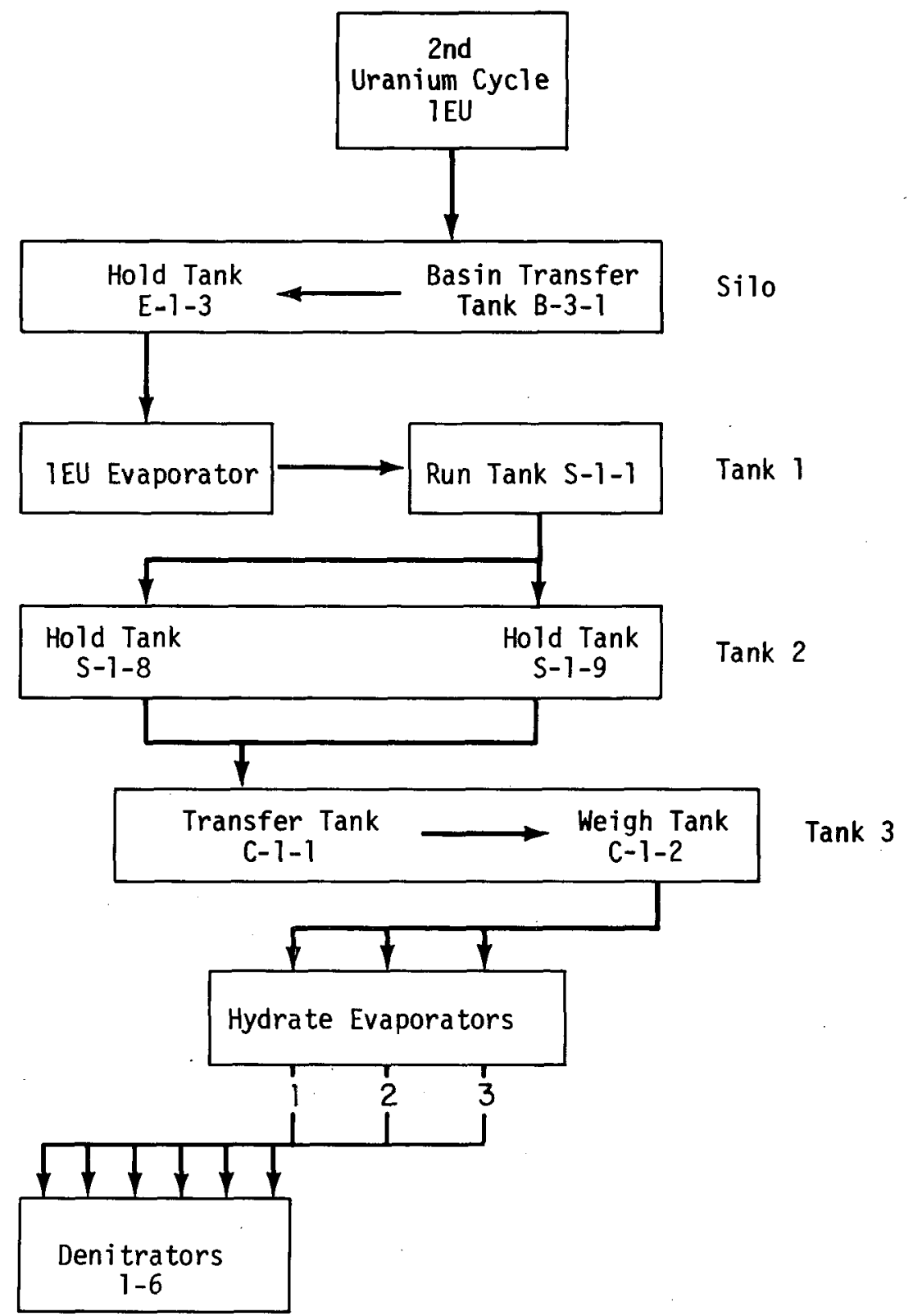

FIGURE 3. Uranyl Nitrate Process Flow Diagram 
TABLE 1

Major Changes in A-Line Operating Procedures

Procedure

ord

New $a$

Organic-to-Aqueous Ratio

Operating Limits, volume $\%$ :

Feed to 1EU Evaporator

Feed to Hydrate Evaporator

$\begin{array}{ll}0.5 & 0.1 \\ 0.5 & 0.1\end{array}$

Sampling Frequency (Tanks):

E-1-3

$S-1-8$ and $S-1-9$

$1 /$ day $^{b} \quad 1 /$ shift

$1 /$ daye $\quad 1 /$ tankful

Inspection and Skimming Frequency (Tanks):

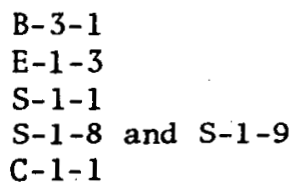

Operating Mode (Tanks):

$$
\begin{aligned}
& \text { S-1-8 and S-1-9 } \\
& \text { C-1-1 }
\end{aligned}
$$

Decanter Agitated

Decanter Agitated

$\begin{array}{ll}e & 1.50^{f} \\ 500 & 0.5 \\ 1^{h} & (\text { see Table 8) } \\ & <0.7\end{array}$

1

Minimum Specific Gravity of 1EU Concentrate, $\mathrm{g} / \mathrm{ml}$

Minimum Denitrator Vacuum, in. $\left(\mathrm{H}_{2} \mathrm{O}\right)^{g}$

Initial Denitrator Skin Temperature, ${ }^{\circ} \mathrm{C}$

Normal Heatup Rate, ${ }^{\circ} \mathrm{C} / \mathrm{min}$

a. Runbook (procedure) values. Denitrator batch size is 1 ton of uranium .

b. In practice, about once a month.

c. In practice, about twice a. week.

d. In practice, about once a year.

e. Not specified.

f. Corresponds to $370 \mathrm{~g} \mathrm{U} / \ell$.

g. This requirement provides an air purge through the denitrator.

$h$. Not measured until after the explosion. 
TABLE 2

New A-Line Controls and Instrumentation

- Automatic pump cutoff at low liquid level in Tank E-1-3.

- Temperature monitoring of denitrator contents.

- Air purge to denitrator (inlet orifice).

- Denitrator vacuum recorder (low vacuum alarm).

- Emergency furnace shutdown and simultaneous stack jet start (button and alarm, exterior to room).

- Interlock to shut down denitrator if skin temperature limit is exceeded.

- Explosive gas monitor (and alarm) on room exhaust.

\section{TABLE 3}

\section{Potential Explosion Mechanisms}

Mechanism

$\frac{\text { Calculated Frequency, } d^{1^{*}}}{\text { ord }}$

Gross organic from hydrate evaporator decomposes in denitrator; flammable gas in denitrator room

$$
2 \times 10^{-5} \quad 1 \times 10^{-10}
$$

Gross organic from reagent 1 ine decomposes in denitrator; flammable gas in denitrator room

$1 \times 10^{-7} \quad 1 \times 10^{-7}$

Near-normal organic decomposes in denitrator; denitrator conditions abnormal; flammable gas in pot

$1 \times 10^{-6} \quad 6 \times 10^{-8}$

Furnace system malfunctions; propane in A-Line basement

$$
2 \times 10^{-5} \quad 2 \times 10^{-5}
$$

\footnotetext{
* $d=$ demand unit, i.e., one process batch, normally one ton of uranium. Al though process rates vary, 12 tons uranium/day and 2400 tons uranium/year have been assumed.
} 


\section{A-LINE PROCESS DESCRIPTION}

A-Line evaporates the uranyl nitrate - nitric acid product solution (1EU) from Purex operations in Building 221-F and denitrates the concentrate to anhydrous $\mathrm{UO}_{3}$ (Figure 4). This oxide is a chemically stable powder suitable for shipment or long-term storage, and it can readily be dissolved in nitric acid or converted to other desired chemical forms. Process equipment is shown in Figure 5. There are two stages of evaporation. The first stage in the continuous 1EU evaporator yields a solution containing about 400 grams of uranium per liter. The concentrate may be passed through a silica gel column for removal of residual fission products; this step was routinely performed in operations prior to the explosion. The second, or hydrate, evaporation step is a batch process. Concentrate from the hydrate evaporators is gravity-fed directly to stirred denitrators where it is heated until only $\mathrm{UO}_{3}$ remains.

Feed to the first evaporator is drawn from a tall, unstirred storage tank. Organic solvent (n-paraffins with $30 \%$ TBP from solvent extraction processing) that reaches this storage tank by entrainment rises and accumulates on the surface where it is removed periodically. Tanks 1 and 2 (Figure 3) downstream of the 1EU evaporator were previously operated as decanters; but, since resumption of A-Line operations in August 1975, they have been continuously agitated to prevent the accumulation of large quantities of organic material in any one tank. The silica gel columns have been bypassed since resumption of operations because additional purification is unnecessary. Fission products are adequately removed in the Purex process.

Each of the six A-Line, pot-type, denitrators is capable of processing a charge containing one ton of uranium. The overall reactions are:

$$
\begin{aligned}
& \mathrm{UO}_{2}\left(\mathrm{NO}_{3}\right)_{2} \cdot 6 \mathrm{H}_{2} \mathrm{O} \rightarrow \mathrm{UO}_{2}\left(\mathrm{NO}_{3}\right)_{2}+6 \mathrm{H}_{2} \mathrm{O} \\
& 2 \mathrm{UO}_{2}\left(\mathrm{NO}_{3}\right)_{2} \rightarrow 2 \mathrm{UO}_{3}+4 \mathrm{NO}_{2}+0_{2}
\end{aligned}
$$

The first step, dehydration of uranyl nitrate hexahydrate (UNH), is complete at about $180^{\circ} \mathrm{C} .{ }^{6}$ During the boiloff of water and nitric acid, the decomposition of quantities $(>0.04$ volume $\%)$ of TBP (from entrained and dissolved Purex extractant) causes foaming, which can become overly vigorous unless the heating rate is carefully controlled. ${ }^{4}$ Vigorous denitration begins at about $200^{\circ} \mathrm{C}$, and the liquid rapidly becomes more viscous. $\mathrm{As}^{\mathrm{UO}_{3}}$ is produced, the mixture becomes dough-1ike; without continuous agitation a this point, the mass would become rock-hard. The temperature is maintained at about $225^{\circ} \mathrm{C}$ until denitration is complete. 
The product, a yellow powder with a nitrate content less than $0.5 \mathrm{wt} \%$, is transferred by vacuum from the denitrators by a pneumatic unloading system, accumulated in a product collector, and loaded into drums for storage or shipment.

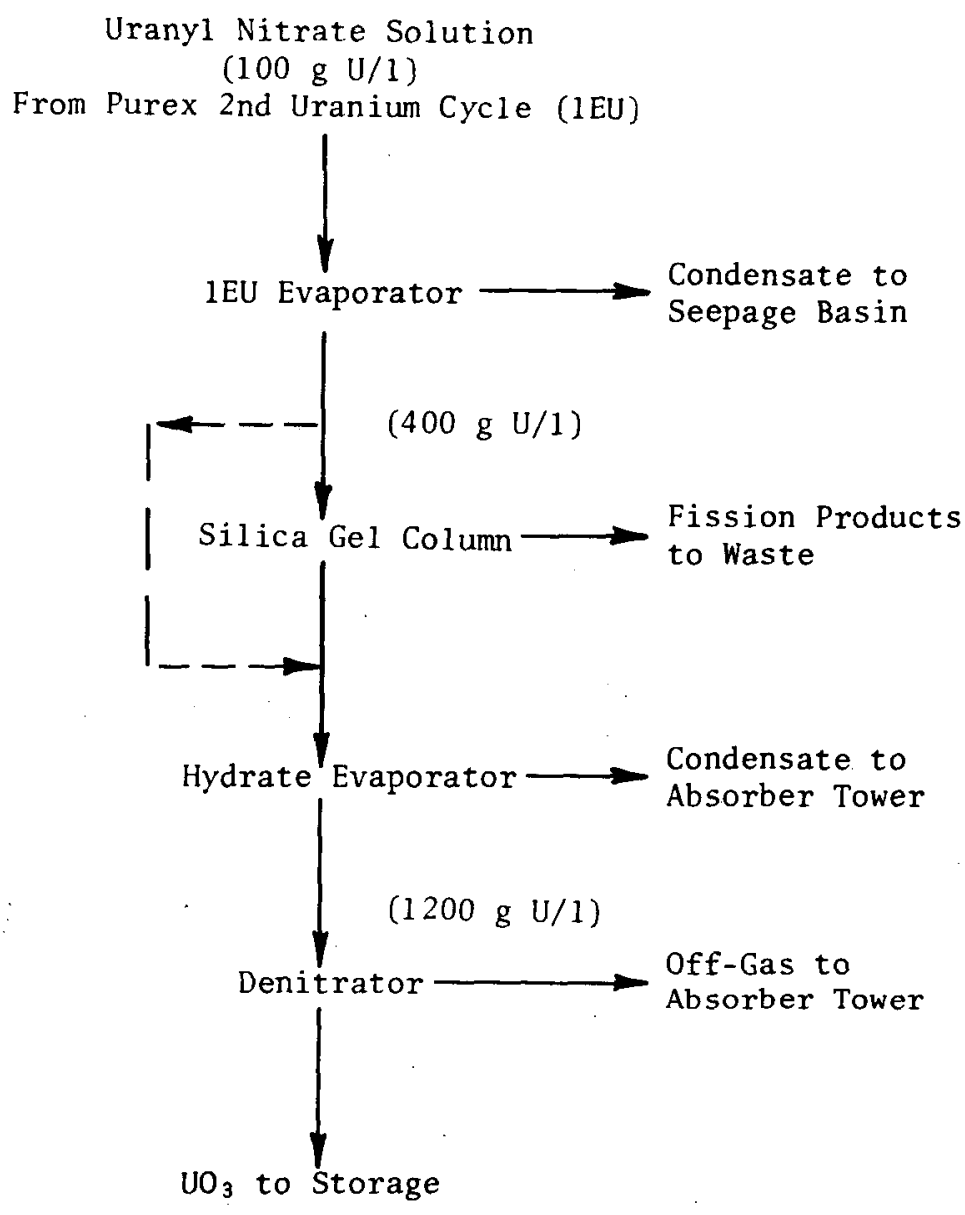

FIGURE 4. A-Line Process 


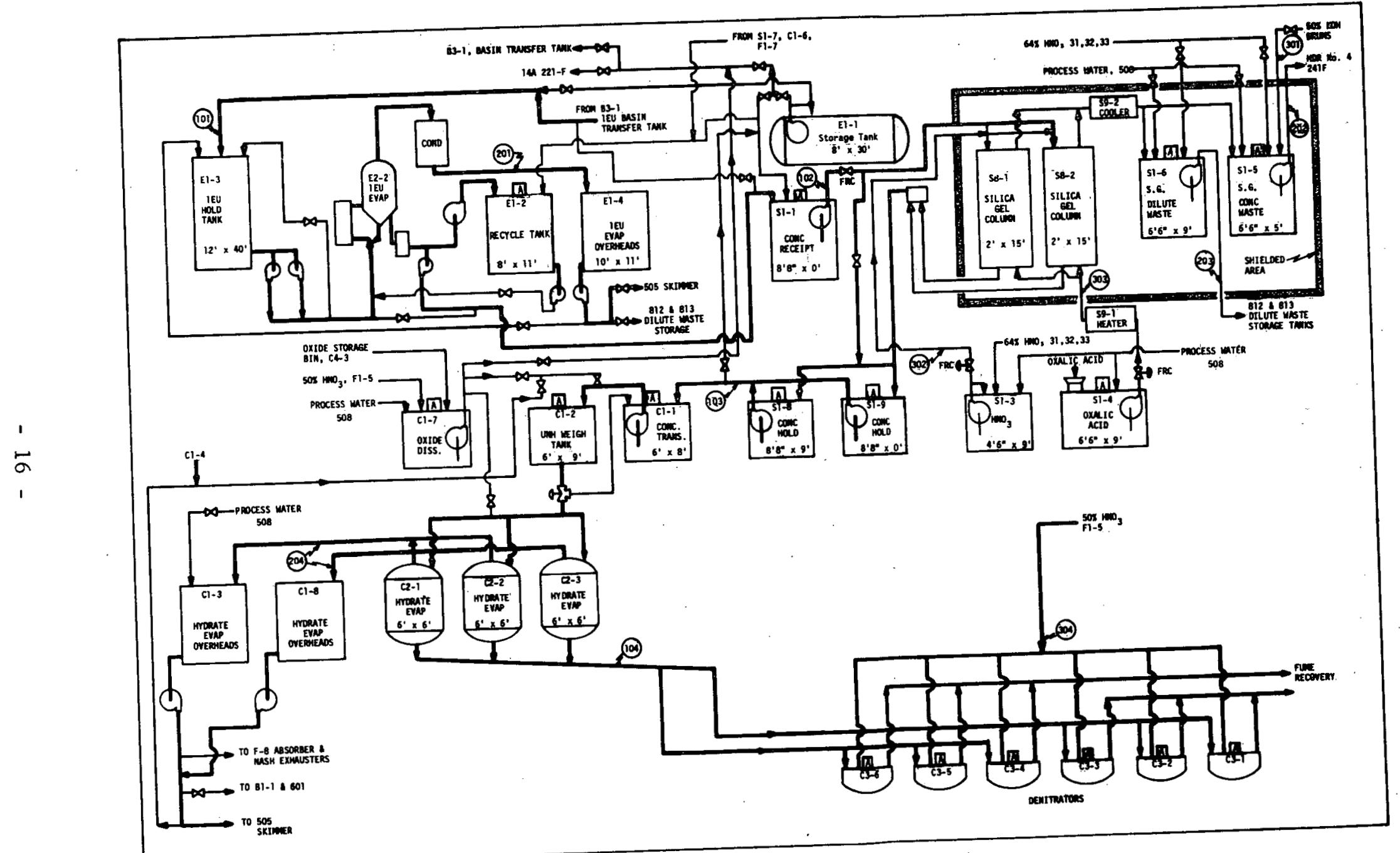

FIGURE 5. A-Line Flow Diagram 


\section{THE EXPLOSION AND ITS CAUSES}

On the morning of February 12, 1975, about 10:25 a.m., a denitrator emitted a dense cloud of gases into the denitrator room. Organic vapors contained in the emitted gases ignited and exploded, causing damage to the building and starting small fires. Personnel, warned by the gaseous cloud, had reached the exits to the room before the explosion, so injuries were minor. However, damages to the building required about 6 months to repair. Operation of the process resumed on August 11, 1975, following repairs, installation of safety equipment and control instrumentation, tests of the new equipment, and implementation of revised procedures designed to prevent recurrence of the incident.

Investigation revealed that the most probable cause of the explosion was the inadvertent introduction into Denitrator 4 of approximately 30 gallons of TBP in the form of $\mathrm{UO}_{2}\left(\mathrm{NO}_{3}\right)_{2}(\mathrm{TBP})_{2}$, its adduct with uranyl nitrate. TBP decomposes when heated with nitrates to temperatures $>130^{\circ} \mathrm{C}$ and produces flammable gases. ${ }^{4}$ This reaction had been thoroughly studied as the result of an earlier evaporator explosion at SRP. ${ }^{7}$ In the A-Line incident, the decomposition became so rapid that the gases could not be removed through the off-gas 1 ine from the denitrator. These gases, along with part of the liquid contents of the denitrator, erupted through the vessel port into the adjacent area where they ignited and exploded. The denitrator was essentially undamaged. Hydrated uranium compounds were found inside the vesse1, which indicated that the overall temperature in the denitrator had not exceeded $200^{\circ} \mathrm{C}$. However, uranium dioxide was found on the walls of the denitrator room; therefore, local temperatures in the area of the explosion must have exceeded $1000^{\circ} \mathrm{C}$, the temperature at which $\mathrm{UO}_{3}$ decomposes to $\mathrm{UO}_{2} \cdot{ }^{3}$

Investigation of the incident further revealed that the TBP introduced into Denitrator 4 was only part of the TBP that had accumulated in the process tanks over a period of time. About 28 gallons of $30 \%$ TBP and 45 gallons of $90 \%$ TBP in $\mathrm{NPH}^{*}$ were recovered from various hold tanks and process vessels following the incident. The quantity involved in the explosion ( $\sim 30$ gallons of $100 \% \mathrm{TBP}$ ) was determined from phosphate analyses of the residues. Appreciable TBP, perhaps 15 to 20 additional gallons of $100 \%$ TBP, may have been in the eight batches processed prior to the explosion.

* $\mathrm{NPH}=\mathrm{n}$-paraffin hydrocarbon, a kerosene containing predominantly 13- and 14-carbon n-paraffins and having an average molecular weight of 191 . 
Such a quantity of TBP was not expected to accumulate within the system, nor was it expected that TBP could be pumped from one process tank to the next. Organic material such as TBP was assumed to float and be retained in the tanks. This organic material was removed periodically by skimming off the top layer of solution from each hold tank.

The movement of the TBP through the A-Line process was attributed to the following sequence of events:

- About a year had elapsed since the last thorough cleanout of A-Line tanks. A cleanout had been planned, but had not been made at the startup of this processing campaign.

- One week prior to the explosion, one of the silica gel columns (Figure 5) for removing residual fission products was flushed and regenerated. In the flushing procedure, uranium is flushed from the column with dilute nitric acid. The column is then regenerated by an upflow of oxalic acid solution. The oxalic acid solution is removed separately and discarded; the aqueous uranium flush solution is mixed with normal process solution (1EU concentrate) in tanks downstream from this column

- The above flush-regenerate sequence was run five times in succession to maximize removal of fission products and reduce personnel exposure so as to allow visual inspection and replacement of the silica gel. In each sequence, the dilute nitric acid flush was made even though practically all of the uranium was presumably removed in the first flush. As a result, an unusually large flush solution was mixed with 1EU concentrate and sent through the process. Normally, fewer than five flushes are made if the silica gel is not to be inspected.

- Appreciable quantities of TBP-uranyl nitrate (TBP-UN) adduct probably had accumulated in the process tanks over a long time. The slight solubility of TBP in the UN solution is considerably decreased in the first evaporation; and thus, even if all undissolved TBP is removed prior to evaporation, there is a ready mechanism for slow accumulation of a separate phase in the tanks downstream.

- It is al so possible that the silica gel columns acted as deentrainment colums, and that the flushes contained some TBP-UN washed from the column. 
- When the aqueous phase in each tank became sufficiently dilute from the addition of the flushes, the organic layer unexpectedly settled at the bottom of the tanks and was pumped forward through the process. The specific gravities of UN solutions in the first two tanks were reduced to 1.19 and 1.35 , respectively; the specific gravity of organic material in these tanks was about 1.39 .

- Hydrate evaporation of the flush-concentrate mixture was conducted without incident because temperatures in the hydrate evaporators are not high enough to cause rapid decomposition or reaction of TBP. Rapid reaction occurred on heating to higher temperatures in the denitrator, with the consequences previously described.

Investigation determined that this incident stemmed from both procedural and technical deficiencies in the operation of the process.

Procedural deficiencies include ambiguities in some procedures enabling Production personnel to follow the requirements without achieving the intents of the procedures. In addition, sampling and removing organic layers were not being done as frequently as specified in the procedures, because a high degree of confidence had arisen in the effectiveness of the equipment for separating and retaining organic material.

It had long been established, however, that these organic layers would not float on a more dilute aqueous solution, but could sink and might therefore be pumped forward from the bottom of the tank. The specific gravity of the organic phase depends on the concentration of TBP in the organic phases and on the concentration of uranium in the aqueous phase. ${ }^{4}$ The data in Figure 6 illustrate a considerable range of uranium concentration where the TBP phase is denser than the aqueous. This possibility was not mentioned in the process documentation available to operating personnel; hence, they were not aware that conditions could exist in which the process tanks were ineffective for separating and retaining organic material. 


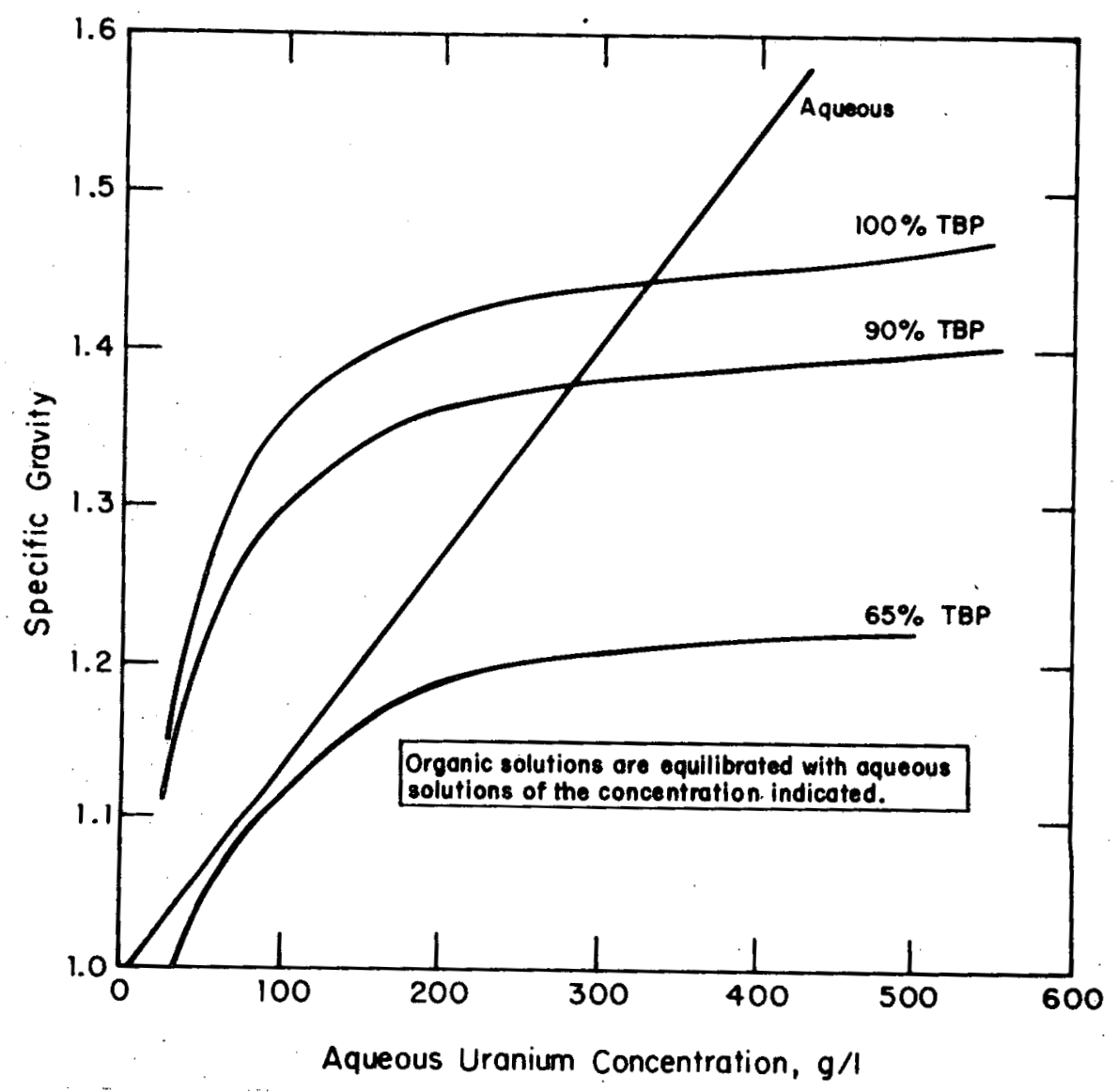

FIGURE 6. Specific Gravity of A-Line Solutions at $25^{\circ} \mathrm{C}$

It was not recognized that a quantity of organic material might be safe in an evaporator (where the temperature is less than $130^{\circ} \mathrm{C}$ ) but could be unsafe in a denitrator (where the temperature routinely reaches $225^{\circ} \mathrm{C}$ ). Rather, the converse was believed true; hydrate evaporators were placed in remote areas behind shielding, while denitrators are in an open room where they are directly maintained during operation. Foaming in denitrators, caused by decomposition of organic material, had sometimes led to foam-outs, i.e., overflow of liquid from the denitrator to the floor. The frequency of these foam-outs had been reduced by additions of an antifoam agent and by slower heating with close attention to the foam level. These methods were effective in controlling the intensity of foaming, as long as the quantity of organic material was relatively small, but were ineffective with the large quantity of organic material involved in the explosion. 


\section{HAZARDS AND SAFETY MEASURES}

Four types of safety hazards peculiar to the A-Line process and the equipment and procedural safeguards instituted to prevent accidents from these hazards are reviewed: 1) exposure of personnel to harmful chemicals, 2) exposure of personnel to radiation, 3) fires, and 4) explosions. Ordinary chemical, mechanical, electrical, or other hazards common to general industrial operations, building maintenance, etc., are not included.

\section{Exposure of Personnel to Harmful Chemicals}

Two chemicals encountered in A-Line are potentially hazardous to the health of operating personne1. These are uranium oxide (the product of A-Line) and nitrogen dioxide (evolved during denitration).

\section{Uranium Oxide Dust}

In the human body, uranium and its compounds behave as heavy metal poisons and also cause biological damage through radioactivity. ${ }^{8}$ Special precautions against the hazards of uranium oxide dust, such as the wearing of respirators or assault masks, are required when unloading the denitrators, pulverizing the oxide, and packaging it. Escape of oxide dust to the atmosphere is minimized by keeping equipment under negative pressure and by use of special hoods. Masks are required whenever any denitrator contents (fumes, liquid, or powder) escape a denitrator, and whenever process ventilation should become inadequate.

\section{Nitrogen Dioxide Fumes}

Nitrogen dioxide fumes also constitute a health hazard. The initial effects of inhalation may appear to be only mild irritation of the upper respiratory tract, but potentially fatal edema of the lungs may develop. ${ }^{8}$ These fumes can escape if the denitrator off-gas system malfunctions. These fumes are normally removed by the room ventilation system; however, operating personnel are required to evacuate the room or wear approved respiratory protection, such as a Scott Air-Pak (Scott Aviation, Lancaster, ND), whenever nitrogen dioxide can be detected by its odor or color. 
Escape of nitrogen dioxide into the denitrator room is prevented by operating the denitrator under vacuum. If vacuum cannot be maintained, the denitrator must be shut down. Audible and visible alarms alert both the control room and denitrator room personnel if the header vacuum drops to 0.6 in. $\left(\mathrm{H}_{2} \mathrm{O}\right)$. In this situation, extra off-gas capacity is available in addition to the exhausters. A steam-operated stack jet can be activated manually in response to the alarm; however, the jet is automatically activated (Table 4) whenever the header vacuum drops to $0.5 \mathrm{in} .\left(\mathrm{H}_{2} \mathrm{O}\right)$. When the jet is operating, the off-gas route is changed to bypass the acid absorber column (EP 301.19 in Figure 2). This route change results in increased flow of offgas and a loss of nitric acid that could have been recovered from nitrogen dioxide in the stacked fumes.

TABLE 4

Denitrator Services and Instrumentation

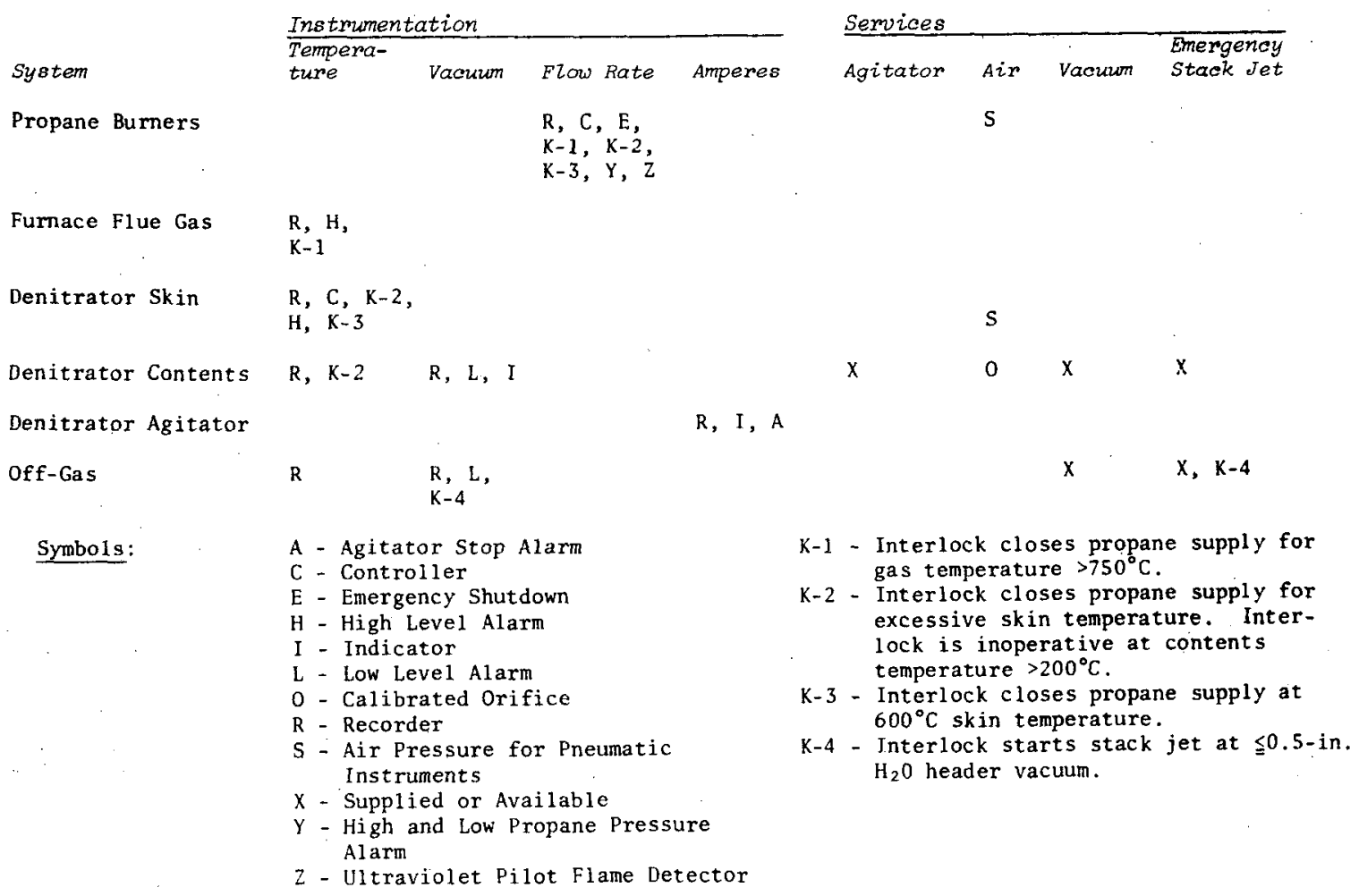


The off-gas system can become plugged and cause inadequate vacuum. Therefore, about 200 gallons of $50 \%$ nitric acid solution are boiled to dryness in each denitrator each week to dissolve. solids that have accumulated in the off-gas piping. Experience indicates that off-gas piping is effectively cleaned by this procedure.

If the off-gas system becomes plugged during denitration and causes the vacuum on an individual pot to decrease but the header vacuum to remain unaffected, an alarm on a vacuum recorder on each pot alerts denitrator room personnel that manual response is required. The pot vacuum can be increased by the stack jet and by bypassing the acid absorber column. If these methods are ineffective, the denitrator room is evacuated, and the furnace is shut down via emergency buttons outside the denitrator room.

\section{Exposure of Personnel to Radiation}

A-Line personnel are routinely exposed only to low levels of radiation. The main sources of radiation are the daughters of uranium-238 and fission products. The level of radiation from actinides is highest near large accumulations of uranium such as containers of the final product. The level of radiation from fission products (zirconium and niobium) is highest at the silica gel columns. Shielding around the columns reduces the exposure of personnel to radiation, but precautions must be taken in handling the relatively active waste solutions during silica gel regeneration. Special procedures cover all work inside this shielding, such as maintenance of the columns. The silica gel columns have been bypassed since resumption of process operations.

During periods of high process throughput or when process malfunctions cause decreased fission product removal efficiency, traces of radioruthenium may. be evolved during denitration. This volatile beta-gamma emitter tends to accumulate in denitrators and their off-gas 1 ines. Excessive exposure could result from prolonged exposure of personnel to these sources. Radiation levels in work areas and personnel radiation exposures are measured regularly to ensure that established conservative operating guides are not exceeded.

\section{Fires}

Oil leaking from the agitator gear box onto the top of a hot denitrator has occasionally resulted in fires. These fires were small and were easily extinguished with a wet mop or a portable 
fire extinguisher. Little or no damage and proces s delay were incurred. To minimize the possibility of the fires, equipment was modified to include improved oil seal and an oil collection cup on the agitator shaft. Improved procedures require inspections for oil leaks and cup cleanout before startup and during denitrator operation. There has not been a fire from this source since 1971 .

Fires have also occasionally occurred from spontaneous combustion in the wastes generated during cleanup operations following a foam-out. The reduction in the frequency of foam-outs expected from the improved denitrator operation discussed above should make this type of fire rare.

\section{Explosions}

Explosion hazards are a major concern for the safe operation of A-Line. Because organic material is inherent throughout A-Line operations, emphasis is placed on methods to minimize quantities of organic material in process solutions. Organic material can create an explosion hazard during evaporation and denitration. Propane explosions in the denitrator heating system are also pósibie:

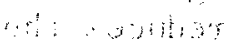

\section{Organic Materials}

Traces of dissolved TBP, entrained $30 \%$ TBP, and the products of therma 1 and radiolytic decomposition of TBP accompany the 1EU uranium solution that is processed in A-Line. These materials enter from the solvent extraction process and, therefore, are inherent to A-Line process solutions. Provisions were made to minimize amounts of these organic materials in A-Line.

Accumulation of substantial amounts of TBP solutions in the A-Line process is avoided by the following precautions:

1. Purex solvent $(30 \% \mathrm{TBP}-70 \% \mathrm{NPH})$ in feed to the 1 EU evaporator is minimized by repeated decantation.

2. Gradual accumulation of dilute or concentrated TBP in process tanks is minimized by frequent inspection and organic removal (skimming) prior to evaporation, or by agitation of stored concentrate solutions in subsequent processing.

3. The organic content of all evaporator feed is measured; the second (hydrate) evaporation does not begin until the limits on organic content are met by settling and removing the floating organic layer, if necessary. 
4. The density of evaporator feeds is maintained so that any organic present will float in a settled tank and can be detected by inspection.

The detailed application of these principles is discussed below.

Minimizing Solvent Input. The quantity of Purex solvent associated with feed to A-Line is minimized during processing by decantation. Four decantations are made: the 1E bank decanter in Building 221-F; a small box decanter; Tank B-3-1; and Tank E-1-3. (The process equipment and equipment locations are shown in Figures 2 and 5.)

Plant experience indicates that the quantity of entrained $30 \%$ TBP escaping the $1 \mathrm{E}$ bank decanter and removed in the box decanter is routinely small. The box decanter acts as a backup in case of failure or upset of the $1 \mathrm{E}$ bank decanter; these two decanters combined provide the first line of defense against organic materials in A-Line by preventing large, sudden inputs of Purex solvent. Tank B-3-1 (8x $11 \mathrm{ft})$ is a transfer tank. Solution flows in by gravity from the box decanter and is pumped from the bottom of this tank to Tank E-1-3.

Tank E-1-3 is a $12 \times 40-\mathrm{ft}$ silo tank where feed is stored for 1 to 2 days to allow entrained $30 \%$ TBP to separate as a floating layer. The shape of this tank reduces the surface-tovolume ratio of solutions and thereby increases the efficiency of inspections to detect floating organic layers and of skimming to remove these layers. Tank B-3-1 is a less efficient decanter than Tank E-1-3 because the residence times for solutions are shorter.

Decantation efficiency in this part of the A-Line process is enhanced by procedures and by physical controls. No agitators are installed on these tanks. Procedures place minimums on the liquid levels in each tank (40\% in Tank B-3-1, 52\% in Tank E-1-3), so that they are never pumped empty and floating organic layers (which are never very thick, as shown below) cannot be pumped forward. A low-level alarm sounds, and the pump cuts off automatically if Tank E-1-3 is pumped below the minimum level. Tanks B-3-1 and E-1-3 have inlet baffles that ensure smooth blending of incoming solutions with stored solutions and avoid splashing or re-entrainment of organic layers.

Reliance on decantation for organic control is not new. This safeguard was included in the original A-Line process and has been used since startup in 1954. No equipment changes were made in this part of the A-Line system, except for the automatic pump cut-off for Tank E-1-3. 
Plant experience indicates that the amount of $30 \% \mathrm{TBP}$ entrained in the $1 \mathrm{EU}$ stream is small, and that these decanting tanks effectively remove the small amount of entrained Purex solvent. For instance, the accumulation of organic material in A-Line tanks beyond Tank E-1-3 is small compared to the large volumes of aqueous solution processed. At an annual throughput of 6 million gallons of 1 EU solution (2400 tons of uranium) and 0.1 volume $\%$ entrainment, 6000 gallons of $30 \%$ TBP would have collected annually in A-Line tanks. Inspections of tanks in the past and after the explosion revealed much lower volumes in A-Line. The equivalent of only about 330 gallons* of $30 \%$ TBP are estimated to have been present at startup of the February 1975 campaign, in spite of the fact that over a year had elapsed since the tanks were last cleaned.

Analyses of process solution also indicate that the level of entrained solvent in lEU solution is low. The concentrations of phosphate in solutions in Tanks B-3-1 and E-1-3 after the explosion were 60 and $42 \mathrm{ppm}$, respectively, which indicated TBP concentrations of 167 and $117 \mathrm{ppm}$, respectively. The concentrations are about the quantity of TBP expected in solvent-saturated Purex product solution; the solubility of TBP in this solution $(100 \mathrm{~g} \mathrm{U} / 1)$ is about $140 \mathrm{ppm}$ (Figure 7). ${ }^{4}$

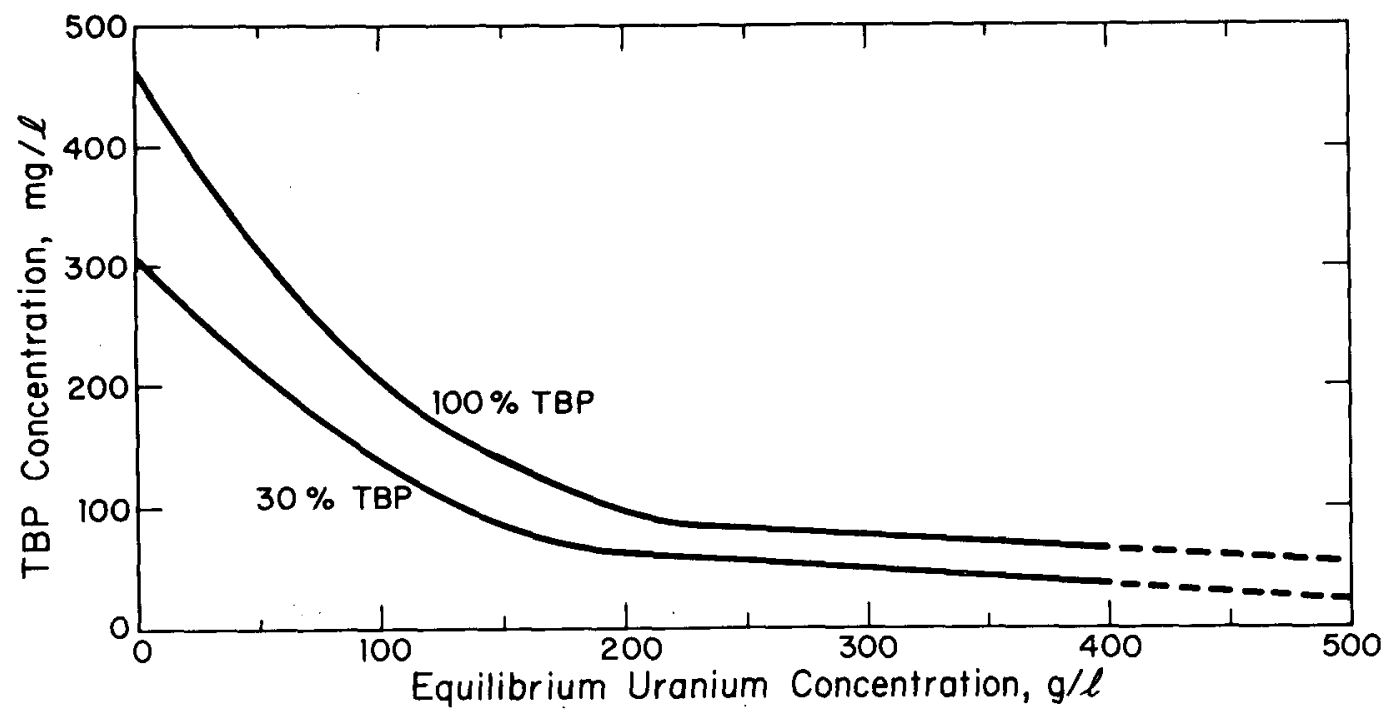

FIGURE 7. Solubility of TBP in Aqueous Uranyl Nitrate Solution at $25^{\circ} \mathrm{C}$

* 28 gallons of $30 \%$ TBP +45 gallons of $90 \%$ TBP +50 gallons of $100 \%$ TBP, see page 17 . 
From the quantities of TBP that had accumulated in A-Line tanks since the last organic cleanout and from the measured phosphate concentrations in process solutions, the IEU solution drawn from Tank E-1-3 for evaporation is estimated to normally contain entrained $30 \%$ TBP at a level considerably below 0.1 volume $\%$, possibly 0.006 volume $\%$. Therefore, decantation in Tank E-1-3 is considered effective, and a sudden accumulation of organic material in A-Line tanks downstream from Tank E-1-3 is highly unlikely.

Minimizing Gradual Accumulation. Additional methods of organic material control are necessary to prevent slow accumulation of TBP. The 1EU solution fed to the 1EU evaporator contains both dissolved TBP and traces of entrained 30\% TBP. Evaporation concentrates the entrained $30 \%$ TBP by stripping the n-paraffin hydrocarbon diluent so that the TBP concentration increases in the dispersed organic phase. Evaporation also reduces the solubility of the dissolved TBP from $140 \mathrm{mg}$ TBP per liter of 1EU solution to $60 \mathrm{mg}$ TBP per liter of concentrate (Figure 7 ), ${ }^{4}$ forcing TBP from solution as a fine suspension. The net result of these two effects is that a layer of $290 \%$ TBP can form slowly on the 1EU concentrate. The potential accumulation (at 2400 ton $U / y r$ ) from dissolved TBP alone would be over 500 gallons of $290 \%$ TBP/year; TBP entrained in the $1 E U$ solution would add to this potential accumulation. However, only about 100 gallons of $290 \%$ TBP had accumulated since the A-Line concentrate hold tanks were last cleaned.* Thus, it can be concluded that the TBP coalesces into a layer rather slowly after the solubility is reduced, and that most of this TBP ( $~ 0.2$ gal $\mathrm{TBP} /$ ton $\mathrm{U}$ ) is routinely fed to the denitrator along with the uranyl nitrate.

The quantity of TBP that can accumulate is now kept to a minimum by requiring that some tanks be continuously agitated. Agitation is practiced only in the hold tanks downstream of the IEU evaporator; the tanks upstream of the 1EU evaporator are used as decanters, as previously described. Agitation of the concentrated uranyl nitrate solution prevents coalescing and separation of entrained TBP produced by the change in TBP solubility in the lEU evaporator and disperses any entrained TBP already coalesced. These small quantities of TBP can be processed safely in the hydrate evaporators and the denitrators, but the hazard potential increases if the organic is allowed to accumulate for long periods of time in an unagitated hold tank.

* 45 gallons of $90 \%$ TBP +50 gallons of $100 \%$ TBP. 
In case a tank agitator fails, procedures require cessation of process operations with that tank to prevent disproportionate organic accumulation while repairs are being made. In the case of undetected agitator failure, the tank involved temporarily becomes a decanter and the quantity of TBP moving forward in the process will decrease. Regardless of how long the failure remains undetected, the tank contents are agitated and sampled after the agitator is repaired. The organic content of the agitated solution must be less than 0.1 volume $\%$ before the tank contents are processed.

The quantity of TBP that can accumulate in A-Line tanks is further kept to a minimum by requiring that all tanks be frequently skimmed to remove floating organic material. Each week, the A-Line is shut down, all hold tanks are visually inspected for accumulated organic material, and any organic material is removed. This requirement makes possible simultaneous inspection of all tanks weekly. A list of tanks inspected is given in Table 5 .

TABLE 5

A-Line Tank Operation

\begin{tabular}{|c|c|c|c|c|c|}
\hline Tank & Dimensions & $\begin{array}{l}\text { Stored } \\
\text { Solution }\end{array}$ & $\begin{array}{l}\text { Frequency o } \\
\text { Visual } \\
\text { Inspection }\end{array}$ & $\frac{f}{O / A}$ & Agitated \\
\hline B-3-1 & $8^{\prime} \times 11^{\prime}$ & 1EU & Week1y & None & No \\
\hline$E-1-3$ & $12^{\prime} \times 40^{\prime}$ & 1EU & Weekly & $1 /$ shift & No \\
\hline$E-1-2$ & $8^{\prime} \times 11^{\prime}$ & Miscellaneous & $a$ & $a$ & Yes \\
\hline$S-1-1$ & $8.8 \prime \prime \times 9 '$ & Concentrate & Weekly & Weekly & $b$ \\
\hline$S-1-8,-9$ & $8.81 \times 91$ & S.G. product & Weekly & Each batch & Yes \\
\hline C-1-1 & $6^{\prime} \times 8^{\prime}$ & H.E. feed & Weekly & Week1y & Yes \\
\hline$C-1-2$ & $6^{\prime} \times 9^{\prime}$ & H.E. feed & None $e^{c}$ & None & $\mathrm{No}^{c}$ \\
\hline
\end{tabular}

a. Before evaporation.

b. Not agitated if silica gel columns are in use; agitated if silica gel columns are not in use.

c. Emptied during each transfer to an evaporator.

O/A: organic-aqueous ratio.

S.G. product: solution from the silica gel columns.

H.E. feed: solution to the hydrate evaporators. 
The criterion for skimming any tank is the presence of a continuous layer of floating organic material on the surface. The inspection procedure involves visually examining the surface of the solution and taking dip samples to detect such a layer. To aid in this examination, A-Line operations are to be scheduled so that at each shutdown all tanks are nearly full of solution. Whenever a continuous layer is found, the surface of the solution in that tank is skimmed, according to a written procedure, until the remaining organic material forms into a discontinuous layer. In tanks downstream of the 1EU evaporator, the tank contents are then agitated, sampled, and analyzed for organic content. Inspection results, sample results, and action taken are logged. A-Line operation is not resumed until all tank inspections are complete, al 1 tanks are free of continuous organic layers, and less than 0.1 volume \% organic material is present in all agitated tanks or in the aqueous phase of Tank E-1-3.

Tank S-1-1 represents a special case, because its role in organic control depends on whether or not the silica gel columns are in use. Operation of silica gel columns depends on the need to reduce the ${ }^{5} \mathrm{Zr}-{ }^{95} \mathrm{Nb}$ content of the solutions. When adequate decontamination is attained in the Purex process, the silica gel columns are bypassed, and Tank $\mathrm{S}-1-1$ is operated as an agitated storage tank.

Silica gel columns have not been used since the resumption of A-Line operations, because ${ }^{95} \mathrm{Zr}-{ }^{95} \mathrm{Nb}$ content of the $1 \mathrm{EU}$ solution has been satisfactory. New procedures for resuming operation of these columns have not been formulated.

If the silica gel columns are used, it would be useful to operate Tank $S-1-1$ as a decanter for partial removal of organic from feeds to the silica gel columns. Tank S-1-1 is the hold tank for $1 \mathrm{EU}$ evaporator bottoms in which the solubility of TBP in uranyl nitrate solution has been reduced by the evaporation of 1EU solution. Operation of Tank S-1-1 as an agitated tank could permit gradual accumulation (in the silica gel columns) of the TBP that comes out of solution.

1EU Evaporator Feed Analysis. Feed to the 1EU evaporator is measured in samples taken at the Tank E-1-3 bottom outlet via a sample tap on the pump. Because Tank E-1-3 has no agitator, the se samples of settled solution are representative of solution fed to the IEU evaporator. Samples are taken at a frequency of one per shift during process operation; Tank E-1-3 holds about 14 tons of uranium in solution, enough feed for about 4 shifts at a 12-ton $\mathrm{U} /$ day process rate. 
An enforceable 1 imit cannot be imposed on the quantity of TBP in 1 EU evaporator feed, because evaporation in this continuous evaporator usually begins long before analytical results from a sample can be available. However, the average TBP content of $1 E U$ evaporator feed must be controlled so that the concentration of TBP in the hydrate evaporator feed is within safe limits. Because concentrate hold tanks are agitated to homogenize the process solution and any organic phase present, usually no organic is removed prior to sampling hydrate evaporator feed. If entrained $30 \%$ TBP in 1EU evaporator feed is excessive, the hydrate evaporators will eventually have to be shut down for lack of acceptable feed while the lEU concentrate is settled and skimmed. Consequently, should the average of triplicate 1EU evaporator feed samples exceed 0.10 volume $\%$ organic-to-aqueous $(0 / A)$, the 1 EU storage tank contents are allowed to separate, the organic is skimmed, and the remaining contents resampled. Feed for the lEU evaporator is not drawn from the storage tank until acceptable sample results are received.

Hydrate Evaporator Feed Analysis. Feed to the hydrate evaporators is sampled from Tanks $\mathrm{S}-1-8$ and $\mathrm{S}-1-9$. These two tanks are operated independently. Each is filled from either Tank S-1-1 or from a silica gel column and sampled. When sample results are acceptable, the solution is then fed in 3 or 4 batches to Tank C-1-1 while the other tank is being filled. Samples are taken with the agitator running so that they will be representative of the entire tank contents. Homogeneity has been demonstrated satisfactorily in SRP tests with mixtures of known proportions (Table 6). A batch of hydrate evaporator feed is pumped from Tank C-1-1 to Tank C-1-2, which empties into the evaporator.

The maximum allowable quantity of TBP in a batch of hydrate evaporator feed is the smaller of 0.2 volume \% TBP or 1.2 gallons of TBP-UN adduct. This concentration can be reliably measured and is the maximum safe quantity in a denitrator batch, as discussed later. In practice, the operating limit on TBP is set at 0.1 volume $\%$ of the hydrate evaporator feed. Further, a set of three, 2-ounce samples are taken that must average no more than 0.1 volume $\%$ TBP. This procedure is designed on the basis of plant sampling tests and a statistical analysis of the results, which indicates $95 \%$ confidence that the true value of a sample analyzing 0.1 volume $\%$ of TBP is no greater than 0.2 volume $\%$. Test data are shown in Table 6. Should a set of samples give results that average $>0.1$ volume $\% 0 / A$, procedures require that agitation cease; i.e., the tank contents are allowed to settle for at least 4 hours, the organic is skimmed, the tank is reagitated and then resampled. During this re-analysis, no solution may be processed from the tank, and the process is shut down if no other feed is available. 
TABLE 6

A-Line Sampling Data

$\begin{array}{llllll}\text { Type of } & \begin{array}{l}\text { TBP Content } \\ \text { as Made, } \\ \text { vol \% }\end{array} & \begin{array}{l}\text { Number of } \\ \text { Determi- } \\ \text { nations }\end{array} & \begin{array}{l}\text { Average } \\ \text { Result, } \\ \text { vol \% }\end{array} & \begin{array}{l}\text { Standard } \\ \text { Deviation } \\ \text { from Aver- } \\ \text { age, vol \% }\end{array} & \begin{array}{l}\text { Bias, \% } \\ \text { of True } \\ \text { Value }\end{array} \\ \text { Sampler } & 0.09 & 10 & 0.081 & 0.020 & -9 \\ \text { Sampler } & 0.18 & 10 & 0.168 & 0.044 & -7 \\ \text { Sampler } & 0.08 & 12 & 0.078 & 0.049 & -3 \\ \text { Dipped } & 0.08 & 12 & 0.075 & 0.027 & -6 \\ \text { Sampler } & 0.12 & 12 & 0.108 & 0.042 & -10 \\ \text { Dipped } & 0.12 & 12 & 0.078 & 0.025 & -35 \\ \text { Samp1er } & 0.16 & 12 & 0.12 & 0.066 & -25 \\ \text { Dipped } & 0.16 & 12 & 0.13 & 0.043 & -19\end{array}$

a. All samples were taken with tank agitators operating.

Detecting Heavy Organic Layers. Decantation and skimming do not remove organic materials heavier than the aqueous phase. Such heavy organics can mix with the aqueous contents of a hold tank or can form layers on the tank bottom. Thus, sampling may not be reliable when heavy organic material is present; in unagitated tanks, a thin layer might not be sampled; and in agitated tanks, mixing may be incomplete.

Heavy organic material can form in A-Line from several sources. TBP and uranyl nitrate react chemically to form an adduct $\left.\left[\mathrm{UO}_{2}\left(\mathrm{NO}_{3}\right)_{2} \text { (TBP }\right)_{2}\right]$ that is relatively insoluble in UN solution. ${ }^{4}$ The specific gravity of an organic solution containing this adduct depends on the concentration of urany1 nitrate in the aqueous phase and on the concentration of TBP in the organic phase. Evaporation of 1 EU solution normally results in stored solutions containing about $400 \mathrm{~g} \mathrm{U} / 1$; any $30 \% \mathrm{TBP}$ and dissolved TBP in the 1 EU solution is concentrated to $>90 \%$ by evaporation. As shown in Figure $6,90 \% \mathrm{TBP}$ in equilibrium with aqueous solutions containing $>280 \mathrm{~g} \mathrm{U} / 1$ will float; but $100 \% \mathrm{TBP}$ will not float unless the aqueous solution contains $>330 \mathrm{~g} \mathrm{U} / 1$. Consequently, once a $1 E U$ solution is evaporated, the potential exists for a heavy organic phase that will sink to the tank bottom if the aqueous solution is diluted below $330 \mathrm{~g} \mathrm{U} / 1$ ( pecific gravity $=1.445 \mathrm{~g} / \mathrm{ml}$ ) . 
Uranyl nitrate can also form a heavy organic compound, sometimes referred to as red oil, with the thermal and radiolytic degradation products of TBP. The quantity of these degradation products in Purex second uranium cycle solvent is minimized by solvent washing and by the low radiation levels in the process area. No evidence of this adduct was found during tank inspections. ${ }^{3}$

The safeguards against these heavy organic layers are to agitate the 1EU concentrate hold tanks (S-1-1, S-1-8, S-1-9, and $\mathrm{C}-1-1)$ and to maintain the specific gravity of these aqueous solutions above 1.48 so that $90 \%$ and $100 \%$ TBP will float. Visual inspection and skimming safeguards are effective for floating organic materials. As discussed previously, tests have shown that in aqueous solutions of this density the organic phase will mix with the aqueous phase when agitated to ensure that a representative sample is obtained.

Maintenance operations, such as flushing a tank or column to remove uranium, sometimes create solutions of low density. Lowdensity solutions are also produced during startup of the 1EU evaporator. Blending these solutions with 1EU concentrate could lower the specific gravity of the blend below 1.48. A low-density flush solution could also contain adduct flushed from a tank or column. Consequently, these solutions are handled by a special procedure requiring that they be routed to a tank (usually Tank E-1-2) designated for storage of dilute solution. 1EU evaporator drawoff is routinely routed to Tank E 1-2 until the specific gravity of the concentrate reaches 1.50. Only then is the 1EU concentrate sent forward to Tank S-1-1. Any time that the specific gravity is less than 1.50 , concentrate is again diverted to Tank E-1-2, unti1 evaporator operation is corrected.

Solutions of low density that are recycled to the continuous evaporator must meet the same requirements that are met by evaporator feed from Tank E-1-3. That is, each batch of solution from Tank E-1-2 must be $\leqslant 0.1$ volume $\% 0 / A$. Because Tank E-1-2 is agitated (unlike Tank E-1-3), samples are taken during agitation to ensure representative samples. Moreover, the agitator must be on and operable at all times to homogenize the contents so that layers of organic cannot form either on the surface or the bottom of Tank E-1-2. If the agitator on Tank E-1-2 is inoperable, the tank must be isolated from process operation so that no feed can be pumped to the continuous evaporator.

Adherence to procedures described in this section will prevent hazardous quantities of organic material from reaching the denitrator. 


\section{Explosions in Evaporators}

Explosive pressures and combustible gases could be produced in the IEU and hydrate evaporators through decomposition of entrained solvent or the TBP-UN adduct. The principal safeguard is control of solution temperatures. Temperature in the 1EU evaporator is controlled by automatically limiting the steam pressure in the steam coils of this evaporator to $25 \mathrm{psig}$, which corresponds to a maximum steam temperature of $130^{\circ} \mathrm{C} .9^{9}$ Loss of heat from the steam to the equipment and to the evaporator condenser results in a solution temperature 1 ess than $130^{\circ} \mathrm{C}$. At or below $130^{\circ} \mathrm{C}$, there is no hazard from decomposition reactions because reaction rates are slow (Figure 8 ). The kinetics of the decomposition reactions are discussed in Reference 4.

In the hydrate evaporators, temperature is controlled to $130^{\circ} \mathrm{C}$ or less by an automatic interlock between the steam supply and the solution temperature. Temperature is controlled directly in the hydrate evaporator (rather than by controlling steam pressure to $25 \mathrm{psig}$ as in the 1EU evaporator) because high steam pressures (up to $80 \mathrm{psig}$ ) are required in the coils of the hydrate evaporator for process efficiency.

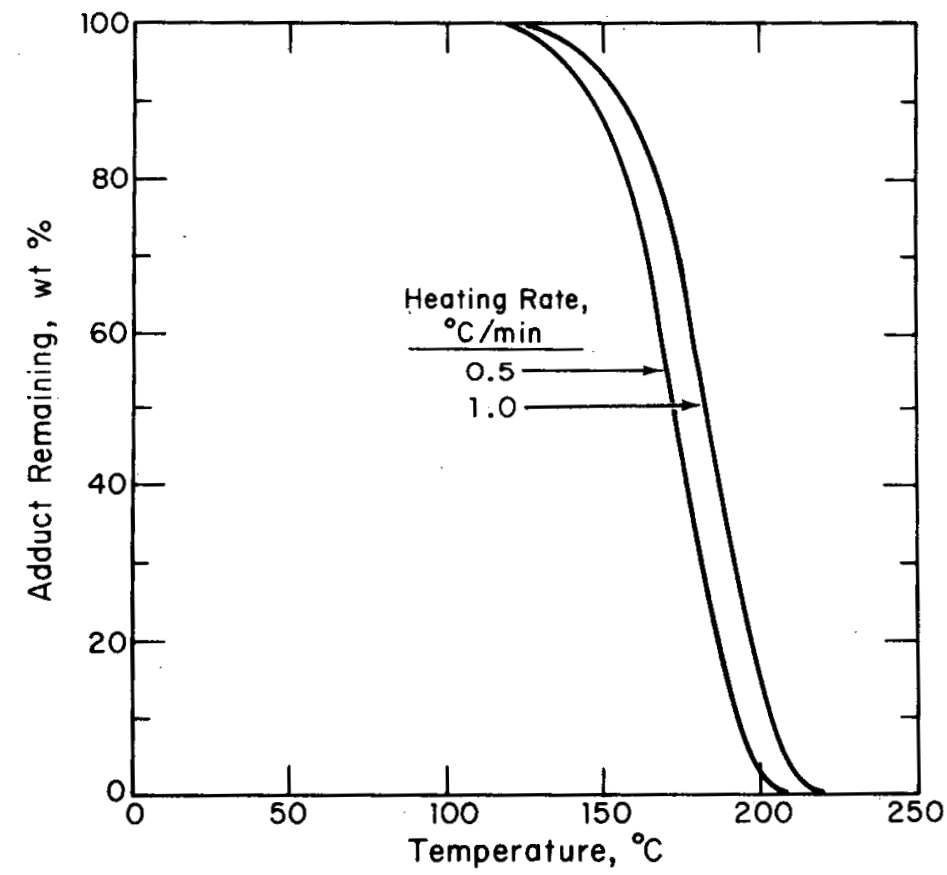

FIGURE 8. Thermal Stability of $\mathrm{UO}_{2}\left(\mathrm{NO}_{3}\right)_{2}(\mathrm{TBP})_{2}$ Adduct 
Should the temperature controls on these evaporators fail in spite of this instrumentation, the quantity of organic material in the feeds must be tolerably small. Limitation of entrained solvent in feed to the $1 E U$ and hydrate evaporators relies on the administrative, procedural, and physical controls already discussed (see. "Organic Materials"). Prior to February 1975, the hydrate evaporator had been operated with a limit on organic content of 0.5 volume $\%$ in the feed and a maximum temperature of $125^{\circ} \mathrm{C}$. The 30 gallons of TBP involved in the February 1975 incident were heated safely in the hydrate evaporator because the temperature reached only $121^{\circ} \mathrm{C}$.

\section{ExpZosions in Denitrators}

Explosions can occur during denitration, if excessive TBP-UN adduct is present. Studies following the February 1975 explosion established the maximum quantity of TBP permitted in a denitrator as that equivalent to 0.2 volume $\%$ of the feed to the hydrate evaporator. ${ }^{4}$ Evaporator operation under a limit of 0.5 volume $\%$ was satisfactory for 21 years, although foaming in the denitrators occurred frequently. The denitrator limit is imposed on feeds to the hydrate evaporators because TBP is less difficult to measure in, and to remove from, hydrate evaporator feed than from the hydrate evaporator product. Control of the quantities of TBP in the denitrators depends on the methods discussed above.

Because complete removal of TBP from denitrator feed is impractical in existing equipment, safe operating conditions have been defined for the limited amount of TBP permitted in the denitrator. Safe denitrator operation depends on three principles:

1. The quantity of organic material in the denitrator, measured in feed to the hydrate evaporator, is maintained as low as practicable and below a reliably detectable value.

2. The rate of temperature rise of the denitrator contents is limited, so that the allowable quantity of TBP-UN adduct decomposes at a controlled rate.

3. The flow of air through the denitrator during the decomposition of the TBP-UN adduct must be adequate to dilute gaseous decomposition products below their flammability limit.

These three principles are mutually interdependent. For instance, at a given temperature, doubling the quantity of TBP-UN adduct requires that the air flow be doubled to produce the same off-gas concentration. As the rate of temperature rise increases, a given quantity of TBP-UN adduct decomposes more rapidly and 
the air flow must be increased accordingly. Laboratory studies of the thermal decomposition of TBP in uranyl nitrate solution have established the interdependent relationship of these three parameters under safe operating conditions, which can be summarized by a correlating equation:

where:

$$
\left(\mathrm{V}_{\mathrm{o}} \cdot \Delta \mathrm{T}\right) / \mathrm{F} \leqq 0.0125
$$

$$
\begin{aligned}
& \mathrm{V}_{\mathrm{o}}=\text { volume of TBP-UN adduct, gallons } \\
& \Delta \mathrm{T}=\text { rate of temperature rise of denitrator contents } \\
& \text { between } 150 \text { and } 200^{\circ} \mathrm{C} \text {, }{ }^{\circ} \mathrm{C} / \mathrm{min} \\
& F=\text { off-gas flow, } \mathrm{ft}^{3} / \mathrm{min}(\mathrm{cfm})
\end{aligned}
$$

The correlating value $(0.0125)$ is conservatively chosen from calculated values varying from 0.0125 to 0.0140 , for temperature rates between 0.5 and $2.0^{\circ} \mathrm{C} / \mathrm{min}$, and for off-gas flows up to 200 cfm. ${ }^{4}$ The correlating value is also conservative in maintaining gaseous decomposition products below their flammability limits because of the following assumptions:

1. Three moles of combustible gas are produced per mole of TBP decomposed.

2. The flammability limit ( 1.5 volume $\%$ in air $\left.^{4}\right)$ is based on the most combustible gas that can be produced, butyl nitrate. (Actually a complex mixture of $\mathrm{C}_{4}$ hydrocarbons, carbon dioxide, and nitrogen compounds is produced, with the composition dependent on temperature and mixing conditions.)

3. No credit is taken for dilution by noncombustible gases (e.g., carbon dioxide) that are produced, nor for gases with higher flammability limits.

4. A minimum airflow into the denitrator is maintained by admitting air through a calibrated orifice at a differential pressure maintained above a minimum value $\left(0.5-i n . \mathrm{H}_{2} \mathrm{O}\right)$. No credit is taken for expansion of the gas by heating within the denitrator, for air inleakage at other points in the denitrator, or for steam from the process solution.

As an example of safe denitration conditions derived from the correlating formula, one ton of uranium at an $0 / A$ of 0.2 volume $\%$ (when fed to the hydrate evaporator) would contain 1.2 gallons of TBP-UN adduct. This quantity can be denitrated safely so long as air flow through the denitrator is at least $96 \mathrm{cfm}$ and the rate of temperature rise does not exceed $1^{\circ} \mathrm{C} / \mathrm{min}$. 
Laboratory studies indicate that the temperature and off-gas conditions need not be imposed after the denitrator contents reach $200^{\circ} \mathrm{C} .^{4}$ Calculations and experiments have shown that for these slow heating rates, the decomposition of TBP is practially complete at $200^{\circ} \mathrm{C}$ (Figure 8 ).

The correlating equation above should not be applied to concentrations of TBP larger than 0.2 volume $\%$. Calculations indicate that the heat of reaction of TBP can significantly increase the temperature of the denitrator contents. ${ }^{4}$ Large quantities of TBP could therefore cause a self-accelerating reaction, so that the rate of temperature rise could no longer be controlled by the normal method of limiting the denitrator skin temperature, as discussed below.

Temperature Control. Instrumentation (Table 4) in the denitrators measures the temperature of the denitrator contents. The temperature of the outside of the denitrator bottom, known as the skin temperature, is a primary control parameter. P1ant tests correlated the denitrator contents temperature to the skin temperature, via a thermocouple installed in Denitrator 1 (Figure 9 and Table 7). The data are for a solution containing one ton of uranium between 150 and $200^{\circ} \mathrm{C}$ (the region of maximum heating rate and the crucial region for organic decomposition). From these data and similar tests in the other denitrators, the initial skin temperatures in Table 8 were chosen for a nominal contents heatup rate of $0.6^{\circ} \mathrm{C} / \mathrm{min}$.

The denitrator contents temperature is monitored continuously by a recorder and periodically by the operator to determine that the heatup rate is the desired $0.6^{\circ} \mathrm{C} / \mathrm{min}$. Operating procedures require that the operator calculate the rate of rise of the denitrator contents temperature every 20 minutes. Should the average rate over a 20 -minute period reach $0.7^{\circ} \mathrm{C} / \mathrm{min}$, the skin temperature controller setting is reduced until the rate is less than $0.7^{\circ} \mathrm{C} / \mathrm{min}$.

A control system prevents operator error in setting the initial skin temperature. An interlock automatically shuts down the propane burners if the skin temperature exceeds a specified maximum value before the denitrator contents reaches $200^{\circ} \mathrm{C}$ (a violation of written procedure). The maximum value is $25^{\circ} \mathrm{C}$ higher than the initial setting in Table $8\left(475^{\circ} \mathrm{C}\right.$ in Denitrator 1$)$. When the denitrator contents temperature reaches $200^{\circ} \mathrm{C}$ in normal operation, the interlock opens to permit a higher skin temperature (see Table 4). 


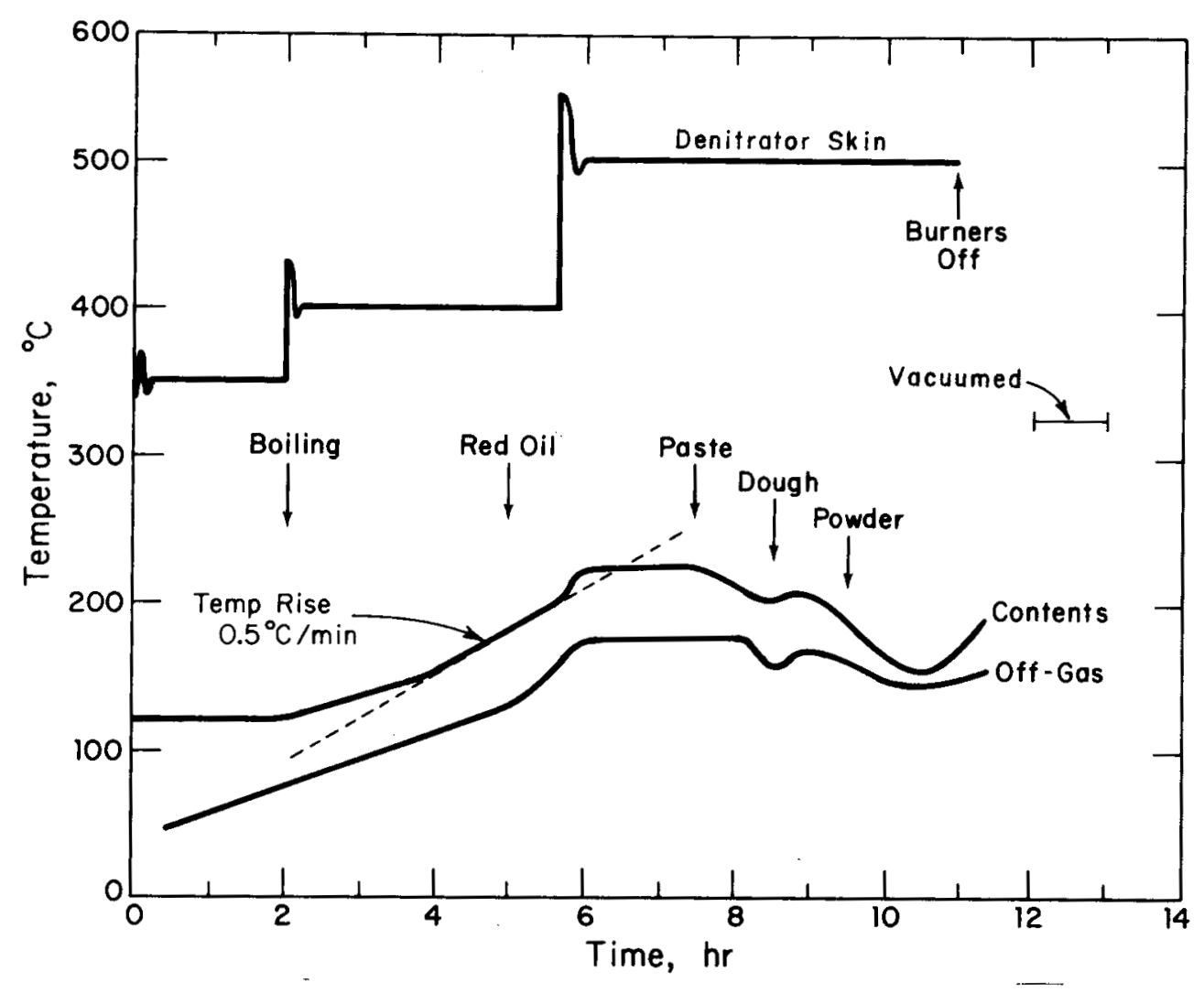

FIGURE 9. Denitrator Temperatures

TABLE 7

Denitrator Heatup Rates

Skin

Contents Rate of

Temperature, ${ }^{\circ} \mathrm{C}$ Rise, ${ }^{\circ} \mathrm{C} / \mathrm{min}^{a}$

400

0.5

450

0.6

500

1.0

a. Approximate (less than $0.1^{\circ} \mathrm{C} / \mathrm{min}$ variation) results from tests in Denitrator 1 . 
TABLE 8

Denitrator Skin Temperatures; Operating Values

$\begin{array}{lll}\begin{array}{l}\text { Denitrator } \\ \text { Number }\end{array} & \begin{array}{l}\text { Initial Skin } \\ \text { Temperature, }{ }^{\circ}{ }^{a}\end{array} & \begin{array}{l}\text { Final Skin } \\ \text { Temperature, }{ }^{\circ} C^{b}\end{array} \\ 1 & 450 & 500 \\ 2 & 450 & 500 \\ 3 & 450 & 500 \\ 4 & 400 & 450 \\ 5 & 400 & 450 \\ 6 & 475 & 525\end{array}$

a. The initial setting produces a $0.6^{\circ} \mathrm{C} / \mathrm{min}$ heatup rate and is used unt il the denitrator contents temperature reaches $200^{\circ} \mathrm{C}$ (see Table 7). Propane is shut off automatically at a setting $25^{\circ} \mathrm{C}$ greater than the se values (see Table 4).

$b$. The final setting is used after the denitrator contents temperature reaches $200^{\circ} \mathrm{C}$ and is necessary for efficient operation. An alarm sounds at $535^{\circ} \mathrm{C}$. Propane is shut off automatically at $600^{\circ} \mathrm{C}$. (see Table 4).

After the denitrator contents reach a temperature of $200^{\circ} \mathrm{C}$ in normal operation, the skin temperature controller is manually increased to the final setting (Table $8 ; 500^{\circ} \mathrm{C}$ in Denitrator 1 ). At this point, organic material is almost completely decomposed and increasing the heat input reduces the time necessary for complete denitration. The skin temperature is controlled to avoid damage to the denitrator; experience indicates that, at a high skin temperature $\left(>600^{\circ} \mathrm{C}\right)$, the denitrator may deform or crack. An alarm sounds in the denitrator room if the skin temperature exceeds $535^{\circ} \mathrm{C}$. As shown in Figure 9, a skin temperature of $500^{\circ} \mathrm{C}$ heats the Denitrator 1 contents to about $225^{\circ} \mathrm{C}$ and completes the denitration of a batch in about 5 additional hours.

The traditional method of monitoring the progress of a denitrator batch is to observe the foam level in the denitrator. This method warns of excessive heatup rates as well as foam-outs, i.e., release of 1 iquid to the denitrator room floor. Antifoam solution may be added as required to control foaming. When sufficient freeboard ( 8 inches or more) above the foam in the denitrator cannot be maintained by addition of antifoam, the skin temperature is reduced until the foam is controlled. If foaming cannot be controlled by lowering the skin temperature, the propane burners are turned off. 
Off-Gas Control. The minimum gas flow from the denitrator to the off-gas system is maintained by ensuring that air is flowing into the denitrator at the required rate. A calibrated orifice on each denitrator provides an air purge into the denitrator as long as the denitrator is under vacuum from the off-gas system. This vacuum must be adequate for the air purge through the orifice to comply with that calculated from the correlating equation above. The denitrator off-gas rate is larger than the purge rate because the off-gas consists of the purge, air inleakage at other points, and steam and gaseous reaction products from the denitrator contents. Further, air pulled into the denitrator expands on heating in the denitrator. Plant tests with an orifice designed to deliver $100 \mathrm{cfm}$ at a vacuum of 0.5 in. $\mathrm{H}_{2} \mathrm{O}$ showed that a vacuum of at least 1.0 in. $\mathrm{H}_{2} \mathrm{O}$ can be maintained in each of three operating denitrators.

Malfunction of the off-gas system was discussed under the section Nitrogen Dioxide Fumes.

When the temperature of the denitrator contents reaches $200^{\circ} \mathrm{C}$, the air purge orifice is closed by a valve. Air flow is no longer required because organic material is almost completely decomposed (Figure 8). Cutting the air flow into the vessel increases the efficiency for converting oxides of nitrogen to nitric acid in the acid absorber column and also reduces the probability that fumes from uranyl nitrate decomposition will escape the denitrator.

\section{Propane Explosions}

In 1956, a minor explosion in the A-Line basement resulted from the delayed ignition of propane from a denitrator furnace. Recurrence of a propane explosion during furnace startup or during operation has been avoided by improvements in the propane burner control system (Figure 10) to ensure that:

1. The furnace is thoroughly purged with air to remove residual propane before the pilot light is 1 it.

2. The pilot light is lit before the main propane supply valve opens.

3. The furnace shuts down automatically in the event of a control malfunction. 


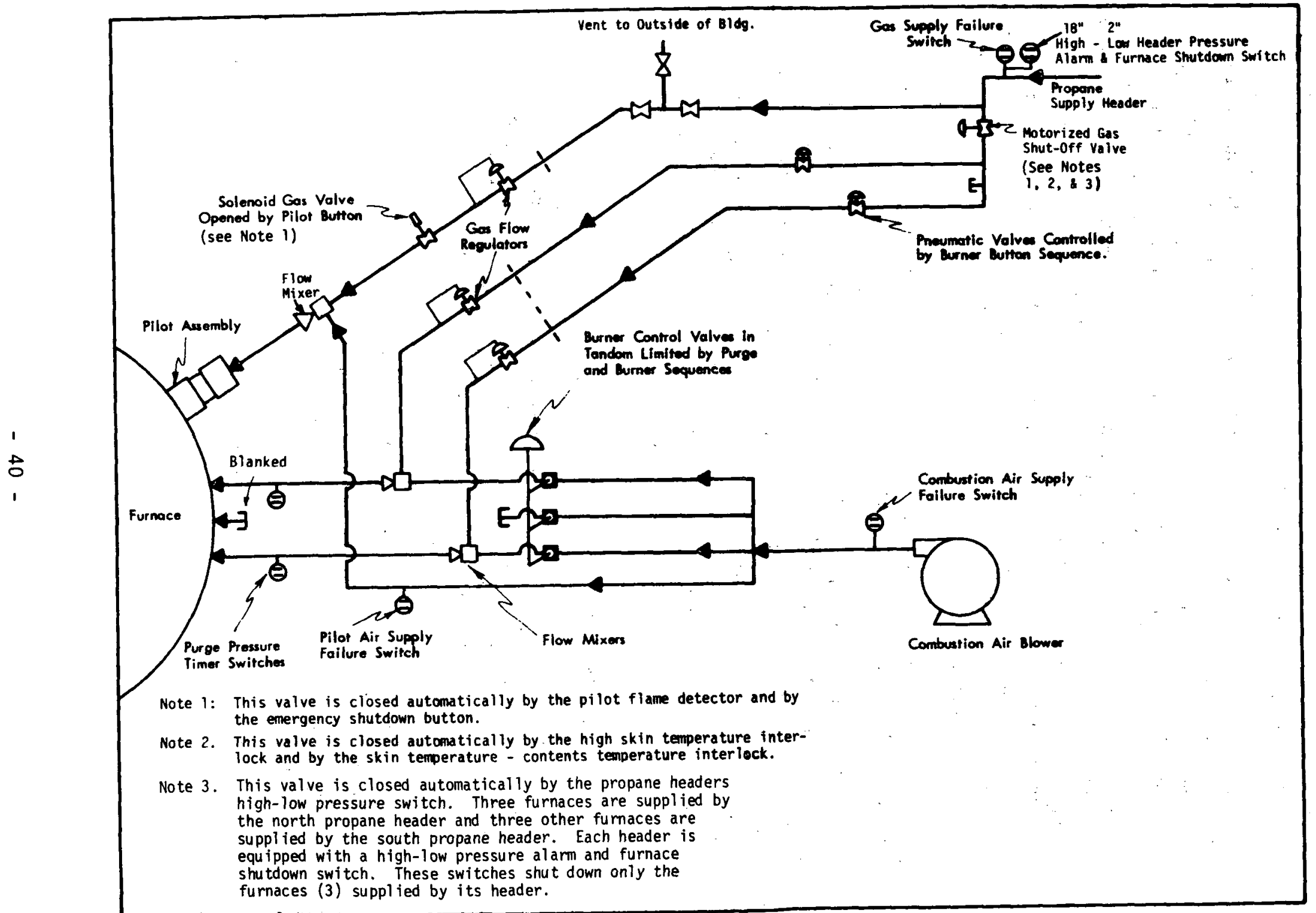

FIGURE 10. Denitrator Furnace Controls 
Each denitrator is heated by a propane gas furnace with a maximum heat output of about two million Btu/hr. Burners are arranged in two separate concentric rings of 48 and 78 burners. A temperature control system continuously monitors the denitrator skin temperature. As denitration proceeds, the heat transfer of the charge changes, and the flow of propane gas varies accordingly. The sensing element is a thermocouple, springloaded against the denitrator bottom. The thermocouple output controls the furnace air and gas flow.

At startup, the furnace control goes through an automatic sequence for lighting the burner. The following instruments aid safe burner ignition and safe operation:

1. U1tra-violet flame detector.

2. High or low propane pressure gage.

3. Low burner air pressure gage.

4. Low instrument air pressure alarm.

5. Pilot burner air valve position indicator.

6. Electrical power failure indicator.

7. High denitrator skin temperature indicator.

8. High flue-gas temperature indicator.

A combustion air blower purges the furnace before the pilot burner can ignite. The pilot must ignite within a short time or the purge is repeated. The furnace will shut down automatically if the pilot flame, combustion air pressure, propane pressure, instrument air pressure, or electrical power fail. A flue gas temperature exceeding $750^{\circ} \mathrm{C}$ or a denitrator skin temperature exceeding $600^{\circ} \mathrm{C}$ will al so shut the furnace down. 


\section{RISK ANALYSIS}

A quantitative assessment of the risk reduction achieved by the changes in equipment and procedures following the explosion was made to determine the adequacy of these measures. A faulttree analysis ${ }^{5}$ was made to compare the probability of potential explosion mechanisms before the explosion with the potential after these modifications. The development of the fault trees is in three parts :

1. Conditions of organic accumulation and transport existing prior to February 1975.

2. The corresponding conditions for future operation.

3. Conditions that could lead to an explosion from other sources.

Data for evaluating the fault trees are based on failure and maloperation incidents, calculated values from the analysis of Purex operation, and communications with A-Line operating personnel. The development of the fault trees is discussed in this section and presented in the Appendix.

The fault-tree sequence of events is developed along the potential flow path of organic material as it moves from the Purex operation through the A-Line system to the denitrators. Two upper-level events are considered: 1) denitrator foam-outs which are indicative of organic concentrations in hydrate evaporator feed equal to or greater than about 0.5 volume $\%,{ }^{4}$ and, 2) explosions which are assumed to correspond to organic concentrations of about 6 volume $\%{ }^{3}$

Figure 1 depicts the flowsheet and vessel identifications referred to throughout this report. Note that for purposes of this analysis, tanks and equipment are grouped as shown in this figure. Table 1 summarized the major changes in A-Line operating procedures.

The fault trees developed for the analysis are presented in the Appendix. Numerical values are based on a demand unit "d", that corresponds to one denitrator charge of about one ton of uranium. During typical operating conditions, one demand unit corresponds to about two hours of real time during periods of operation. An annual rate of $2400 \mathrm{~d} / \mathrm{yr}$ is assumed. Event frequencies are shown on the fault trees both for conditions existing prior to the recent explosion and for those anticipated in the future. The latter are enclosed in parentheses (see Appendix). 
Pre-Accident Conditions

The primary entry point for organic material into the A-Line process is Tank E-1-3 (Silo, Figure 1). This tank serves as a decanter and feed tank for the 1EU evaporator. Organic material from solvent extraction can enter the silo in significant amounts in three ways: decantation of smal1 amounts of entrained $30 \%$ TBP in $1 E U$ solution from Building 221-F, gross entrainment from the same source resulting from failure of the A-Line box decanter, or transfer error from an unspecified source. Based on operating data, calculated frequencies of these respective occurrences were $1 / \mathrm{d}, 2 \times 10^{-5} / \mathrm{d}$, and $1 \times 10^{-7} / \mathrm{d}$, respectively. The controlling mechanism was decantation and subsequent accumulation of organic from the canyon.

Organic material left in the silo is subject to being pumped to the 1EU evaporator. This organic layer was not removed because either it was not detected or the tank was not skimmed because of procedural inadequacy or procedural violation. Based on a sampling frequency of once per day and on the method of sampling, the frequency of failure to detect organic was $0.2 / \mathrm{d}$. Past practice for cleaning the silo was about once per year, even though written procedures required it once per week. The frequency of organic accumulation because of failure to clean the tank was calculated as $0.96 / \mathrm{d}$.

Because the silo is unagitated and bottom-pumped and because the accumulated $30 \%$ TBP-UN adduct will float, the only mechanism identified for moving undissolved organic forward was to pump the silo too low. This assumes that the quantity of organic is much less than the quantity of aqueous solution present. Prior to the incident explosion, the level in the silo was procedurally controlled, and the silo was equipped with a low level alarm. The frequency of either procedural violation or alarm failure was estimated to be $2 \times 10^{-5} / \mathrm{d}$ which yielded a calculated frequency of $4 \times 10^{-5} / \mathrm{d}$ for pumping too low. No automatic low-level cut-off was used. By combining the frequency of excessive organic accumulation with that of pumping accumulated material forward, the frequency of moving significant undissolved organic through the 1 EU evaporator to the Tank S-1-1 was calculated to be $4 \times 10^{-5} / \mathrm{d}$ (Appendix).

Organic could have accumulated rapidly in Tank S-1-1 by decantation of the grossly entrained quantities discussed above or slowly by decantation of entrained micro-material, viz., the highly dispersed TBP that is driven from solution in the 1EU evaporation step. In past operations, Tank S-1-1 was not agitated but, rather, operated as a decanter. Based on the frequency of 
foam-outs in the denitrators, the explosion, and the ability to move organic forward, the usual inventory of organic in Tank S-1-1 was at least 0.6 volume $\%$, and about 7 volume $\%$ occurred at a frequency of $4 \times 10^{-3} / \mathrm{d}$. The predominant source of these amounts of organic was a slow accumulation of decanted liquid rather than gross transfer from the silo, by about two orders of magnitude (Appendix).

In this analysis, the Silica Ge1 Columns S-8-1 and S-8-2 were considered as a unit with Tank $S$ 1-1. This simplification is justified by the considerations that organic material would accumulate in either the tank or the columns by processes discussed previously, and further movement of organic would require similar mechanisms. The probability of movement was calculated from the history of organic behavior in A-Line. Actually, the introduction of low-density wash solutions into the columns may be the primary means for moving organic accumulations forward. If these columns are to be used in future operation, it will be necessary to give special attention to their potential for accumulating organic material.

Under the original conditions, movement of accumulated organic from Tank S-1-1 to Tank S-1-8 or Tank S-1-9 resulted from an inversion of the organic and aqueous layers. The frequency for such a condition was calculated to be $6 \times 10^{-3} / \mathrm{d}$ for any given vessel in the sequence, by assuming that the frequency of inversions was the same as that for foam-outs. Because an inversion could move organic sequentially through all the vessels involved, the frequency of organic transfer was applied to movement from Tank C-1-1 to the hydrate evaporator. The calculated frequency for movement from Tank S-1-1 to Tank S-1-8 or Tank S-1-9, and from Tanks S-1-8 or S-1-9 to Tank C-1-1, was considered to be $1 / \mathrm{d}$. Movement of organic could also result from pumping Tank $\mathrm{S}-1-1$ too $1 \mathrm{ow}$, but was less likely because of the automatic pump cut-off installed on Tank S-1-1.

A deterrent to movement was the detection and removal of the organic. The inspection frequency for Tanks S-1-8 and S-1-9 was twice per month; and, for Tank $\mathrm{C}-1-1$, once per week. Cleanout of Tank S-1-1 was not required. In practice, tanks were cleaned out about once per year. Therefore, the calculated frequency for failure to remove organic from Tanks $S-1-8$ and $S-1-9$ was $>0.9 / d$; and, from Tank $\mathrm{C}-1-1$ was also $>0.9 / \mathrm{d}$. The availability of organic in Tank C-1-1 was calculated to be $0.7 / \mathrm{d}$ for 0.6 volume $\%$ and $4 \times 10^{-3} / \mathrm{d}$ for 7 volume $\%$. The occurrence of inversions permitted the smaller quantity of organic $(0.6 \%)$ to be transferred to the hydrate evaporator at a frequency of $4 \times 10^{-3} / \mathrm{d}$. Potentially explosive quantities of organic were transferred at a frequency of $2 \times 10^{-5} / \mathrm{d}$ ( 1 explosion $/ 50,000$ batches $\left.=2 \times 10^{-5} / \mathrm{d}\right)$. The small quantities were manifested in the form of foam-outs from the denitrators which occurred about once per month. 


\section{Post-Accident Conditions}

The primary entry point for organic material into the A-Line process is still Silo Tank E-1-3. Mechanisms governing the flow of organic material are al so the same, and no changes have been made that will reduce the quantity of organic material entering the silo. Therefore, the frequency for this occurrence remains at $1 / \mathrm{d}$. The sampling frequency has been increased to once per shift, but the inspection and cleanout frequency remains at once per week.

The frequency for not detecting organic is $1 \times 10^{-2} / \mathrm{d}$, and for not inspecting and cleaning the tank is $4 \times 10^{-2} / \mathrm{d}$ which, together, yield an expected frequency of failure to remove organic of $5 \times 10^{-2} / \mathrm{d}$ (old procedure, $0.96 / \mathrm{d}$ ). The likelihood of pumping the silo too low is significantly reduced by a new automatic, lowlevel, cut-off control which has an estimated failure frequency of $10^{-4} / \mathrm{d}$. Procedural requirements for level control remain in force; however, the expected frequency of their violation is increased to $10^{-3} / \mathrm{d}$ because analysis of Purex operations indicates that personnel alertness is reduced by reliance on automatic protective devices. Combining the expected frequency of excessive organic accumulation with that of pumping the organic forward $\left(1 \times 10^{-7} / \mathrm{d}\right)$, the calculated frequency of moving excessive organic through the 1EU evaporator to Tank $\mathrm{S}-1-1$ is reduced from $4 \times 10^{-5} / \mathrm{d}$ to $5 \times 10^{-9} / \mathrm{d}$.

Tanks $S-1-1, S-1-8, S-1-9$, and $C-1-1$ are to be agitated and will no longer act as decanters. Failure of the agitator on any of these vessels would permit buildup of organic from entrained micro-material. Should this occur and the organic not be detected and removed before agitation is resumed, organic could be transferred to the denitrators. For convenience, the entire effect of agitator non-operation is assumed to occur in Tank S-1-1 with an expected frequency of $10^{-3} / \mathrm{d}$ and decanting in Tank S-1-8 or S-1-9 and in Tank $\mathrm{C}-1-1$ is assumed to be zero.

Even without agitation, detection and removal of organic would prevent excessive accumulation. The inspection and cleaning frequency for Tank S-1-1 has been changed from zero to once per week. Based on $5 \times 10^{-2} / \mathrm{d}$ for failure to detect or clean, smal1 organic accumulations in Tank $S-1-1$ would be expected at a frequency of $5 \times 10^{-4} / \mathrm{d}$. Subsequent transfer to Tanks S-1-8 or S-1-9 would be: expected at a frequency of $5 \times 10^{-4} / \mathrm{d}$ for sma11 quantities of organic and $3 \times 10^{-1} \% / \mathrm{d}$ for gross quantities. Precise amounts of material involved will have to be determined from experience, although a small amount is assumed to be sufficient to cause a foam-out in a denitrator and gross organic is assumed to be potentially explosive. 
While the expected frequency for failure to detect and remove organic from a single vessel is $5 \times 10^{-2} / \mathrm{d}$, the operation among several vessels is closely coupled. If one vessel is not inspected and cleaned, the probability of cleaning the others is severely reduced. It is estimated that if Tank $S-1-1$ is not cleaned, the expected frequency of failure to clean Tanks S-1-8 or S-1-9 is $0.5 / \mathrm{d}$, and the expected frequency of failure to clean Tank $\mathrm{C}-1-1$ is $1 / d$. For these reasons, the expected frequency of small quantities of organic in Tanks $S-1-8$ or $S-1-9$ becomes $3 \times 10^{-4} / \mathrm{d}$ and for gross quantities, $1 \times 10^{-10} / \mathrm{d}$. The expected frequencies for Tank $C-1-1$ are the same as for Tanks $S-1-8$ or S-1-9. Transfer of organic to Tank $\mathrm{C}-1-1$ is tantamount to transfer to a denitrator, except that about $10 \%$ of the total organic is assumed to be removed in the hydrate evaporator.

\section{Other Considerations}

The new procedures and equipment modifications have significantly reduced the risk of an explosion in the denitrator room causea by a large quantity of organic material being transferred to, and decomposed in, a denitrator. The calculated risk is now less than that for some potential explosions from other causes associated with denitration. Mechanisms that were identified are summarized in Table 3 and are briefly discussed in the following paragraphs.

\section{Organic Transfer Through Reagent Lines}

Analysis of Purex operations indicates that transfer errors are essentially random phenomena that may occur at a frequency of about once per month. They seldom occur more than once in the same manner, and it is virtually impossible to predict where one will occur. It is possible for organic to be introduced into the nitric acid tank and subsequently to the denitrators. An expected frequency of $10^{-7} / \mathrm{d}$ was assigned to this event.

\section{ExpZosion from Fume-Out}

The possibility of explosion from fume-out (emission of flammable vapors into the room from processing normal or nearnormal quantities of organic material in the denitrator) was considered separately. This possibility has been considerably reduced by the reduction in probability of organic accumulations entering the denitrator, and was calculated to be less likely than explosions resulting from major quantities of organic in the denitrator. 


\section{Explosion Inside the Denitrator}

An explosion within the denitrator is possible. Normally, decomposing organics are efficiently mixed with uranyl nitrate solution, and the products of the decomposition are almost completely oxidized. The traces of organic vapors that are normally produced are non-explosive because of dilution by inert decomposition products (such as carbon dioxide) and by the air flow through the denitrator. With excess organic and poor mixing such that a substantial amount of separate phase exists, a flammable gas may be produced. ${ }^{4}$ The expected frequency of such a condition with near-normal organic is estimated at $6 \times 10^{-8} / \mathrm{d}$. For grossly abnormal quantities of organic, the expected frequency is estimated at $10^{-12} / \mathrm{d}$.

\section{Fuel System Explosions}

A minor explosion in 1956 in the A-Line basement was apparently caused by a delayed ignition of propane. Subsequently, several other minor problems with fuel flow control have arisen. No recent improvements have been made to the system; thus, an expected frequency of $2 \times 10^{-5} / \mathrm{d}$ was assigned to this event.

\section{Additional Safety-Related Occurrences}

In addition to the explosive mechanisms discussed above, oil leaks and foam-outs are two potential occurrences that could affect denitrator operation in ways that would not involve explosions.

\section{Oiz Leaks}

Gear box oil leaks have caused more than 50 fires on the outer surfaces of the denitrator. As a consequence, the system was modified to prevent these oil leaks. Although no mechanisms were identified for introduction of the oil into the denitrators, the possibility cannot be totally precluded because of the proximity. The risk is considered acceptably low, al though no quantitative assessment was made. There has not been such a fire since November 1971 . 


\section{Foom-Outs}

If the organic content of the hydrate evaporator feed approaches about 0.5 volume $\%$, a denitrator foam-out may occur. ${ }^{4}$ Historically, these have occurred about once per month. The analysis indicates that the new procedures and controls should reduce the occurrence to about once per year. Should foam-outs occur more frequently, it may be indicative of a breakdown in procedural controls or that organic is entering the system via some unconsidered mechanism. 


\section{REFERENCES}

1. R. S. Ondrejcin. "Thermal Denitration of Urany1 Nitrate Hexahydrate." J. Chem. Eng. Data 11, 130 (1966).

2. W. H. Burriss, Jr. "Explosion and Fire in A-Line Facility of the Savannah River Plant." Presented at ERDA Safety Conference, Batavia, Illinois, October 2, 1975. USERDA Report CONF-751084-1 (to be issued).

3. L. W. Gray. "Post-Incident Analysis of an Explosion and Fire that Occurred during the Conversion of Liquid Uranyl Nitrate to Solid Uranium Oxide." Proposed for publication in Nuclear Safety.

4. H. D. Harmon, M. L. Hyder, B. Tiffany, L. W. Gray, and P. A. Soltys. The Behavior of Tributyl Phosphate in A-Line Processes. USERDA Report DP-1418, E. I. du Pont de Nemours and Co., Savannah River Laboratory, Aiken, South Carolina (1976).

5. J. B. Fusse11. Synthetic Tree Model, A Formal Methodology for Fault-Tree Construction. USAEC Report ANCR-1098, Aerojet Nuclear Co., National Reactor Testing Station, Idaho Falls, Idaho (1973).

6. W. H. Smith. "Thermal Dehydration of Uranyl Nitrate Hydrates." J. Inorg. Nucl. Chem. 30, 1761 (1968).

7. T. J. Colven, G. M. Nichols, and T. H. Siddall. TNX Evaporator Incident January 12, 1953. USAEC Report, DP-25, E. I. du Pont de Nemours and Co., Savannah River Laboratory, Aiken, South Carolina (1953).

8. N. Irving Sax. Handbook of Dangerous Materials. Reinhold Publishing Corp., New York (1951).

9. J. H. Keenan, J. G. Keyes, P. G. Hill, and J. G. Moore. Steam Tables. John Wiley and Sons, New York (1969). 
APPENDIX

FAULT TREE ANALYSIS 


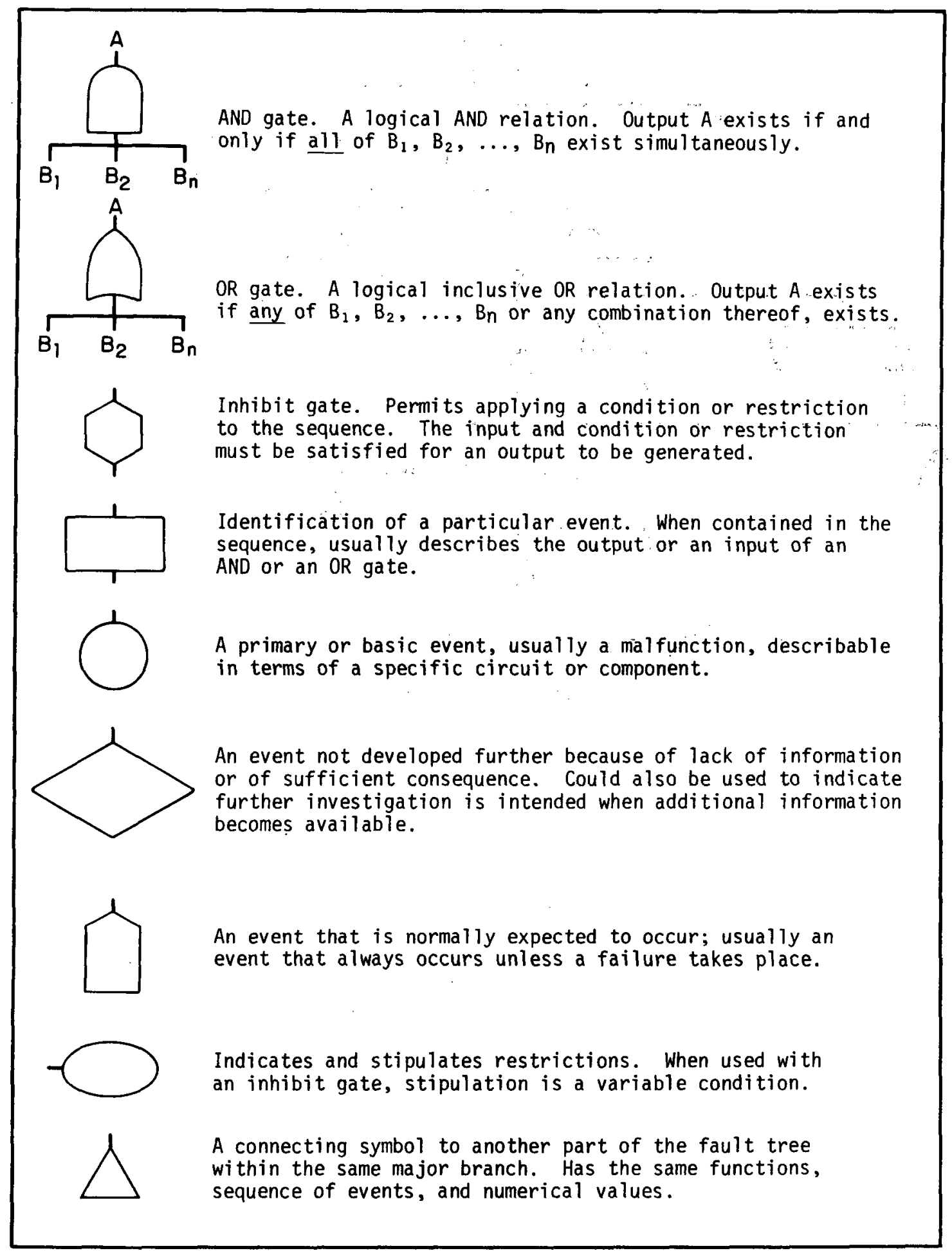

FIGURE A-1. Fault-Tree Symbols 


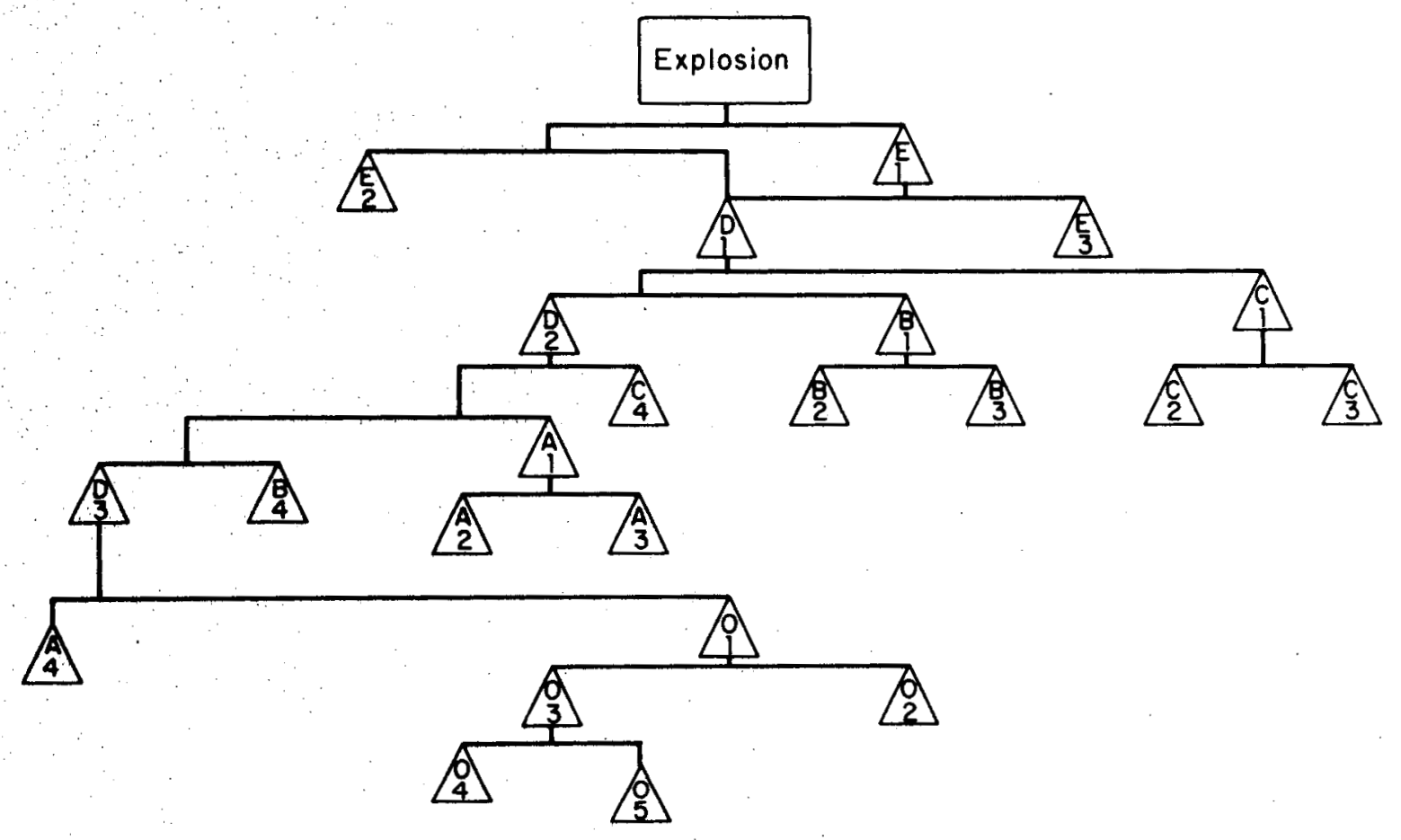

Figure A-2. Guide to Fault Trees 


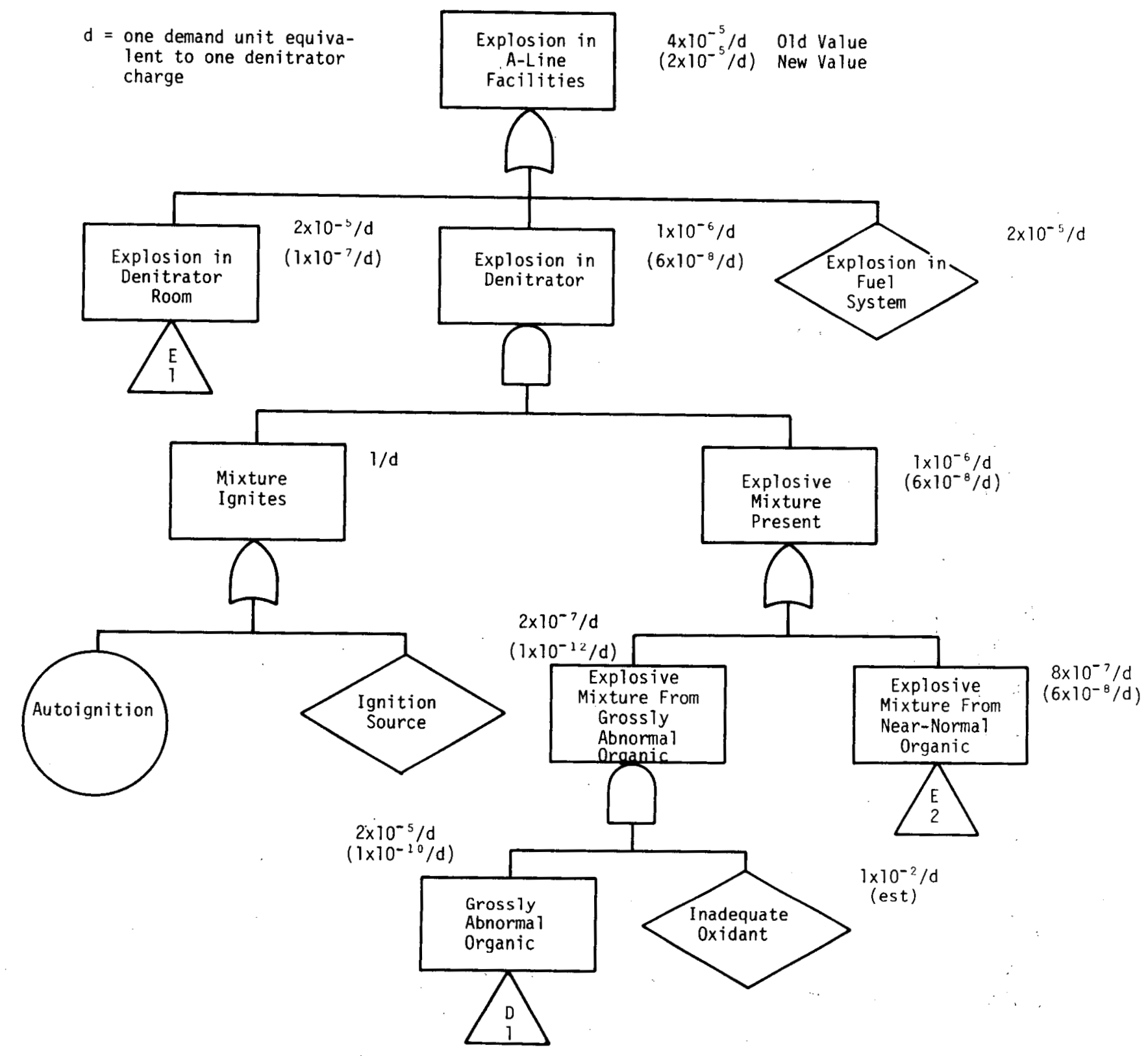

Note: New values are in parentheses.

FIGURE A-3. Fault Tree for Explosion in A-Line Facilities 
EVENT AI

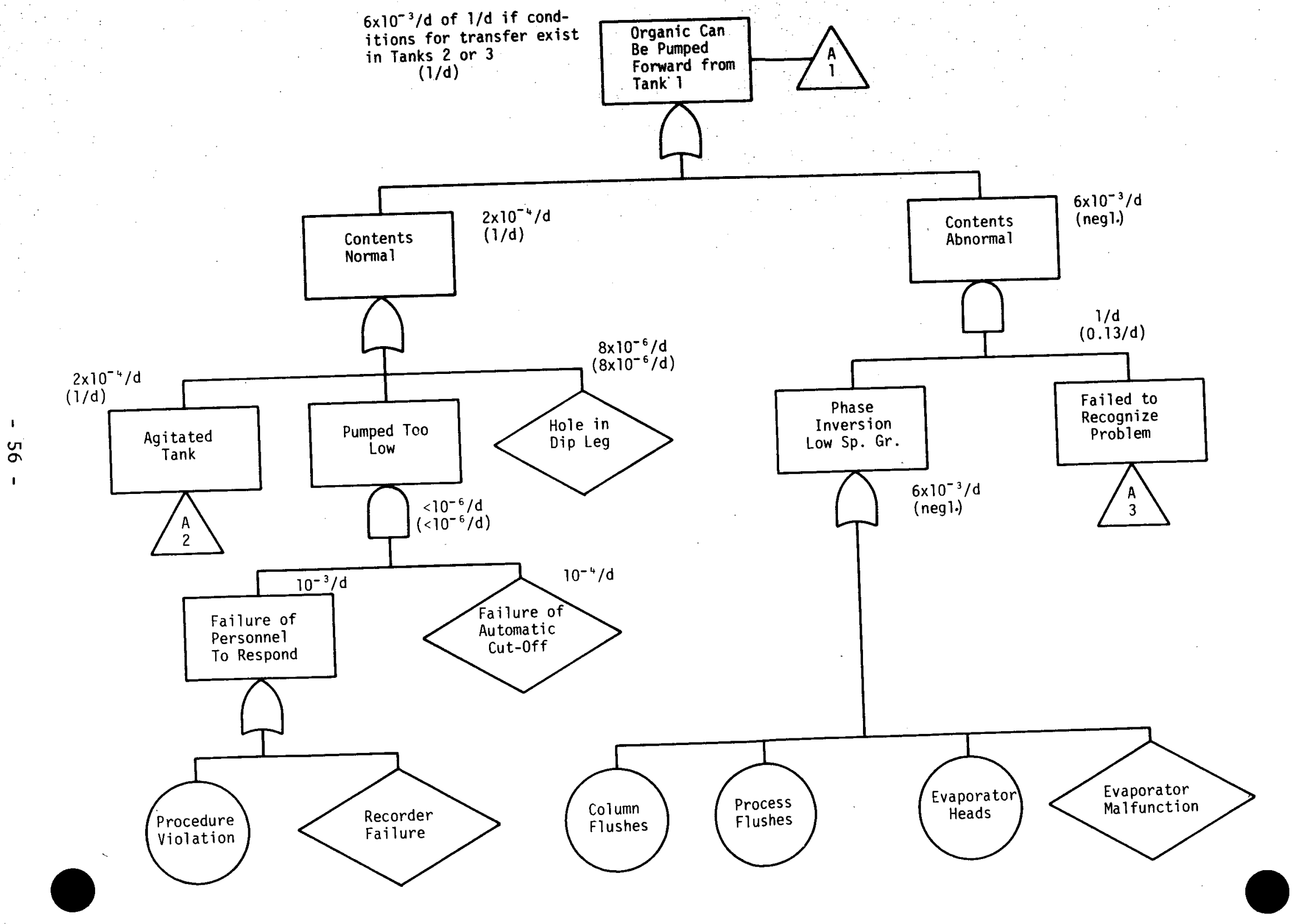


EVENT A2

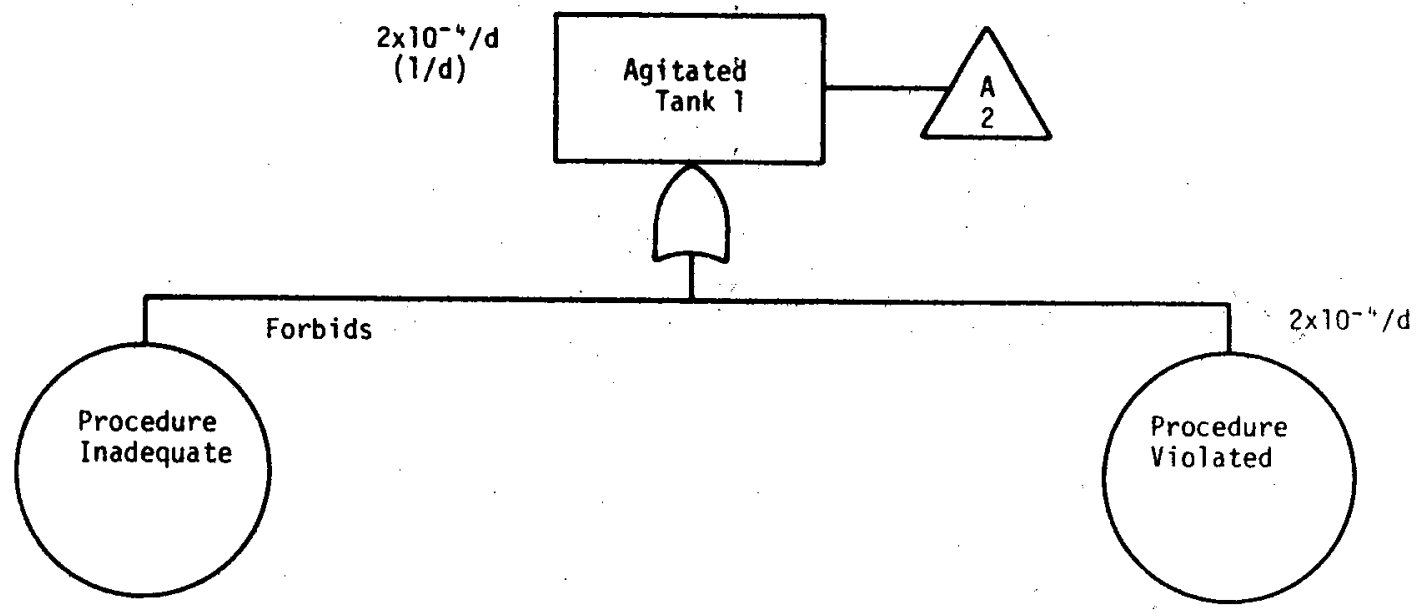




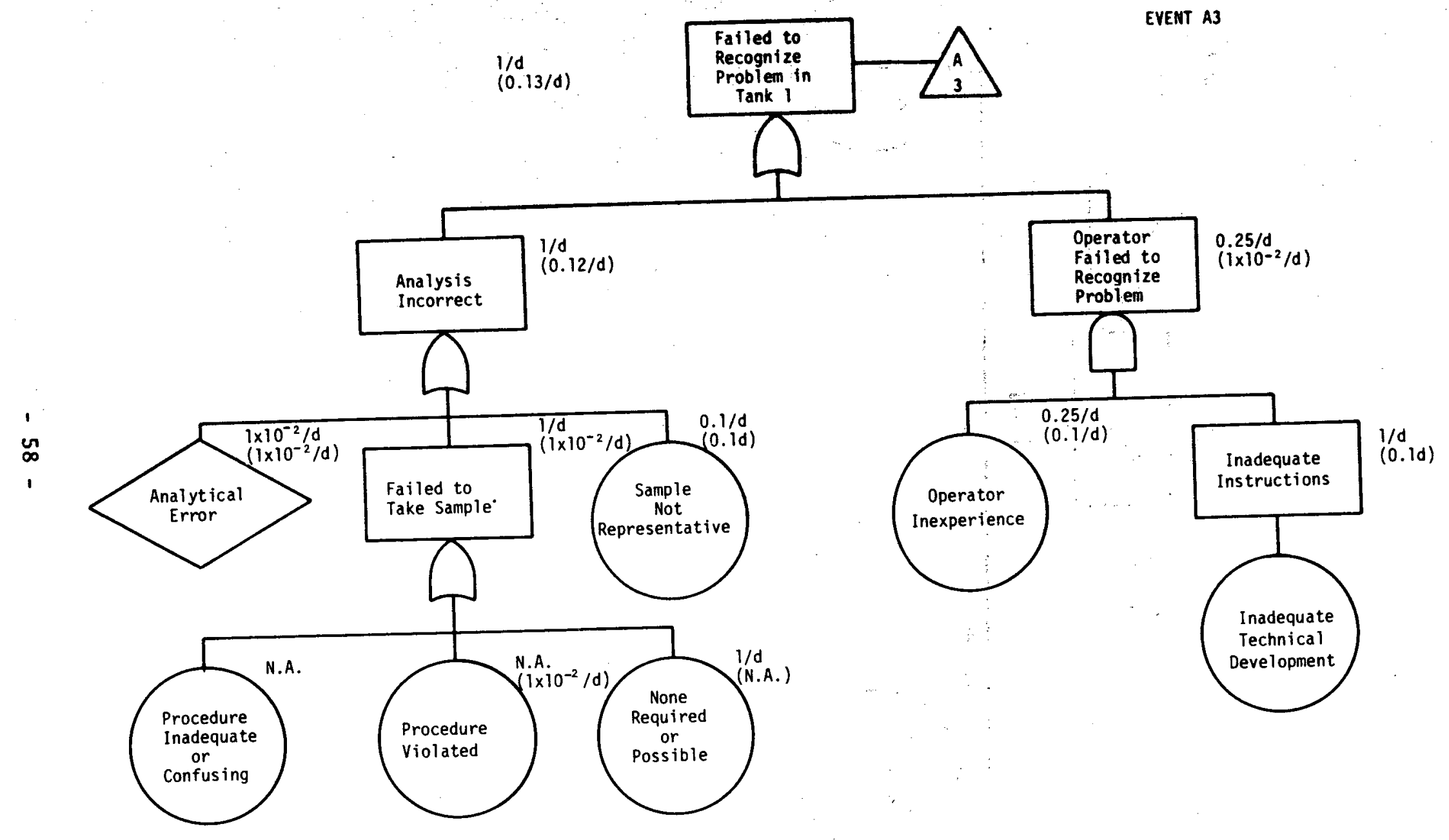




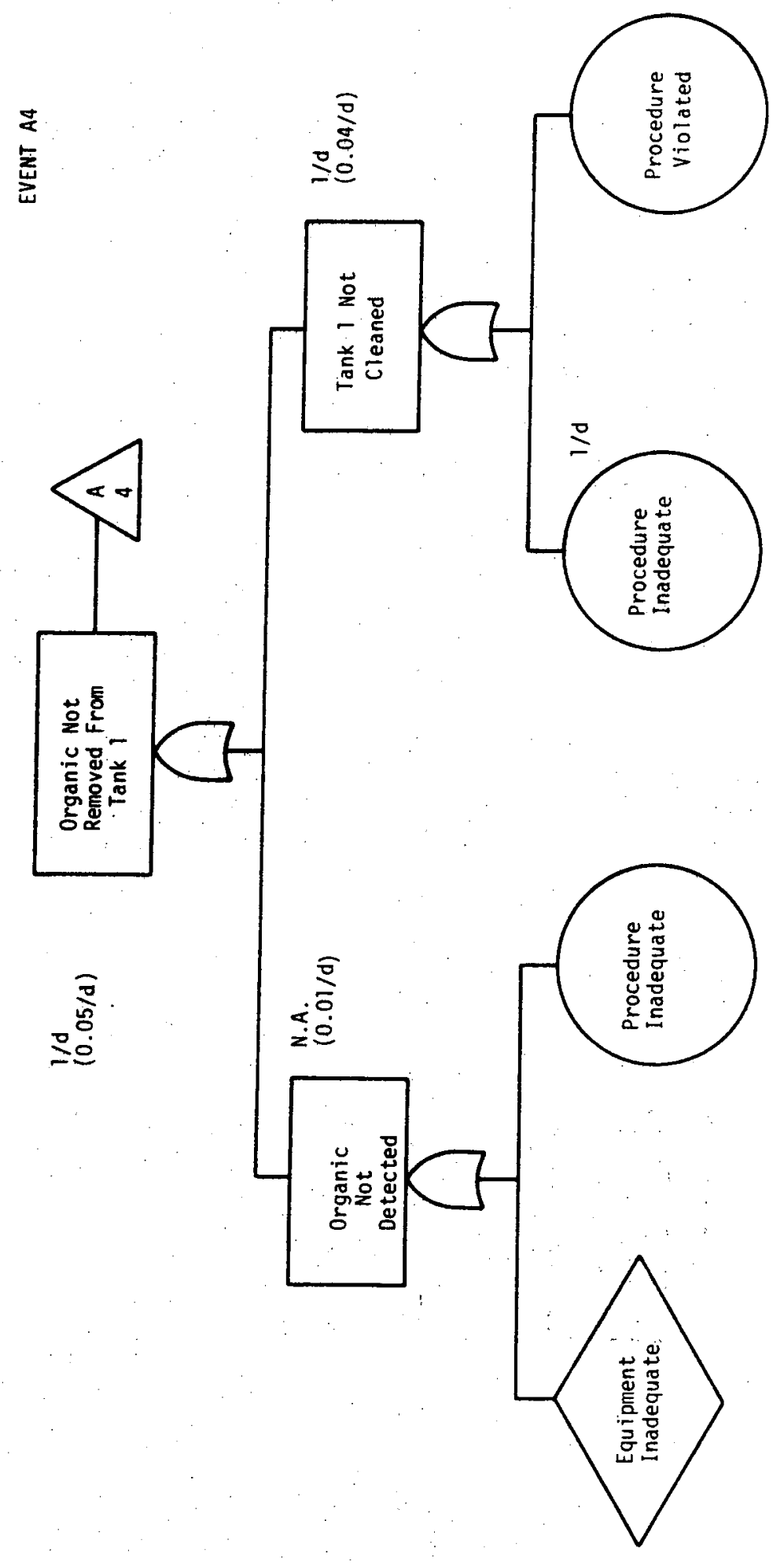




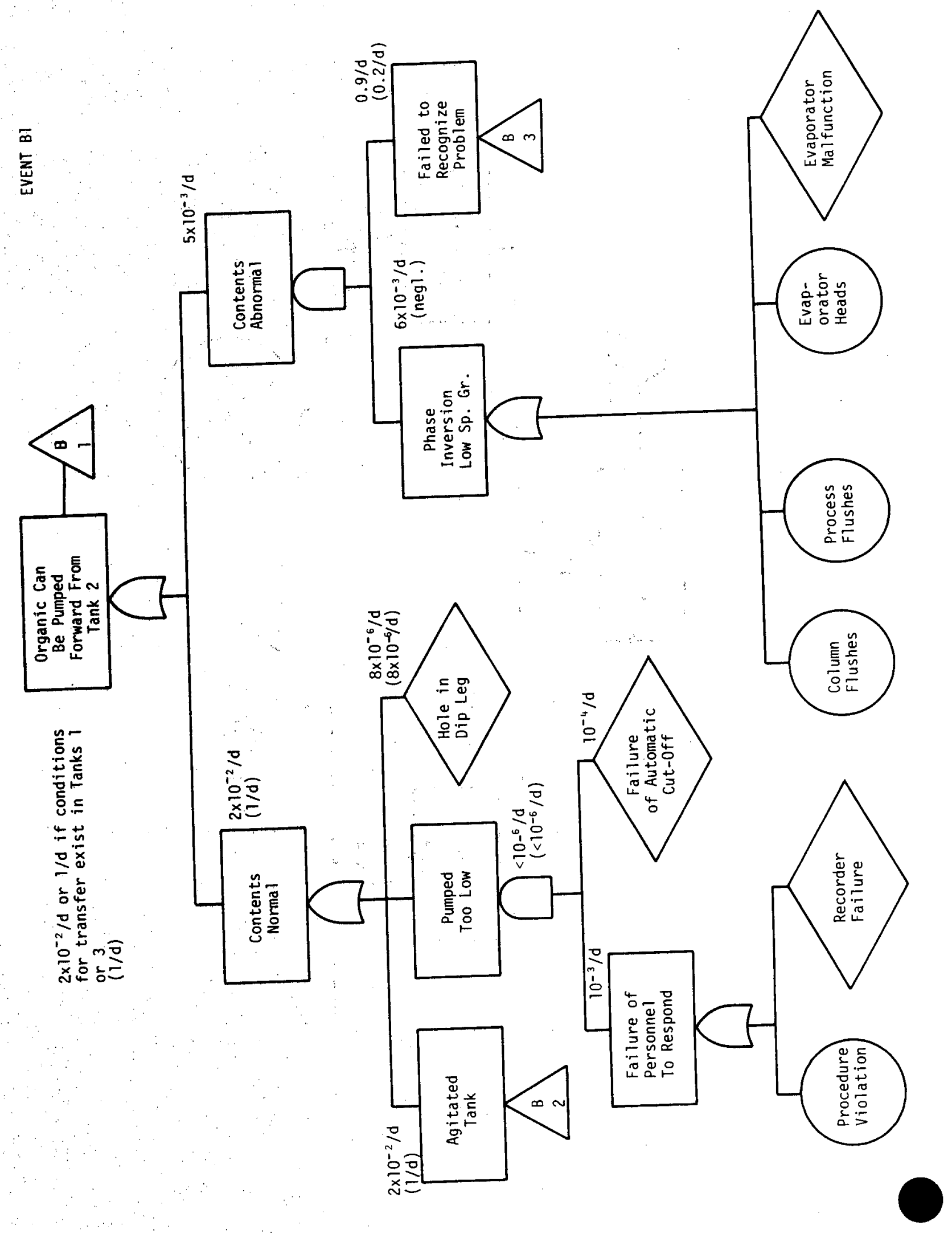




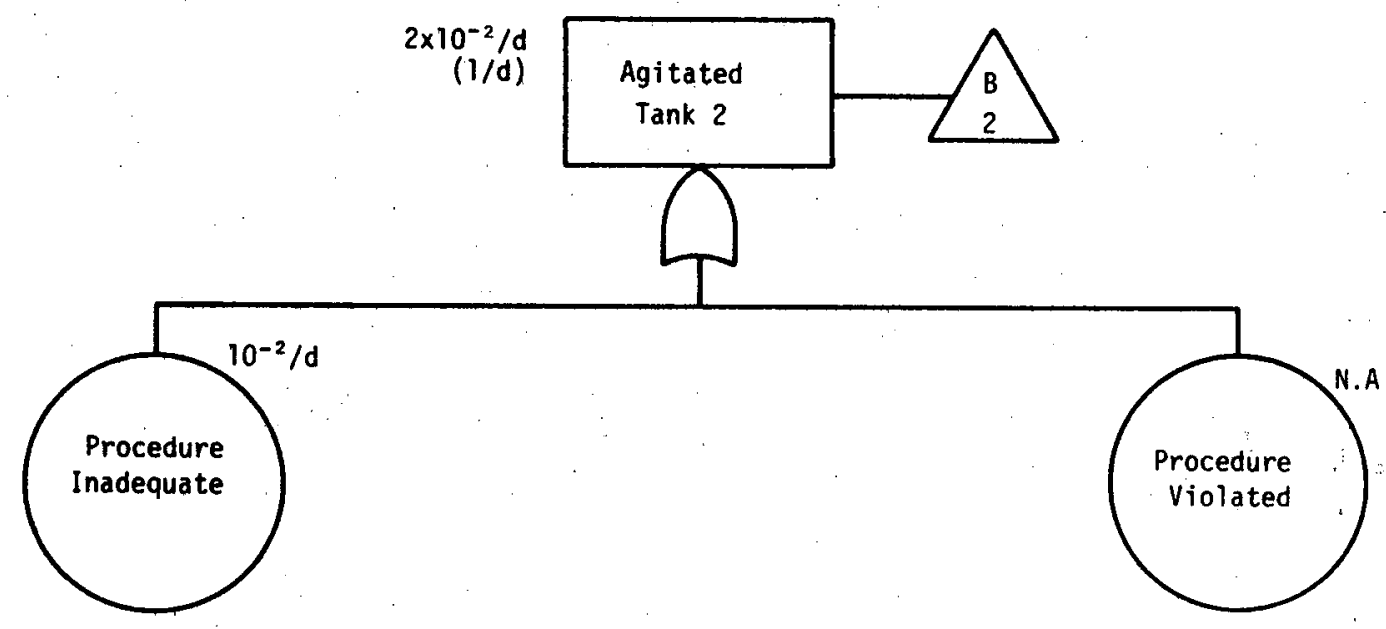




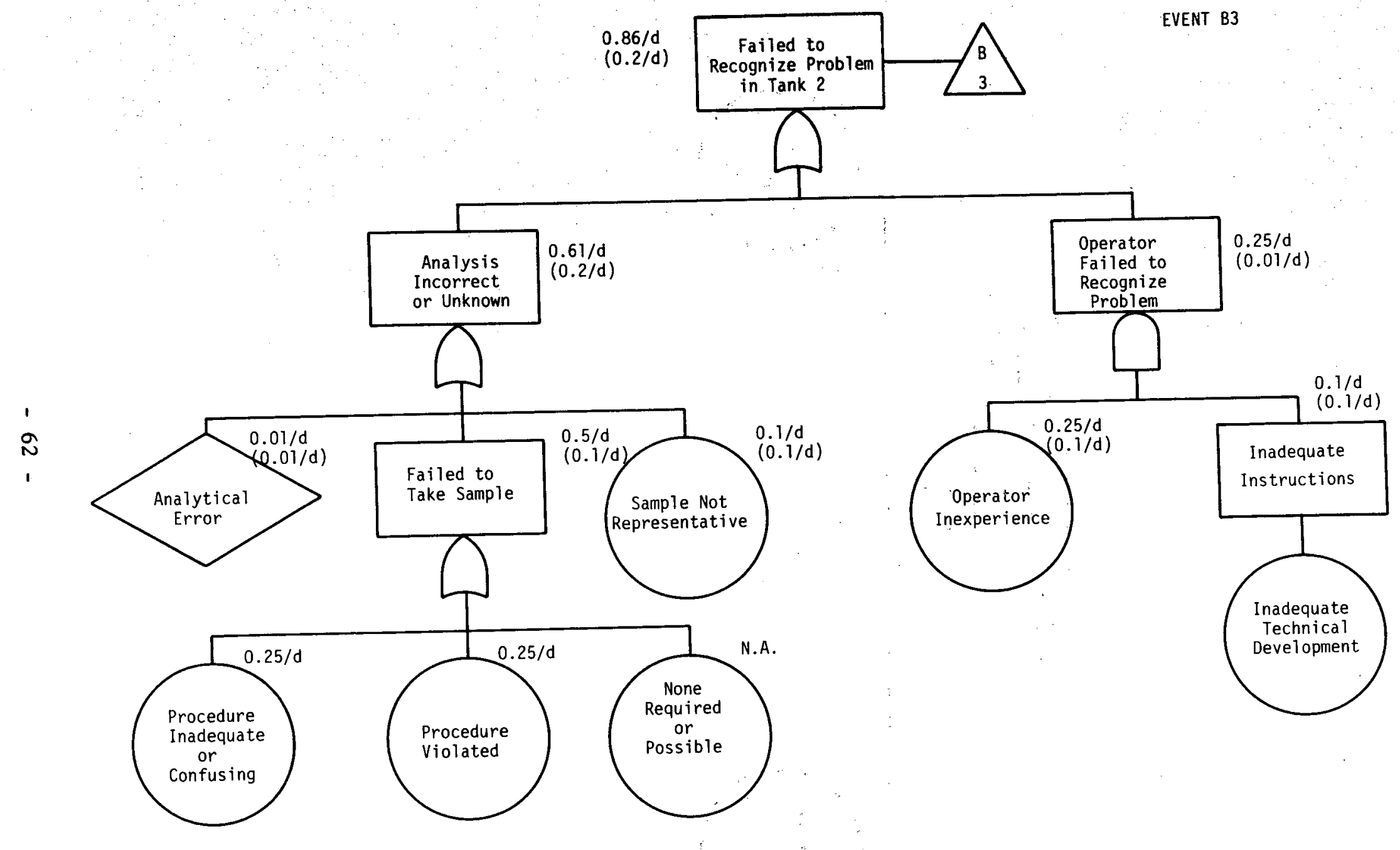




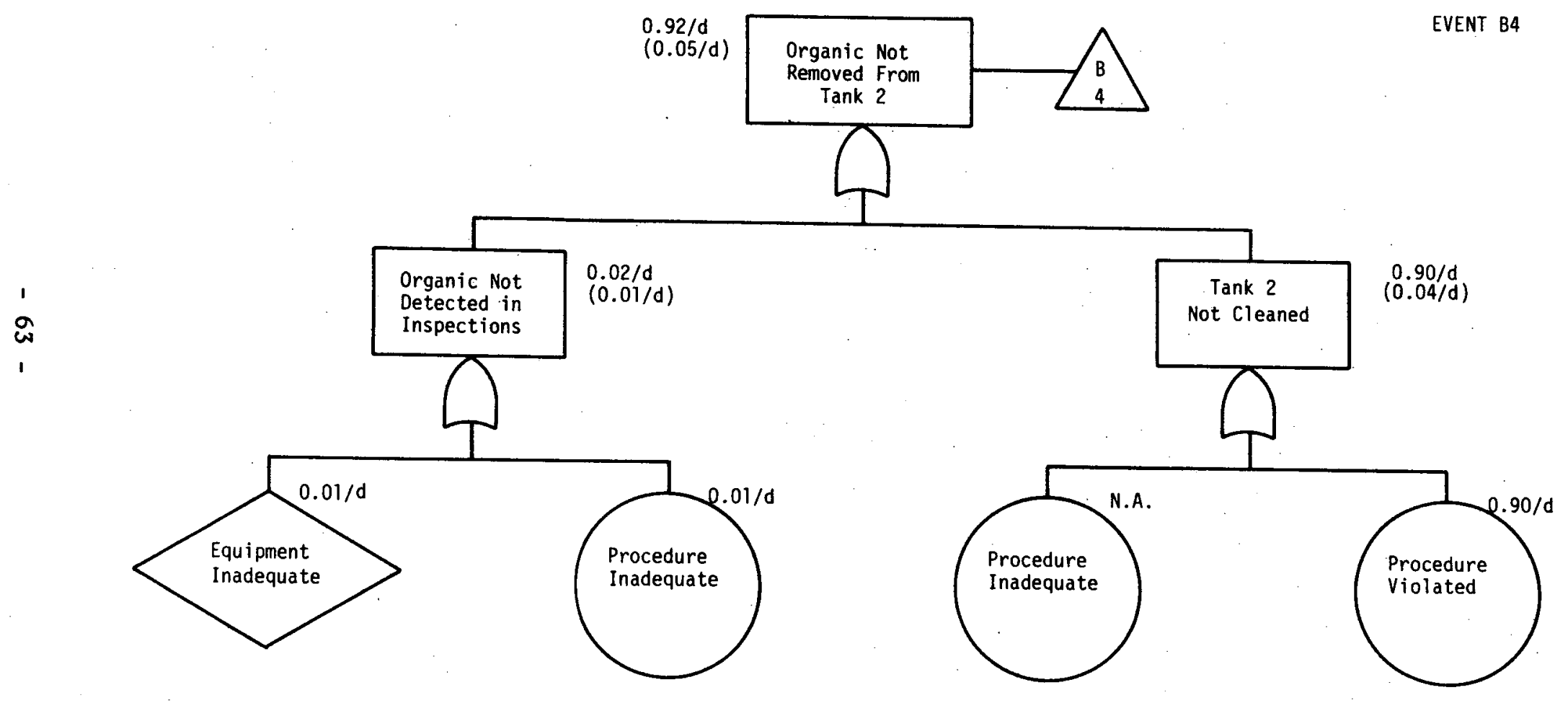




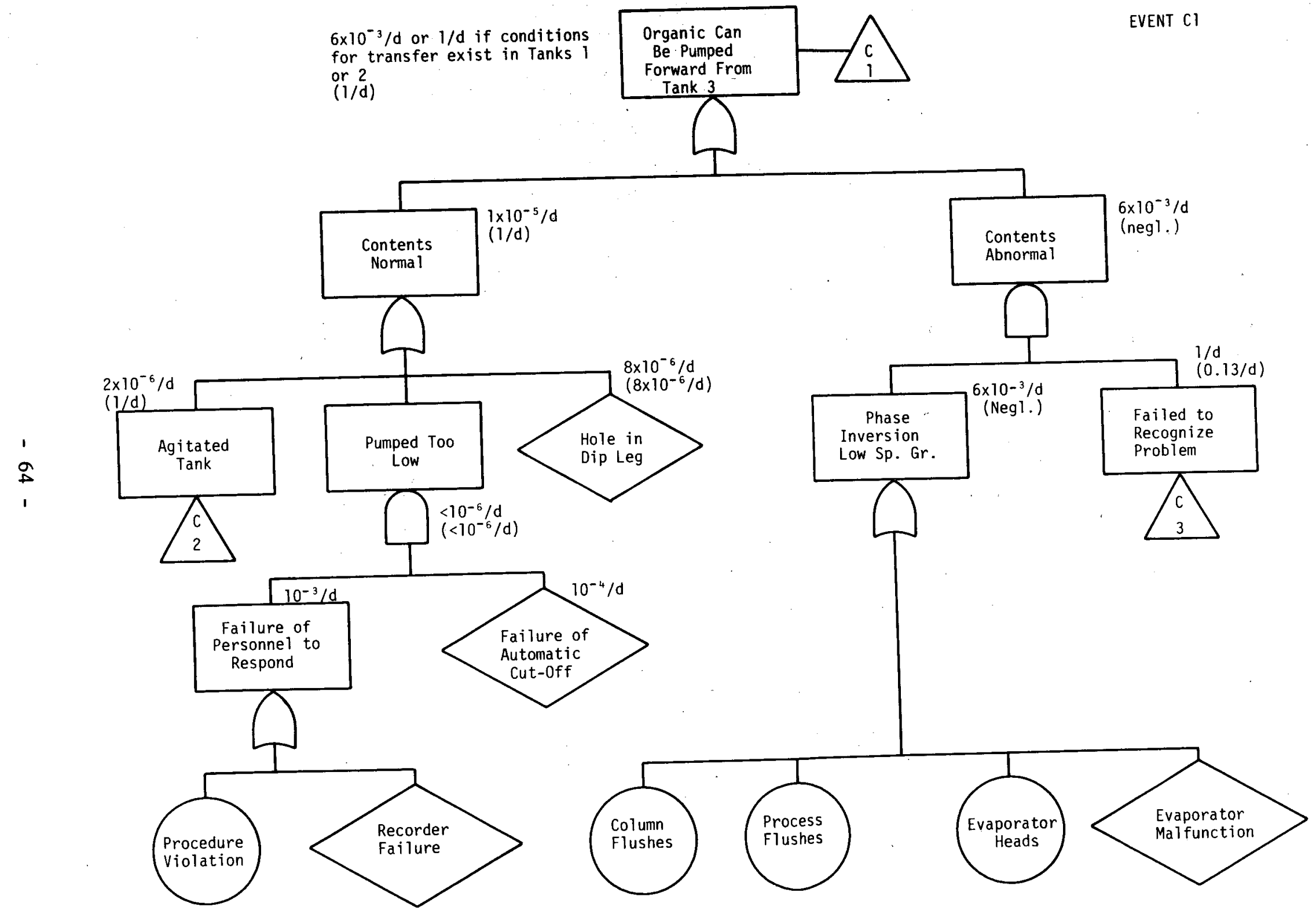


EVENT C2

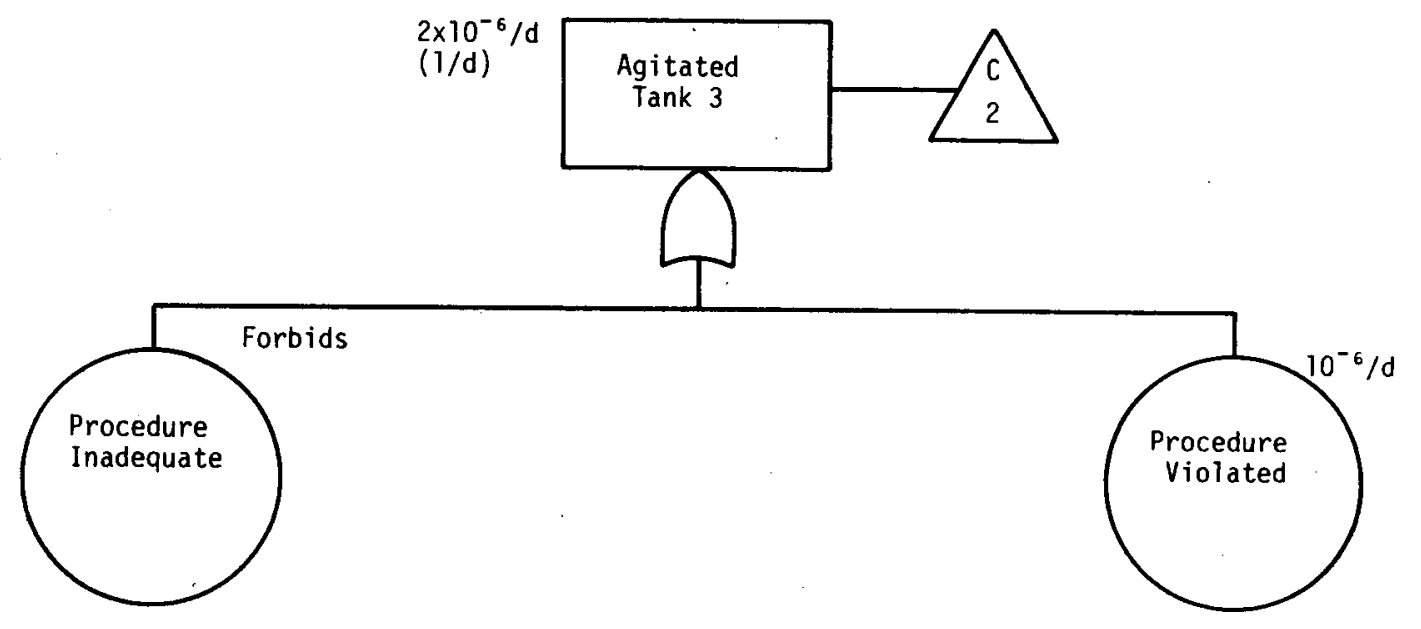




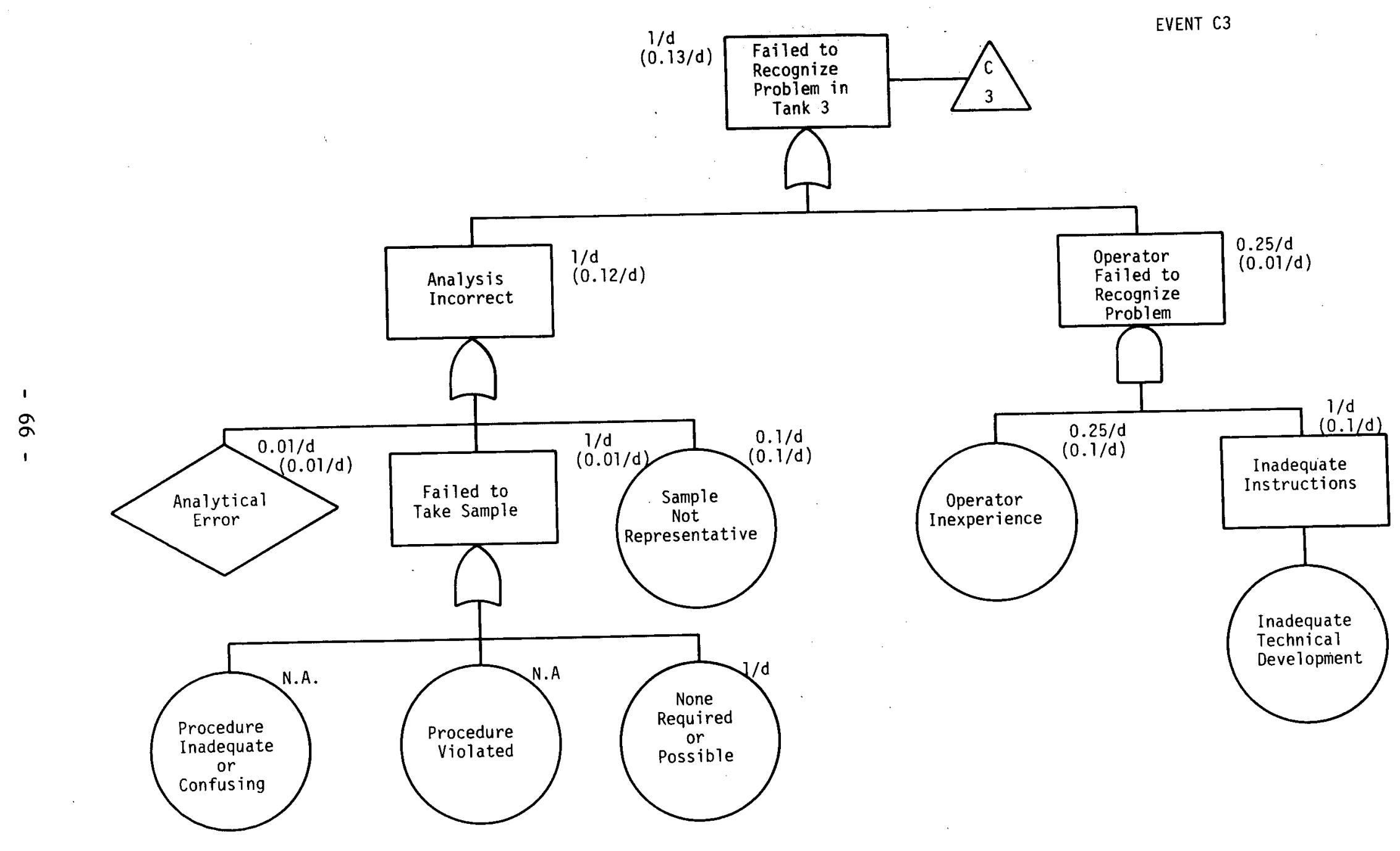




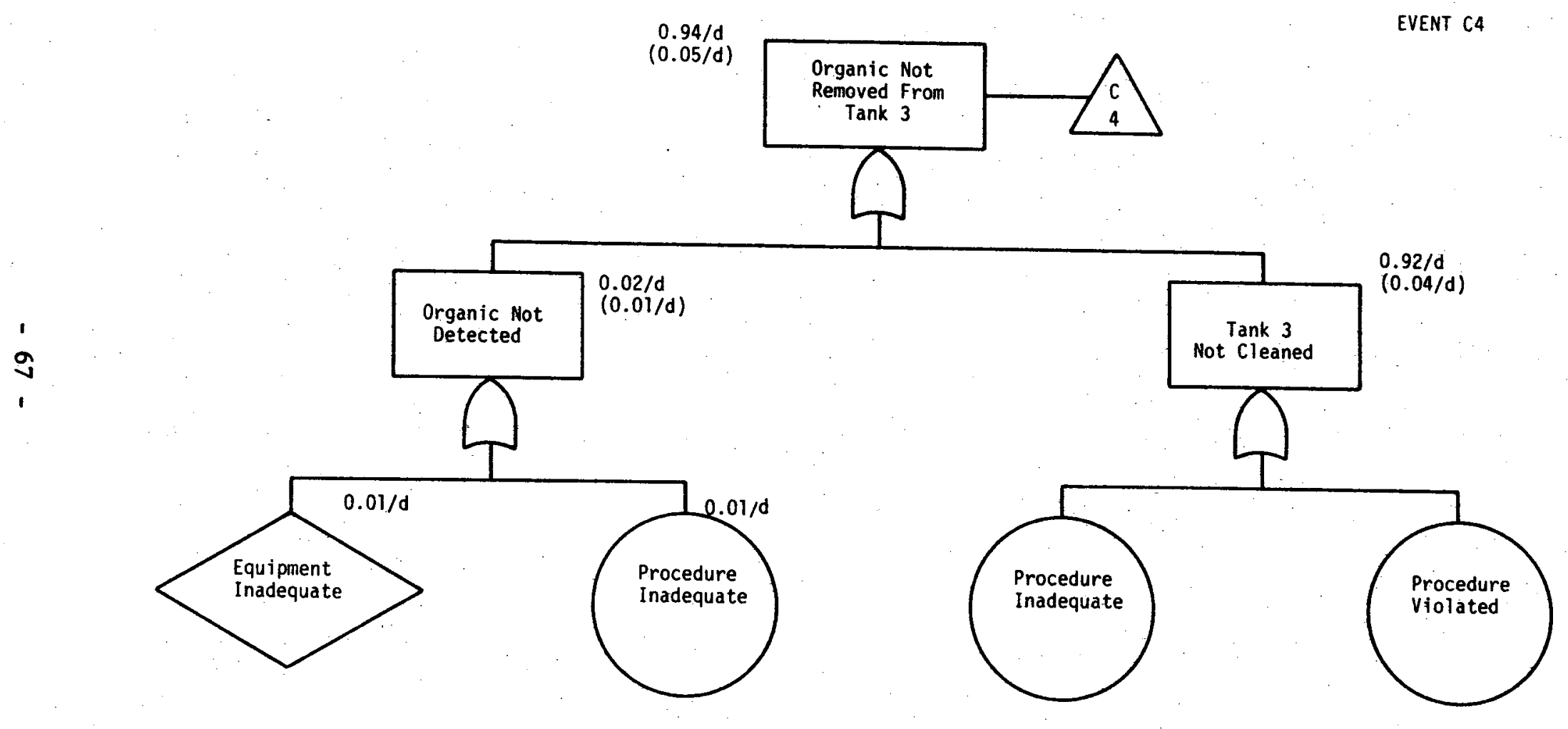




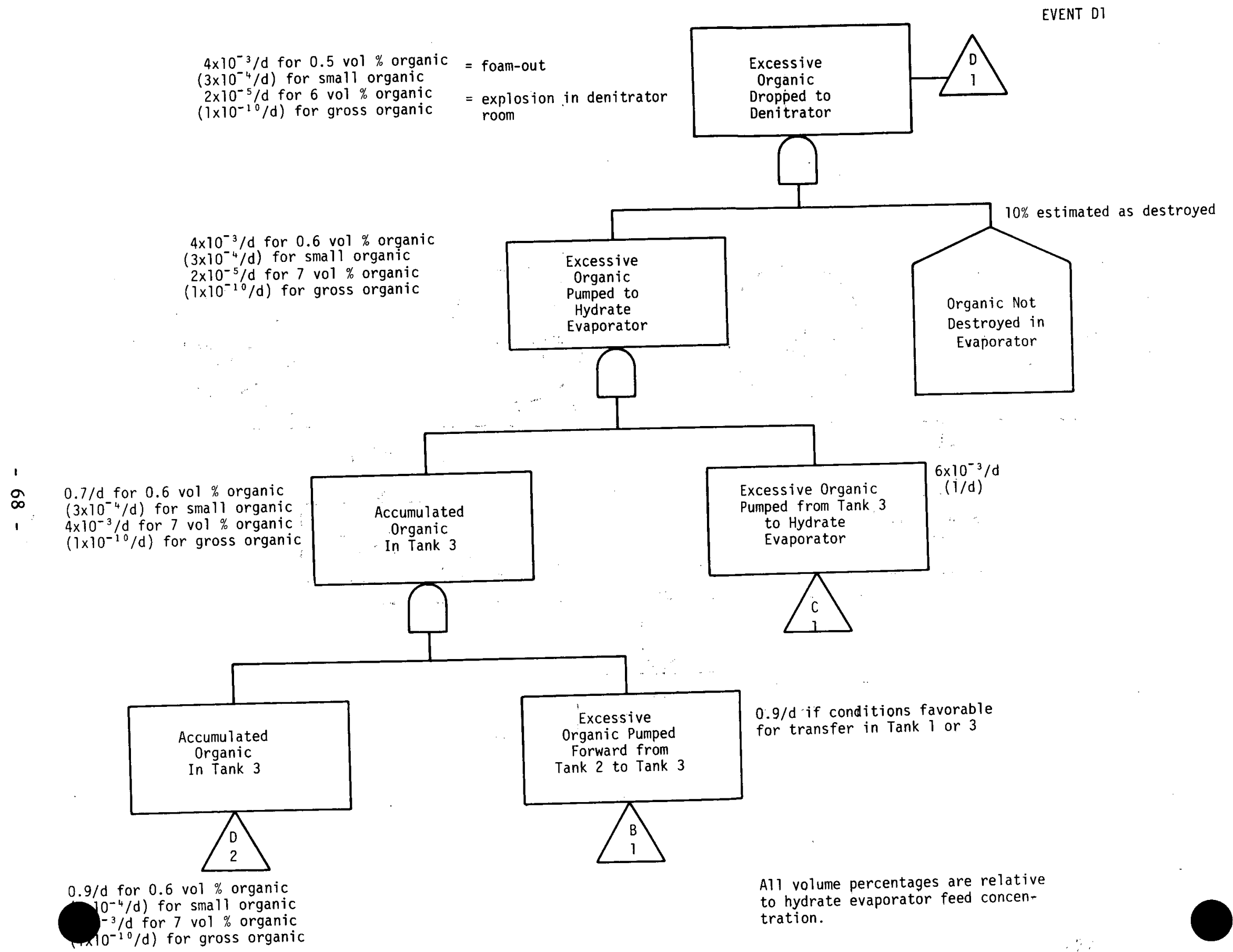


$0.9 /$ d for 0.6 vol \% organic $\left(3 \times 10^{-4} / d\right)$ for small organic $4 \times 10^{-3} / \mathrm{d}$ for 7 vol \% organic $\left(1 \times 10^{-1 \%} / \mathrm{d}\right)$ for gross organic

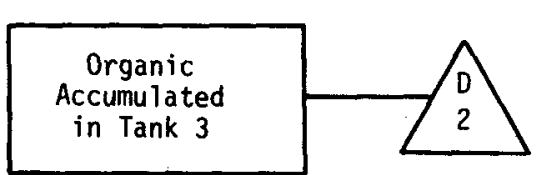

in Tank 3

$0.9 / d$ for 0.6 vol \% organic

$\left(3 \times 10^{-4} / \mathrm{d}\right)$ for small organic

$4 \times 10^{-3} / \mathrm{d}$ for 7 vol $\%$ organic

$\left(1 \times 10^{-10} / \mathrm{d}\right)$ for gross organic

\begin{tabular}{|c|}
\hline Organic \\
Accumulated \\
in \\
Tank 2 \\
\hline
\end{tabular}

\section{Organic Pumped from Tank 2 to} Decanting Tank 3
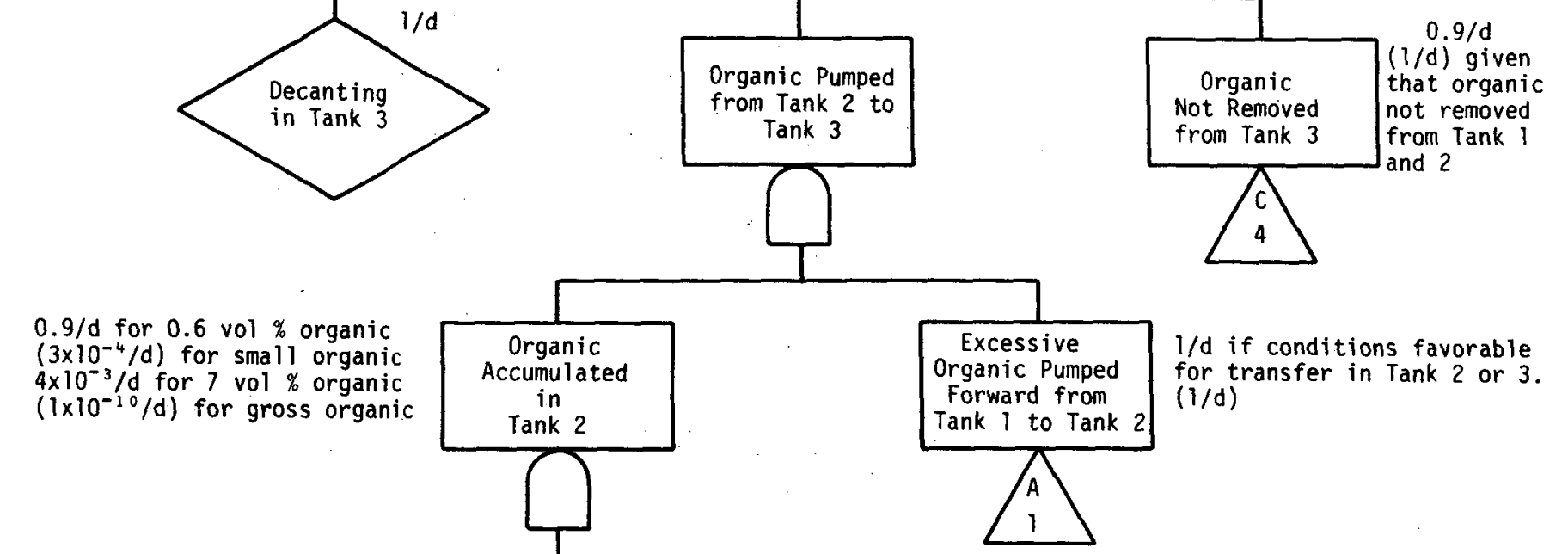

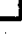

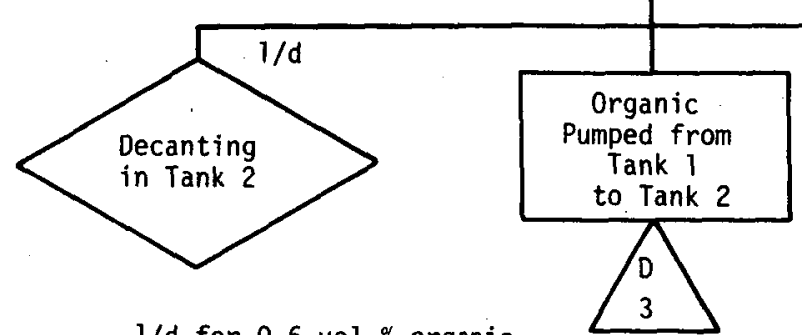

$1 / \mathrm{d}$ for 0.6 vol \% organic

$\left(5 \times 10^{-4} / d\right)$ for small organic

$4 \times 10^{-3} / \mathrm{d}$ for 7 vol \% organic

$\left(3 \times 10^{-10} / d\right)$ for gross organic

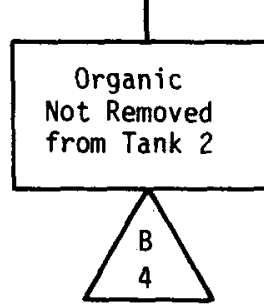

$1 / d$ if conditions favorable for transfer in Tank 2 or 3 .

Organic Pumped

Forward from $(1 / d)$

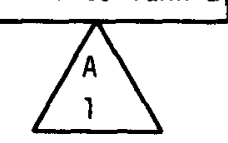

\section{$0.9 / d$}

$(0.5 / d)$ given that organic $(0.5 / d)$ given that organ
not removed from Tank 1 . 


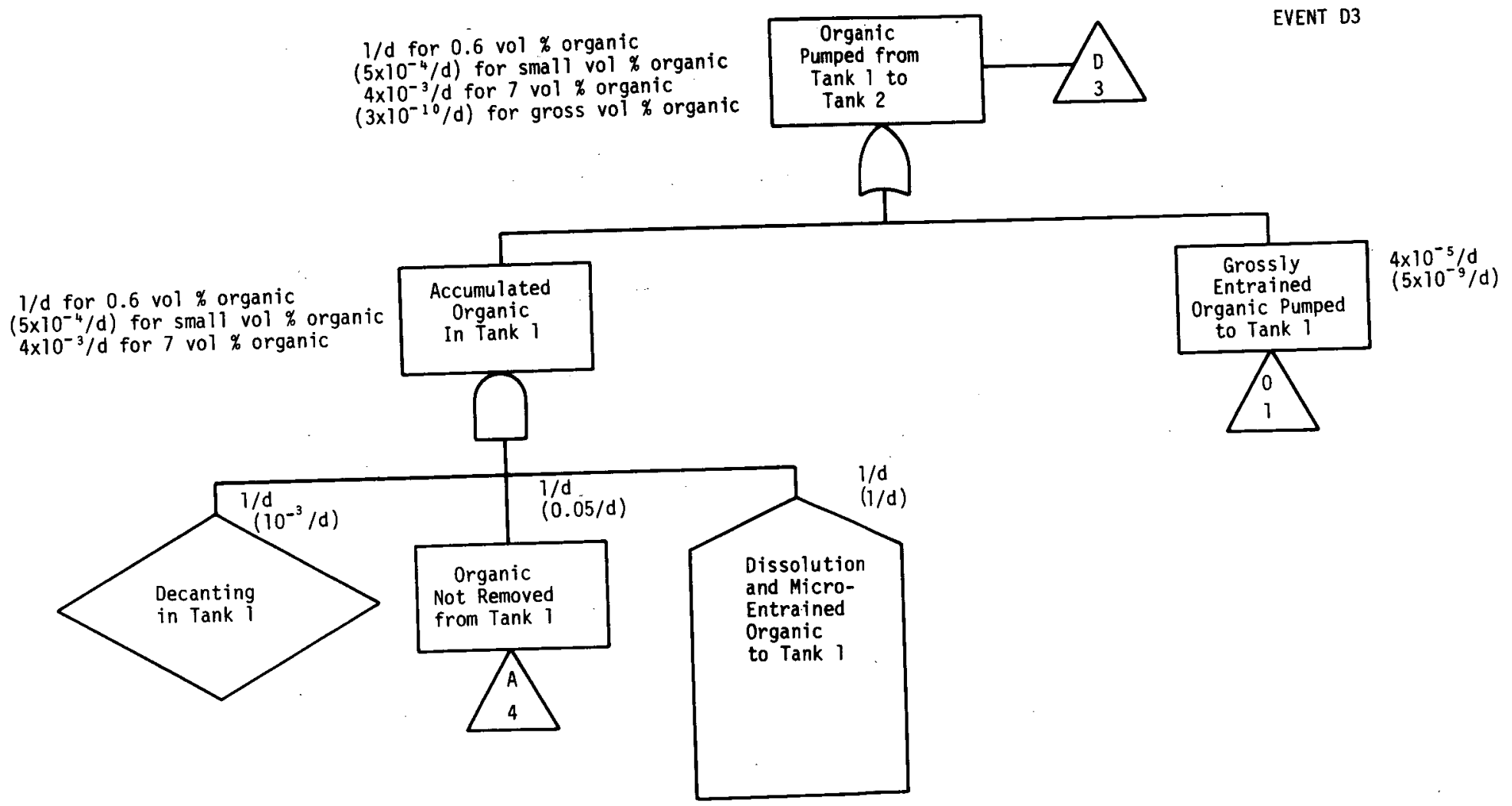




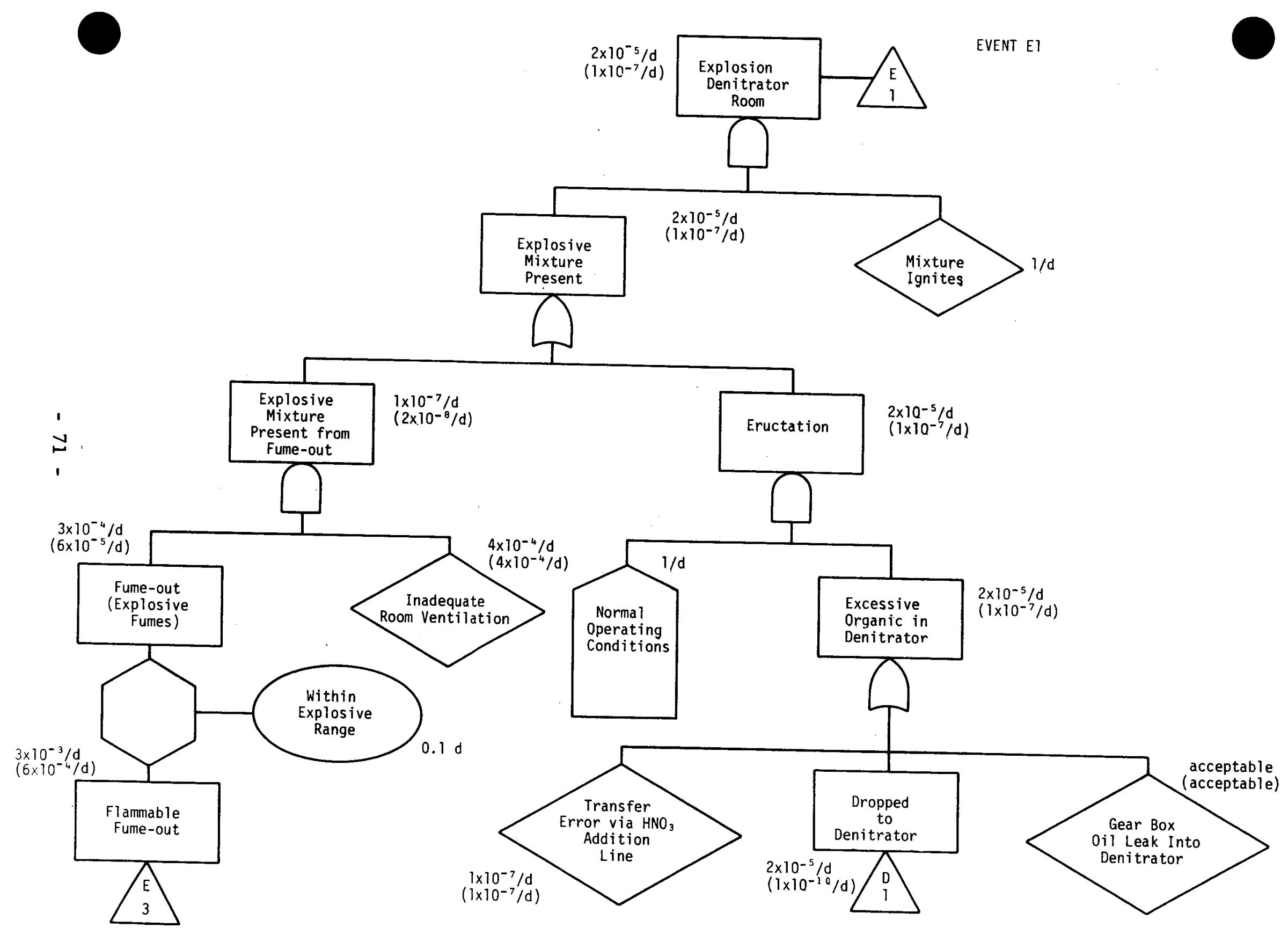




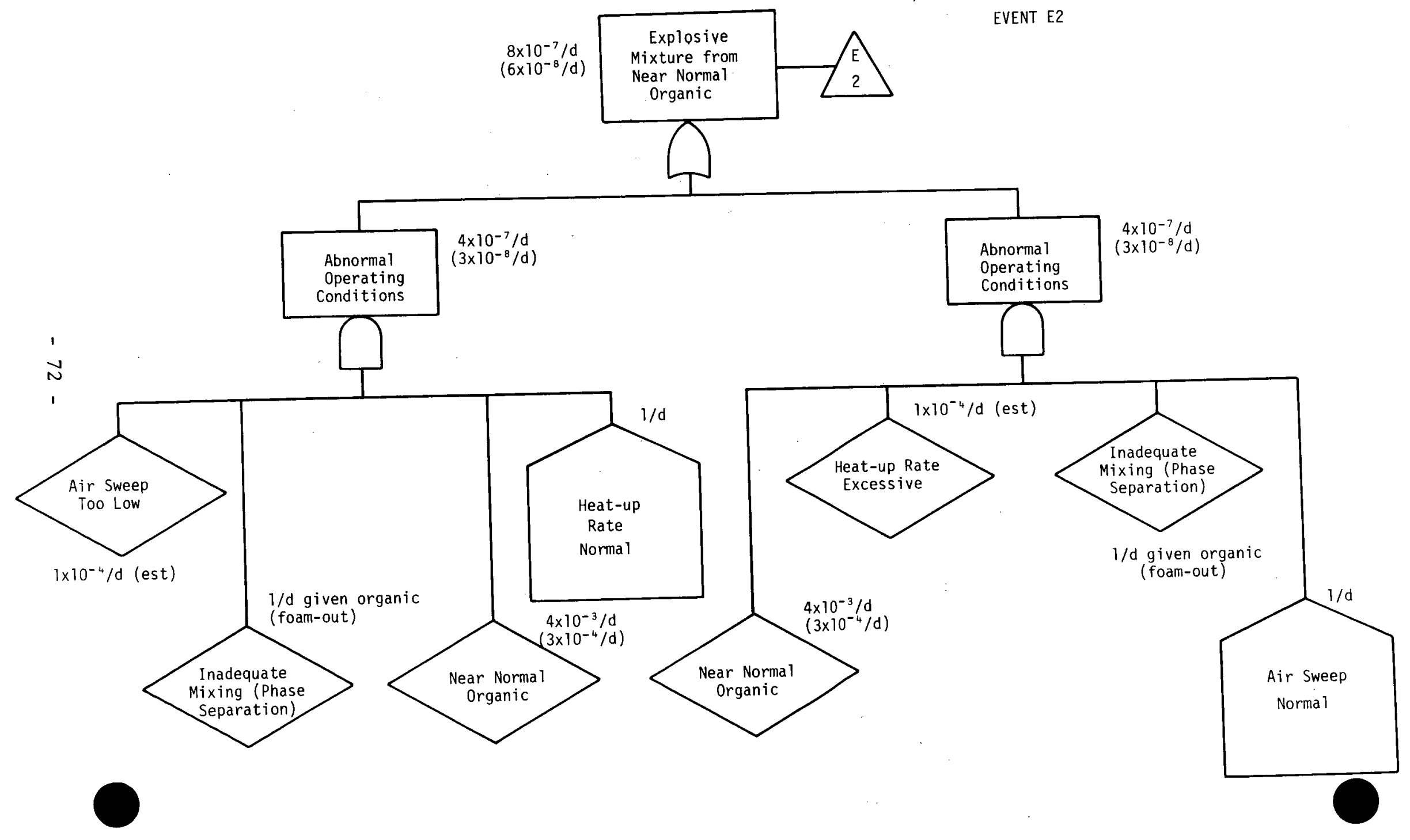




\section{EVENT E3}

$2 \times 10^{-3} / d$

$\left(3 \times 10^{-7} / \mathrm{d}\right)$

Near-

Normal

Conditions

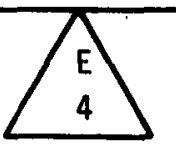

$3 \times 10^{-3 / d}$

$\left(6 \times 10^{-4} / d\right)$

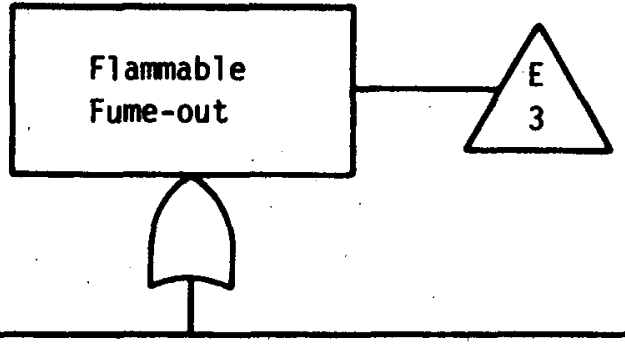

$1 \times 10^{-3 / d}$

$\left(6 \times 10^{-4 / d}\right)$

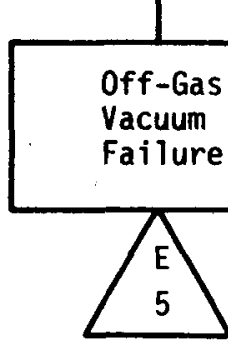


EVENT E4

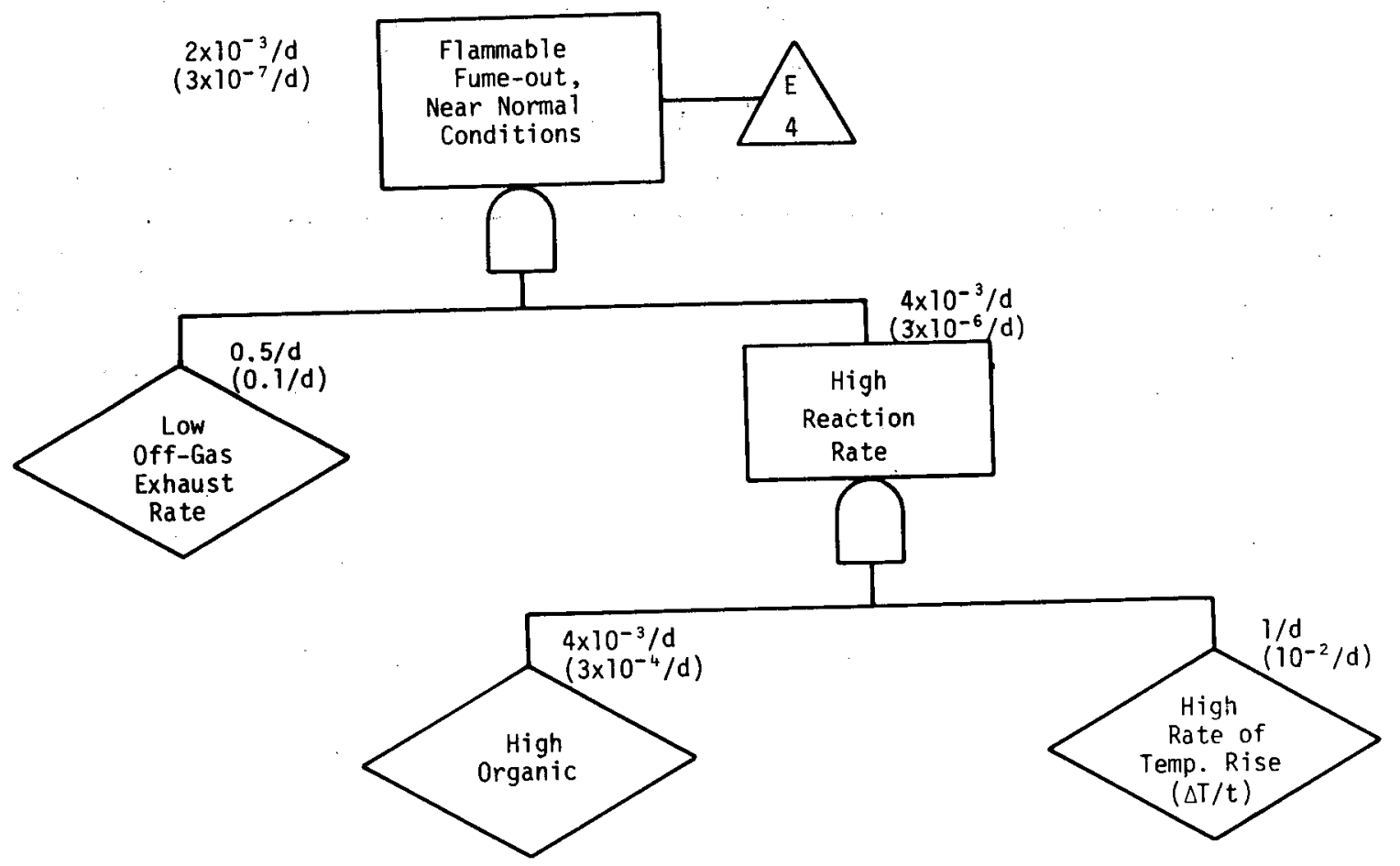




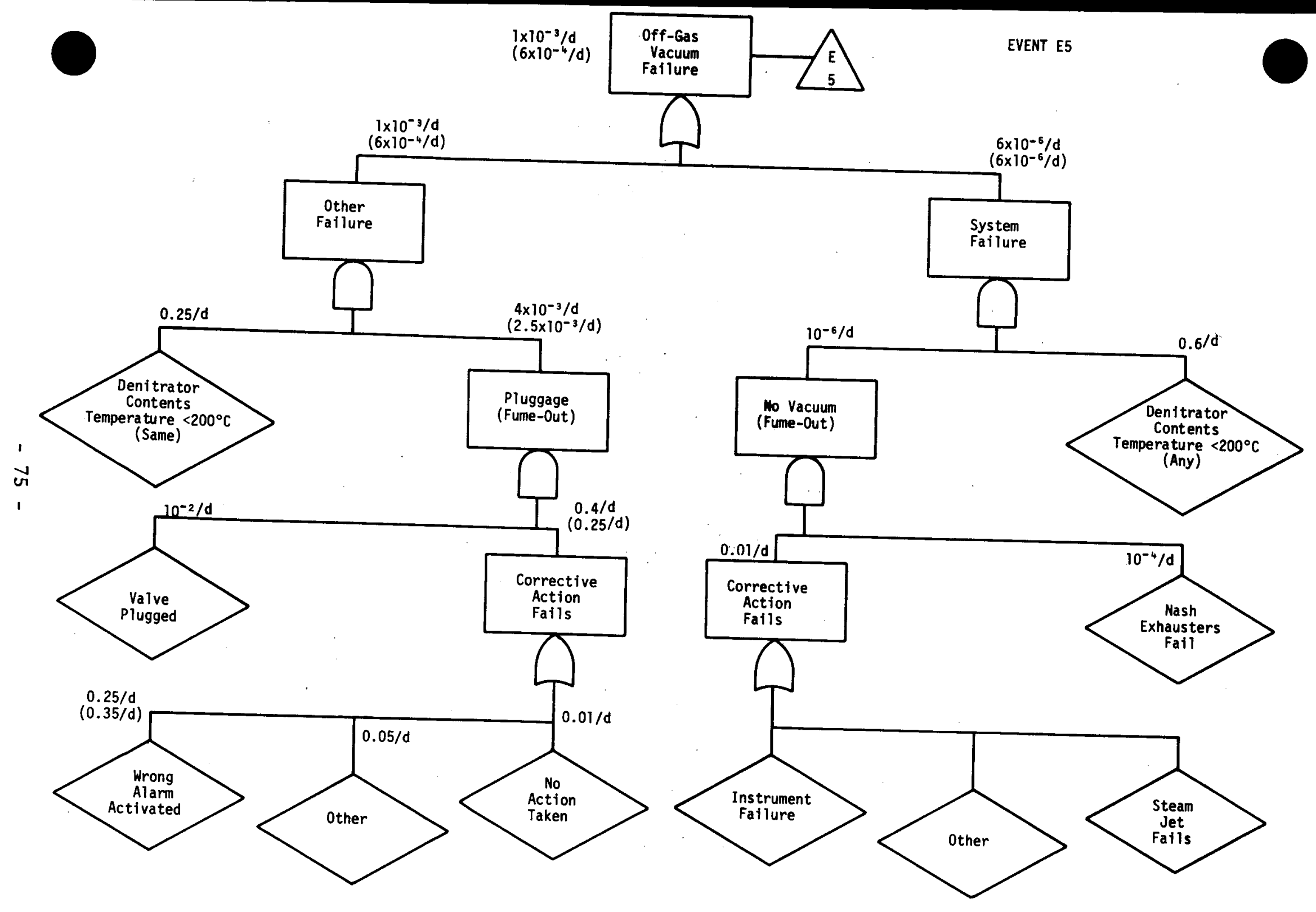


EVENT 01

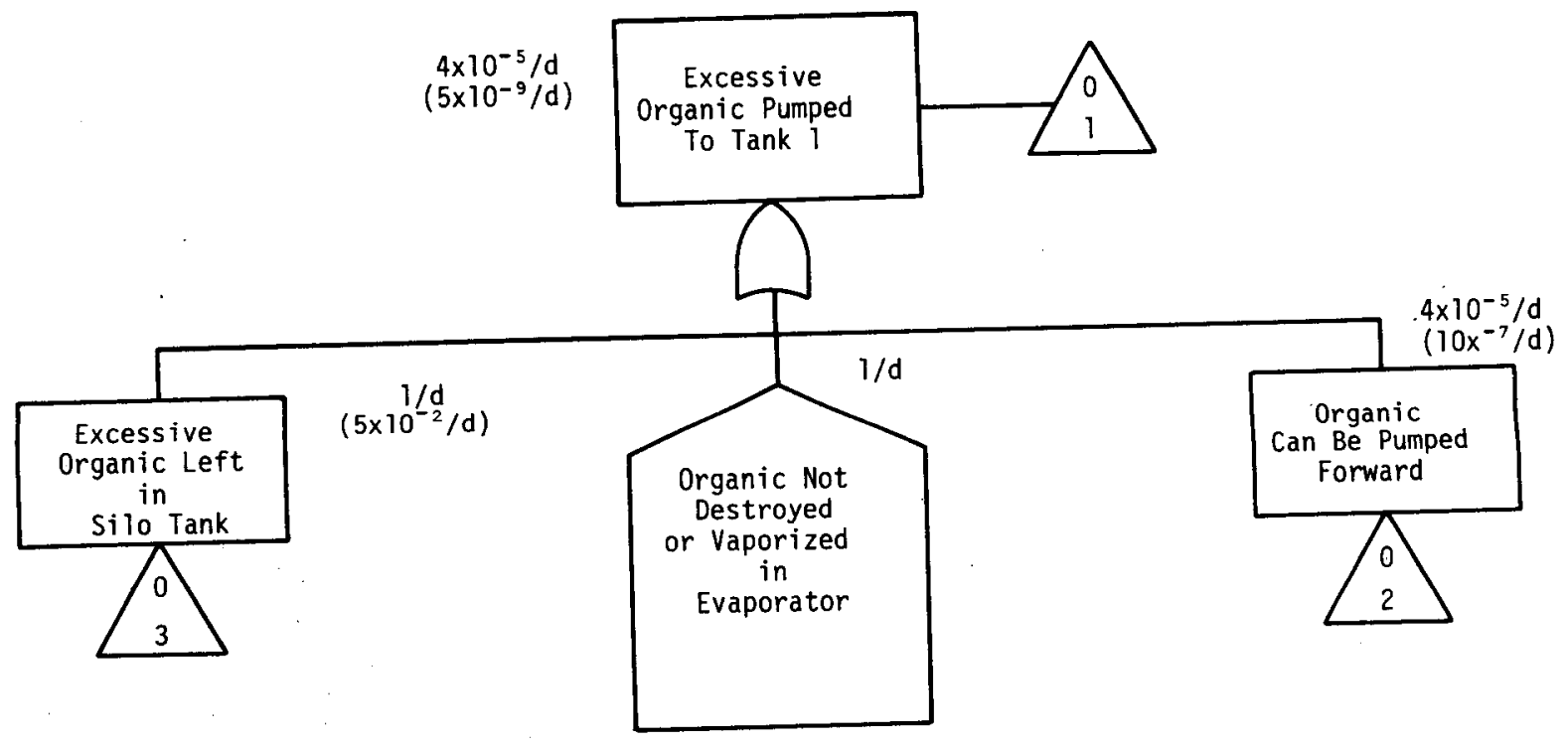




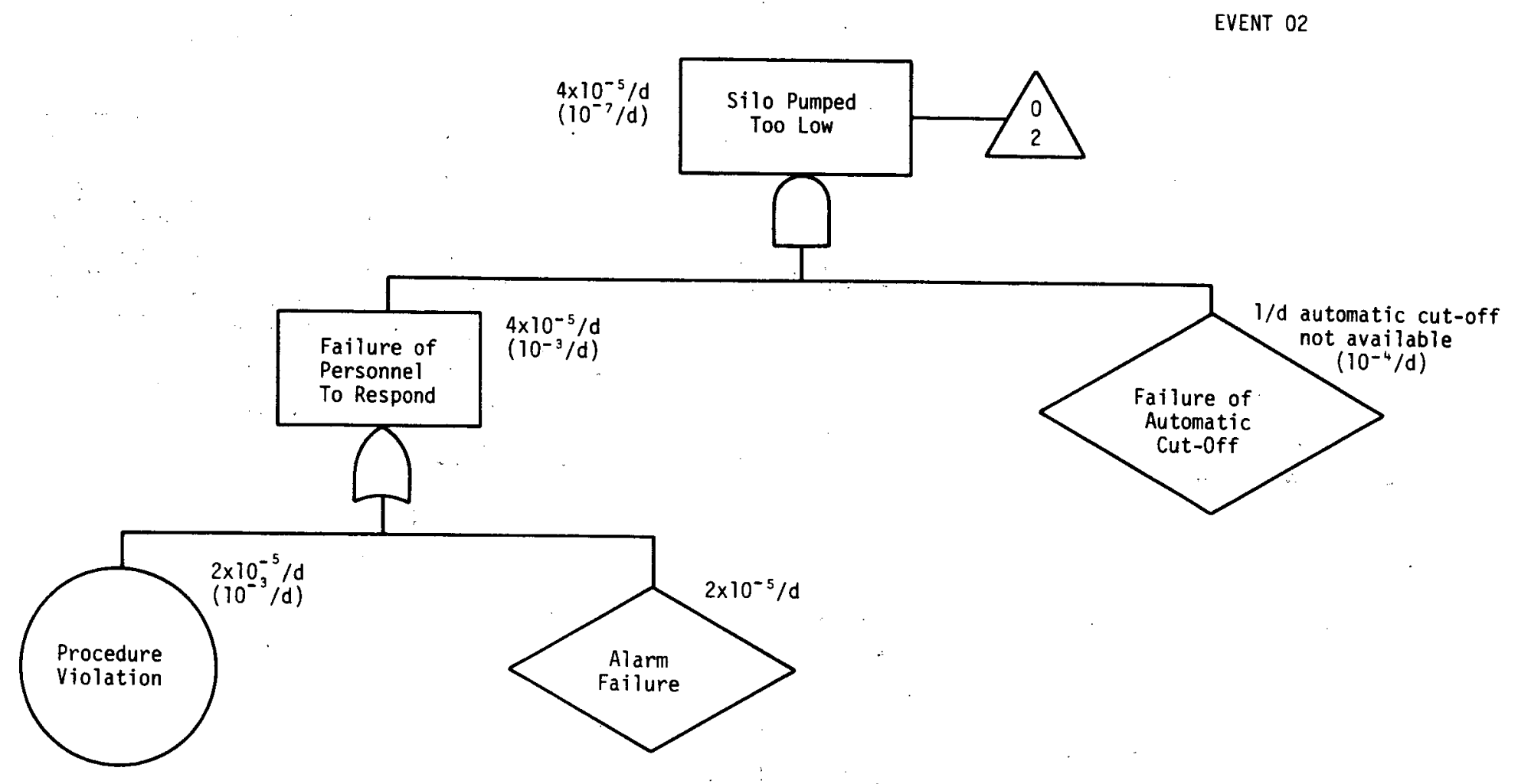


EVENT 03

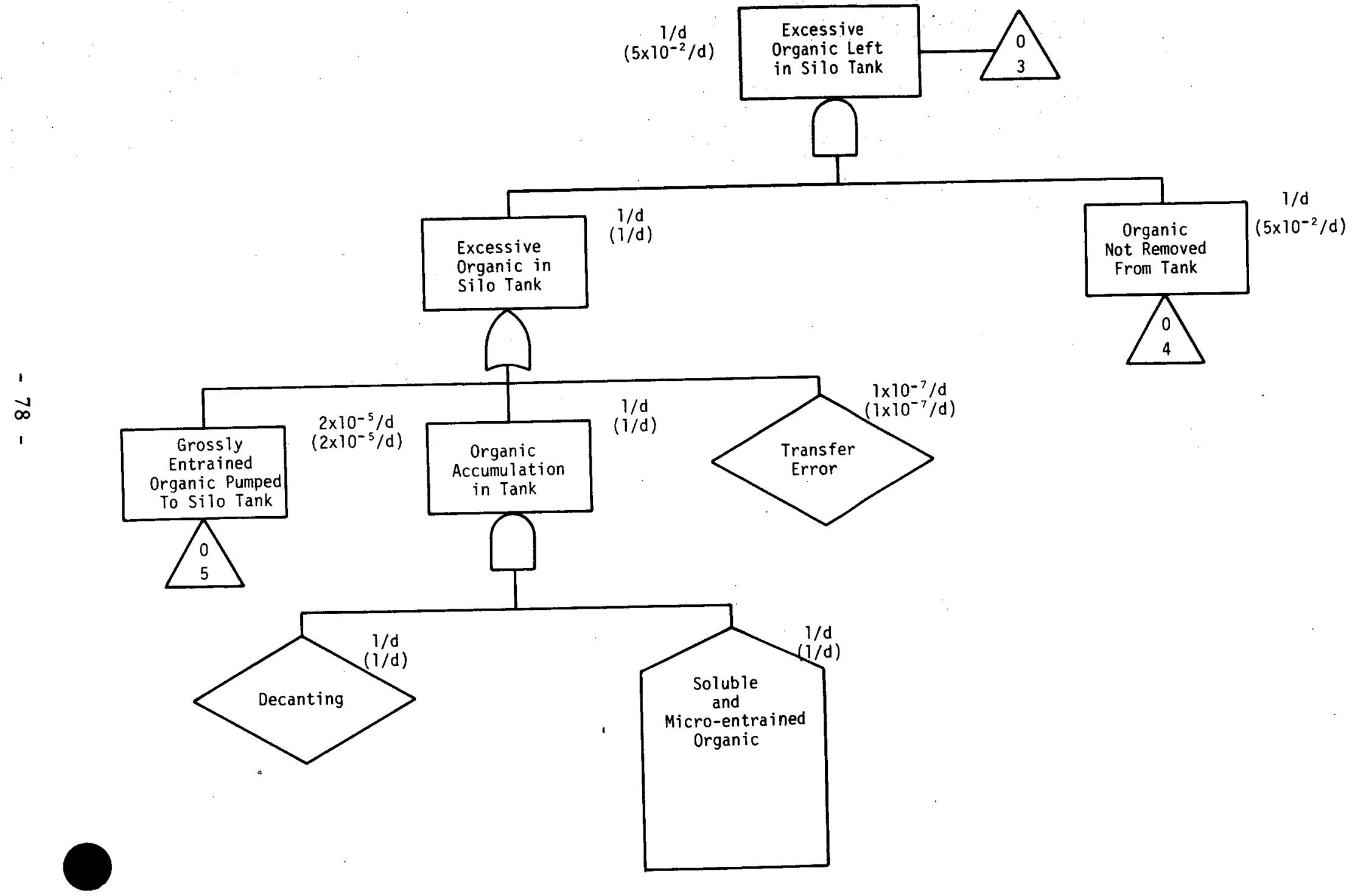


EVENT 04

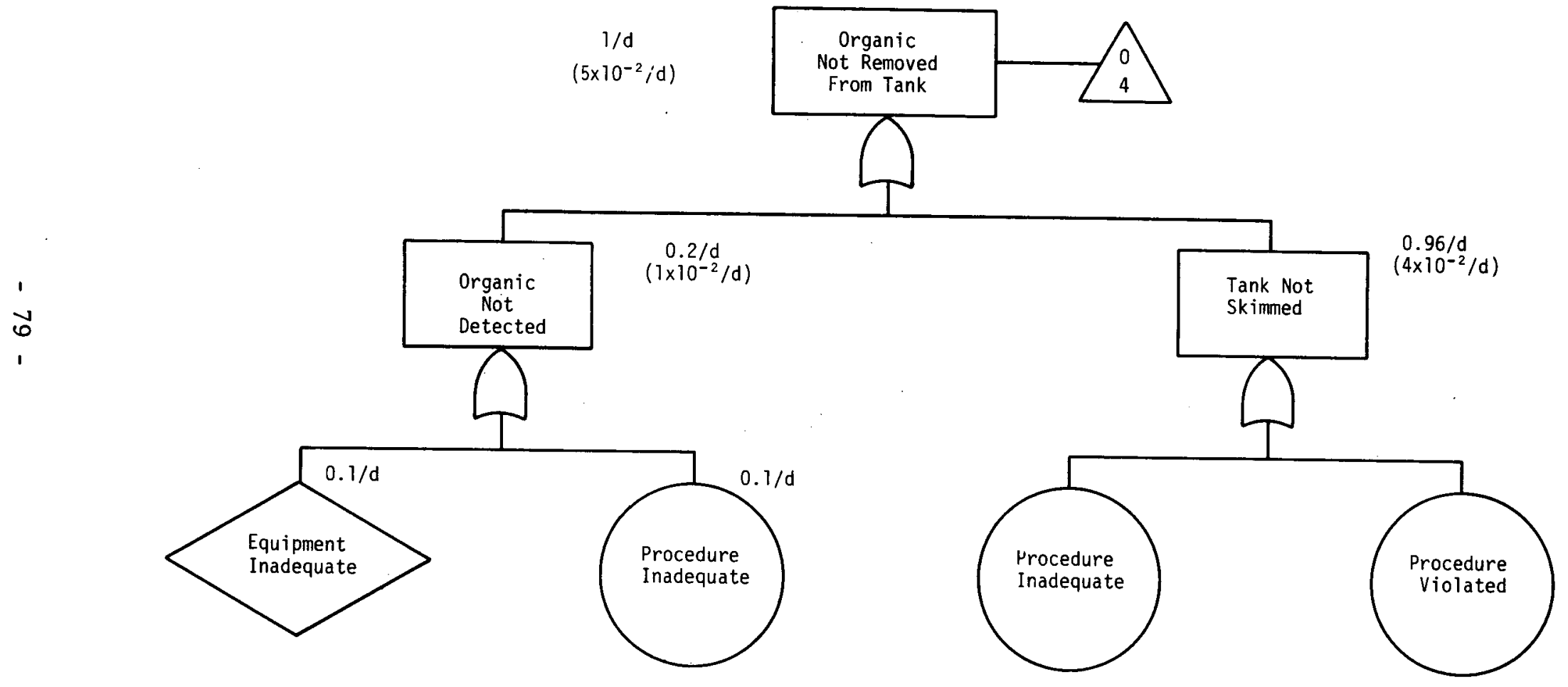




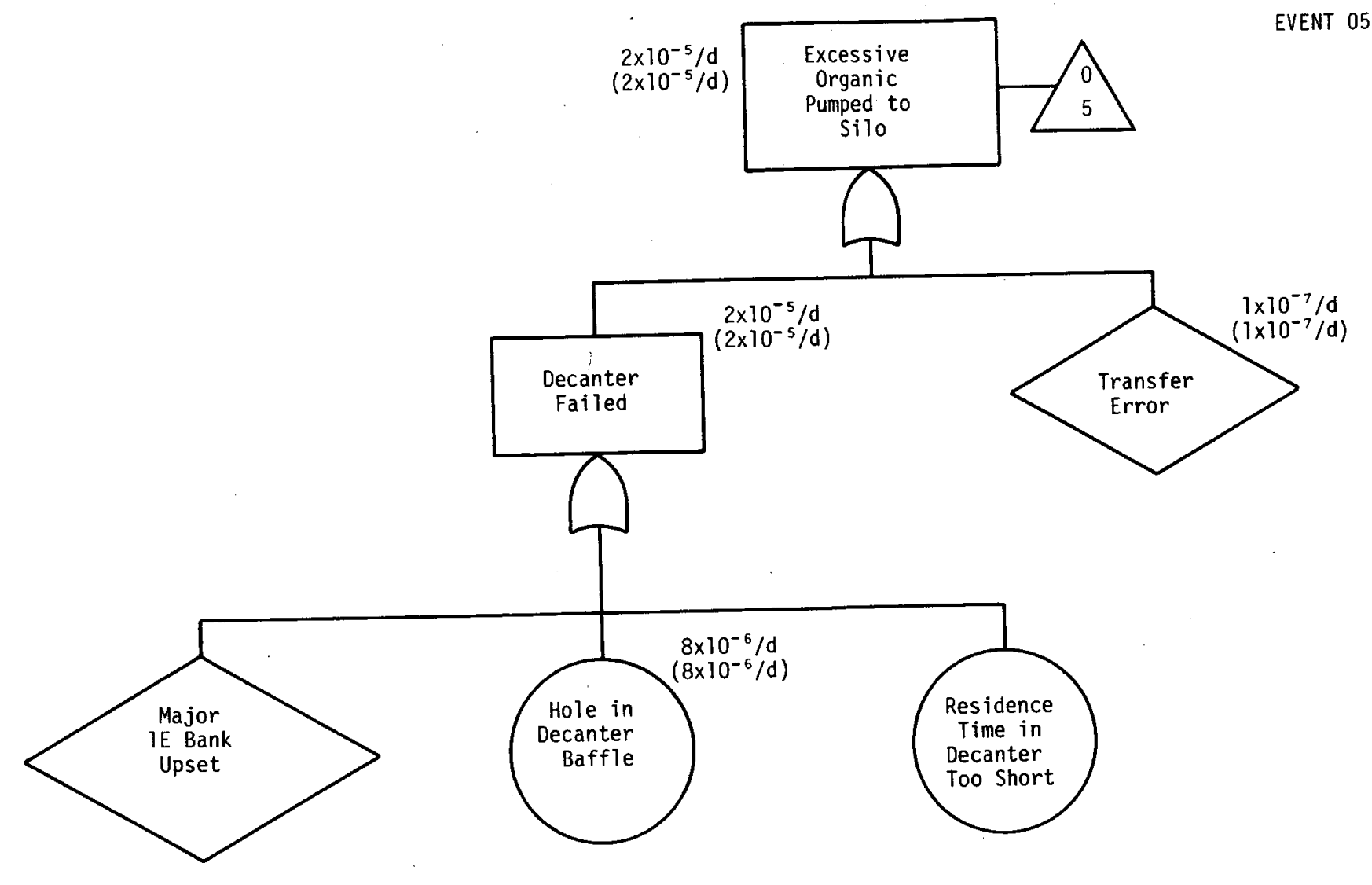

